\title{
EFFECT OF ENVIRONMENTAL STRESS ON THE ABILITY OF LISTERIA MONOCYTOGENES SCOTT A TO ATTACH TO FOOD CONTACT SURFACES
}

by

\author{
L. Michele Smoot \\ Dissertation submitted to the Faculty of the \\ Virginia Polytechnic Institute and State University \\ in partial fulfillment of the requirements for the degree of \\ DOCTOR OF PHILOSOPHY \\ in
}

Food Science and Technology

APPROVED:

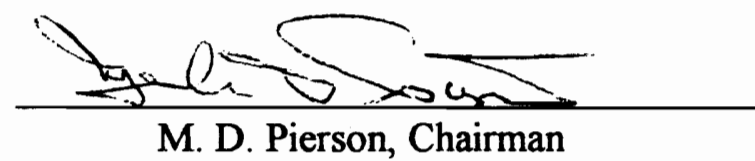

D. Wilinarclaus

G. W. Claus

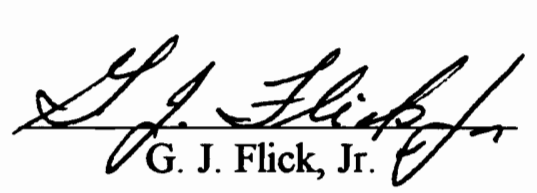

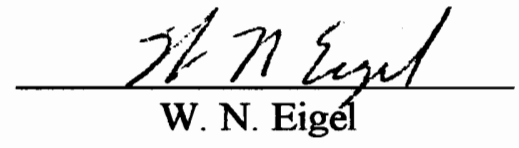

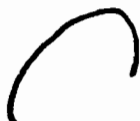

C. R. Hackney

December, 1996

Blacksburg, Virginia

KEYWORDS: Listeria monocytogenes, attachment, stress 


\section{EFFECT OF ENVIRONMENTAL STRESS ON THE ABILITY OF LISTERIA MONOCYTOGENES SCOTT A TO ATTACH TO FOOD CONTACT SURFACES}

by

\section{Michele Smoot}

Merle D. Pierson, Committee Chairman

Department of Food Science and Technology

\section{(ABSTRACT)}

The attachment and detachment of Listeria monocytogenes Scott A to Buna-N rubber and stainless steel under varying conditions of temperature and $\mathrm{pH}$ were investigated. Numbers of attached cells increased with increasing attachment temperatures $\left(10^{\circ}\right.$ to $45^{\circ} \mathrm{C}$ ) and time (up to $120 \mathrm{~min}$ ) for both Buna-N rubber and stainless steel. Cells attached at higher levels on stainless steel at all temperature and $\mathrm{pH}$ levels investigated. Rate of attachment was found to be significantly lower at $10^{\circ} \mathrm{C}$ than $30^{\circ}$ and $45^{\circ} \mathrm{C}$ on Buna-N rubber. When $L$. monocytogenes was grown at $10^{\circ}, 30^{\circ}$, and $42^{\circ} \mathrm{C}$ before exposure to Buna-N rubber at $30^{\circ} \mathrm{C}$, differences in rates of adhesion were not significant. A downward shift in the cell suspension holding temperature immediately prior to attachment to Buna-N rubber at $10^{\circ} \mathrm{C}$ resulted in reduced adhered cell populations. A similar upward shift did not affect attachment at $45^{\circ} \mathrm{C}$. Altering the $\mathrm{pH}$ of the attachment environment within the $\mathrm{pH}$ range of 4 to 9 did not affect the maximum levels of attached cells to Buna-N rubber. However, the measured rates of adhesion indicated slower attachment occurs under alkaline conditions. Growth $\mathrm{pH}$ was also found to significantly affect rates of attachment 
and maximum adhered cell populations to Buna-N rubber. Compared to Buna-N rubber, the rate of attachment to stainless steel was markedly more rapid for all temperature and pH conditions studied and could not be calculated. The ease of removal for cells adhered to Buna-N rubber was significantly affected by growth temperature, but not growth $\mathrm{pH}$. Significant differences in detachment were also found between Buna-N rubber and stainless steel, inferring a stronger attachment to Buna-N rubber. Cell surface hydrophobicity was affected by both growth temperature and growth $\mathrm{pH}$, but differences in hydrophobicity could not be correlated to differences in rates of attachment. Addition of $0.01 \%$ trypsin to the attachment medium during cell suspension exposure to both test surfaces resulted in a $99.9 \%$ reduction in the adhered cell population when compared to controls. This suggests that proteins may play a role in the initial attachment process for L. monocytogenes. 


\section{To my parents}

who taught me to put one foot in front of the other

and to my husband

whose love and support makes each step more enjoyable. 


\section{ACKNOWLEDGMENTS}

The author wishes to express her appreciation to the members of her graduate committee for their guidance during the course of this study. Special thanks go to the committee chair, Dr. Merle Pierson, for his professional advice and encouragement. Much gratitude is extended to my colleagues in Lab 16 for their friendship over the past three years as well as their day to day assistance in my work. Finally to my husband, Les Smoot, whose professional and personnel support was invaluable to the completion of this degree. 
Page

I. INTRODUCTION. . $\quad$. $\quad$. $\quad$. $\quad$. $\quad$. $\quad$. 1

II. REVIEW OF LITERATURE. $\quad$. $\quad$. $\quad$. $\quad$. $\quad$. 5

A. Listeria monocytogenes. . . . . . $\quad$. 5

1. Characteristics of the organism. . . . 5

$\begin{array}{lllll}2 . & \text { Clinical features of listeriosis . } & \text {. } & & \end{array}$

3. Epidemiology . . . . . . . . $\quad$. 7

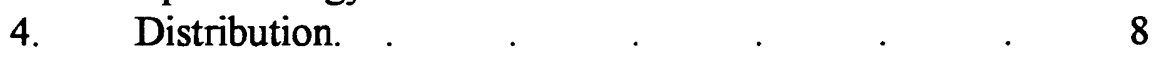

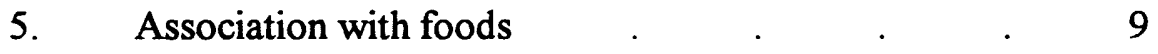

6. Persistence in the environment . . . 10

B. Environmental Stress . . . . . . . $\quad$. 12

1. Increased resistance/tolerance. $\quad$. $\quad$. $\quad$. 12

2. Cross Protection . . . . . . . 13

3. Effect on virulence of L. monocytogenes. . . $\quad 15$

C. Biofilms $\quad$. $\quad$. $\quad$. $\quad$. $\quad$. $\quad$. 17

D. Bacterial Attachment . . . . . 20

1. Bacterial attachment models . . . . 20

2. Mechanisms of attachment . . . . . 21

3. Physiological response of attachment . . . 25

4. Adsorption kinetics of microbial adhesion . . $\quad 27$

5. Detachment from the surface . . . . 30

6. Listeria and attachment. . . . . . . $\quad 32$

MANUSCRIPTS FORMATTED FOR PUBLICATION IN JOURNAL OF FOOD PROTECTION

III. EFFECT OF ENVIRONMENTAL STRESS ON THE ABILITY OF LISTERIA MONOCYTOGENES SCOTT A TO ATTACH TO FOOD CONTACT SURFACES

A. Title page $\quad . \quad$. $\quad . \quad$. $\quad . \quad . \quad$. $\quad 34$ 
B. Abstract . . . . . . . $\quad$. 35

C. Introduction . . . . . . . . 36

D. $\quad$ Materials and methods $\quad$. $\quad$. $\quad$. $\quad$. $\quad$. $\quad 38$

1. Test organism and culture maintenance . . $\quad 38$

2. Test surfaces . $\quad . \quad$. $\quad . \quad . \quad . \quad 38$

3. Attached cell development $\quad$. $\quad$. $\quad . \quad 39$

4. Enumeration of attached cells . $\quad$. $\quad 39$

5. Effect of temperature on attachment . . . 40

6. Effect of $\mathrm{pH}$ on attachment . . . . . 41

E. Results. . . . . . . . 43

1. Effect of temperature on attachment . . . 43

2. Effect of $\mathrm{pH}$ on attachment . . . . 44

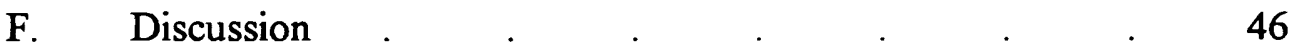

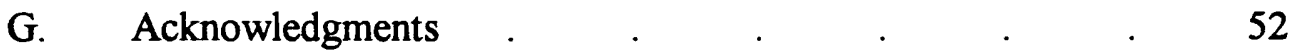

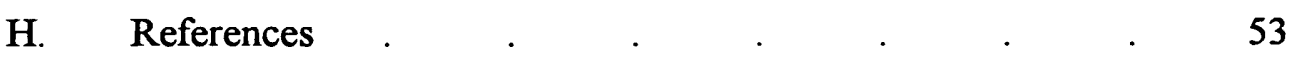

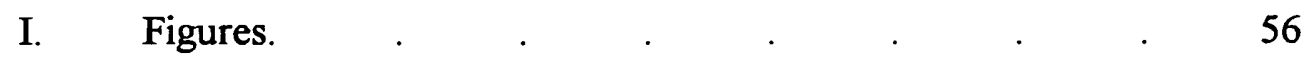

IV. INFLUENCE OF ENVIRONMENTAL STRESS ON KINETICS OF ATTACHMENT OF LISTERIA MONOCYTOGENES SCOTT A TO BUNA-N RUBBER AND STAINLESS STEEL

A. Title page . . . . . . . . 65

B. Abstract . . . . . . . . 66

C. Introduction . . . . . . . . . 67

D. Materials and methods $\quad$. $\quad . \quad 6 \quad$. $\quad 69$

1. Test organism and culture maintenance . . $\quad 69$

2. Test surfaces . . . . . . . $\quad$. 69

3. Attached cell development . . . . $\quad 70$

4. Enumeration of attached cells . . . . 70 
Page

5. Effect of temperature on attachment . . . $\quad 71$

6. Effect of $\mathrm{pH}$ on attachment . . . . . . $\quad$. 71

7. Salt aggregation test. . . . . . $\quad$. 72

8. Effect of trypsin on attachment . . . $\quad 72$

9. Rate of attachment . . . . . . . $\quad$. 73

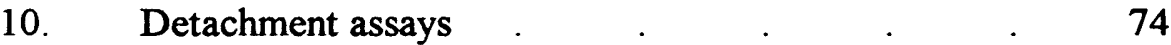

11. Statistical analysis of data . . . . . . $\quad$. 76

E. Results . . . . . . . $\quad 77$

1. Effect of temperature and $\mathrm{pH}$ on rate of attachment . 77

2. Effect of temperature and $\mathrm{pH}$ on hydrophobicity . 78

3. Effect of trypsin on attachment . . . $\quad 78$

4. Effect of growth temperature and $\mathrm{pH}$ on detachment $\quad 79$

F. Discussion $\quad . \quad$. $\quad . \quad \ldots \quad$. $\quad . \quad$. 80

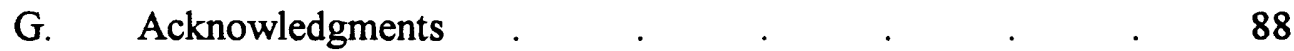

H. References . $\quad$. $\quad$. $\quad$. $\quad$. $\quad$. 89

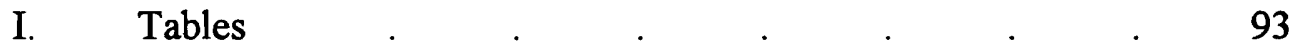

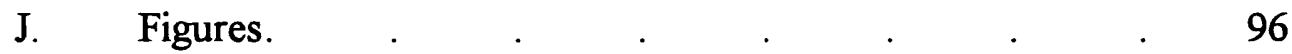

V. LITERATURE CITED $\quad$. $\quad . \quad \ldots \quad$. $\quad . \quad . \quad 101$

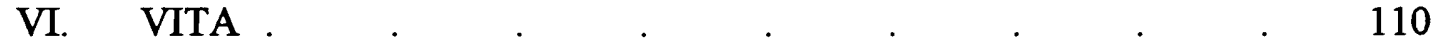




\section{I . INTRODUCTION}

Over the past decade, Listeria monocytogenes, has been regarded as one of the leading causes of food-borne illness. The organism has been found in a wide range of food products including, dairy, meat, poultry, seafood as well as fruits and vegetables (NACMCF, 1991). The infective dose is not known but varies with host susceptibility. Healthy individuals may ingest low levels of the organism unknowingly without occurrence of illness. However, a mortality rate as high as $30-40 \%$ has been documented for the immunocompromised portion of the population (Sutherland, 1989). Its high mortality rate, wide occurrence in nature and ability to grow at refrigerated temperatures has prompted some countries to implement a zero tolerance of $L$. monocytogenes in ready-toeat foods.

L. monocytogenes is ubiquitous in nature, being found on soil, feces, plants and in water samples (NACMCF, 1991). Consequently, it is frequently found on raw materials used in food processing. Cox et al. (1989) demonstrated that listeriae could be found in all types of food production environments. Once present in the processing environment, control of $L$. monocytogenes has proven to be difficult. Refrigerated, moist environments provide conditions which allows survival and growth. Although improvements have been made in controlling L. monocytogenes in food systems, its presence in the processing environment is still readily found.

Both physical and chemical treatments are used in food processing to eliminate and control the presence of pathogenic and spoilage microorganisms in foods. When cleaning 
and sanitizing regimes are poorly executed or inadequate, microorganisms may remain in the processing environment in an injured state. It has been shown that sublethal treatments or stresses can result in unique adaptive responses. For example, Foster and Hall (1990) reported that when Salmonella typhimurium was first preshocked with a mild acid ( $\mathrm{pH}$ 5.5), cells were 100 to 1,000 times more resistant to a subsequent strong acid challenge than their unadaptive counterparts. Kroll and Pratchett (1992) were also able to demonstrate an acid tolerance response in Listeria. This increased resistance to a secondary stress is well documented for a number of stresses such as heat, anaerobiosis, oxidation, starvation and ethanol in a variety of microorganisms (Van Bogelen et al., 1987; Nystrom, 1990; Murano and Pierson, 1992). Increased resistance to treatments which are normally lethal, is due to the production of specific proteins triggered by the presence of sublethal levels of that stress (Foster, 1991). Recent studies indicate that different stresses may trigger the production of similar proteins (Jenkins et al., 1988; Leyer and Johnson, 1993; Lou and Yousef, 1996). In such cases, the microorganism not only exhibits an increased tolerance to lethal levels of that stress which triggered the protein production, but also exhibits an increased tolerance to other stresses which induce the production of similar proteins.

Exposure to stress alters more than the profile of proteins produced (Marshall, 1992). For example, starvation stress not only results in a shift in the production of proteins but is often accompanied by an increase in cell number, a decrease in cell size, an increase in cell surface hydrophobicity and an increase in adhesiveness. It has been 
suggested that these factors make the bacteria more prone to adhere to solid surfaces where they benefit from an enhanced nutrient status (Marshall, 1992). Continued adhesion and growth of adhering bacteria eventually leads to biofilm formation. Biofilms present a problem to the food industry, in that, if allowed to persist in the processing environment they can serve as a source of contamination affecting the quality and safety of processed foods.

Microorganisms existing in biofilms have been shown to have an increased resistance to antimicrobials as compared to free-living microorganisms. This increased resistance may result from nutrient limitation in the biofilm (Brown and Gilbert, 1993). Numerous studies have demonstrated that $L$. monocytogenes existing in a biofilm exhibits increased resistance to common sanitizers (Ren and Frank 1993, Ronner and Wong 1993, Lee and Frank 1991, Frank and Koffi 1990).

The initial stage of biofilm formation in the processing environment is the adhesion of microorganisms to food contact surfaces. To date, the majority of biofilm research in the food industry has focused on the ability of microorganism to resist environmental stresses (Hood and Zottola, 1995). Very little work has addressed the effect of these environmental stresses on the ability of microorganisms to attach to different surfaces. For those microorganisms in which a zero tolerance is in effect, attached bacteria may be as significant a threat to the production of safe food as are well developed biofilms. A better understanding of the environmental conditions which favor attachment should aid in the prevention of adhered bacteria and subsequent biofilm formation. Therefore the objective of this study is to determine in a quantitative manner the effects of environmental 
stresses on the ability and rate of attachment Listeria monocytogenes Scott A to food contact surfaces. 


\section{REVIEW OF LITERATURE}

\section{A. Listeria monocytogenes}

\section{Characteristics of the organism}

Listeria monocytogenes is a gram-positive, non-sporeforming, rod 0.4-0.5 $\mu \mathrm{m}$ in diameter and 0.5-2 $\mu \mathrm{m}$ in length. The organism is a facultative anaerobe but prefers microaerophilic conditions with $5-10 \% \mathrm{CO}_{2}$. It is catalase positive, oxidase negative and $\beta$-hemolytic. Colonies are low convex shaped, $\leq 1.5 \mathrm{~mm}$, with a characteristic bluish appearance when observed with obliquely transmitted light. The organism possesses peritrichous flagella which give it a characteristic tumbling motion. Motility is temperature dependent, with $20^{\circ} \mathrm{C}$ being the optimum temperature to demonstrate motility. Listeria monocytogenes has a wide temperature range for growth between $1^{\circ}$ and $45^{\circ} \mathrm{C}$ and an optimum growth temperature between $30^{\circ}-37^{\circ} \mathrm{C}$. The growth $\mathrm{pH}$ range is between 4.1 to 9.6. Growth occurs up to $10 \% \mathrm{NaCl}$, however, L. monocytogenes is able to survive in up to $25.5 \% \mathrm{NaCl}$ at $4^{\circ} \mathrm{C}$. An extensive review of the growth characteristics of $L$. monocytogenes has been provided by Ryser and Marth (1991).

There are at least 13 serotypes of L. monocytogenes as determined by the somatic antigens (1-4) and the flagellar or $H$ antigens (a-e). Three of these serotypes, $4 b, 1 / 2 b$, and $1 / 2 \mathrm{a}$, account for $90 \%$ of all human listeriosis,. Of these serotypes, $4 \mathrm{~b}$ and $1 / 2 \mathrm{a}$ have been responsible for the majority (59 and $18 \%$, respectively) of foodborne disease outbreaks (Ryser and Marth, 1991). 
All strains of L. monocytogenes produce listeriolysin O (LLO) an essential virulence factor that is responsible for $\beta$-hemolysis of erythrocytes and the destruction of phagocytic cells. Most, but not all, strains that produce LLO are $\beta$-hemolytic. The pathogenesis has been divided into four stages: internalization, escape from a vacuole, nucleation of actin filaments and cell-to-cell spread (Portnoy et al., 1988). LLO aids in the survival of $L$. monocytogenes once engulfed in the phagocyte. Enzymes produced by $L$. monocytogenes, such as catalase (CA) and superoxide dismutase (SOD), are thought to enhance survival inside the phagocytic vacuole by detoxifying cytotoxic oxidants. Although these enzymes may contribute to virulence, they are not considered essential for pathogenicity. LLO is an extracellular protein with a molecular weight of 60,000 daltons, consisting of 504 amino acids. Optimum production of LLO occurs during exponential growth, with maximum levels occurring after 8 to $10 \mathrm{~h}$ of growth (Geoffroy et al., 1989).

\section{Clinical features of listeriosis}

Illness caused by Listeria monocytogenes is most likely to occur in immunocompromised individuals, pregnant women, fetuses and young children, and the elderly. Though not as common, L. monocytogenes also causes disease in otherwise healthy persons with no recognized predisposing factors. Compared to the overall incidence of listeriosis, 0.8 per 100,000, the incidence for pregnant women, persons over 70 years of age, and persons with acquired immune deficiency syndrome have been estimated to be 12.4 per 100,000 live births, 2.1 per 100,000 population, and 200 per 100,000 population, respectively (NACMCF, 1991). The severity of the illness depends, 
to a large extent, upon the host factors. Symptoms of the illness range from flu-like symptoms and mild diarrhea to septicemia, meningitis and in pregnant women, stillbirth or miscarriages. Listeriosis is treated with antibiotics such as ampicillin, penicillin or erythromycin, however, there is still a high mortality rate. Of the reported cases, $25 \%$ end in death as a result of the infection (NACMCF, 1991).

\section{Epidemiology}

Due to the outbreaks of listeriosis in the early 1980s, the Centers for Disease Control and Prevention (CDC) undertook an active surveillance project in to define the epidemiological characteristics of listeriosis. For the U.S., majority of cases of listeriosis are sporadic. Surveillance data indicate that 2000 cases and 450 deaths occur each year in the United States (Schuchat et al., 1992). A higher incidence may be more realistic due to lack of reporting as has been typical of foodborne illnesses.

Epidemiological evidence indicates that exposure to L. monocytogenes is mostly foodborne. (Broome et al., 1990). Outbreaks occurring in the 1980s in North America were associated with cole slaw, pasteurized milk, and Mexican-style cheese. The CDC conducted a case-control study, as part of their active surveillance program, to identify foods commonly associated with cases of listeriosis. Twenty percent of all cases reported could be attributed to undercooked poultry and hotdogs that had not been reheated by the consumer. Persons who had eaten soft cheese were found to have 2.6 times the risk of listeriosis and persons who had eaten foods from a delicatessen counters were found to 
have 1.6 times the risk of listeriosis when the effects of other foods were controlled. The study also reported an association of undercooked poultry and sporadic listeriosis, but only within the immunocompromised population (Schuchat et al., 1992).

The infective dose of a food-borne pathogen depends on host conditions, virulence and infectivity of the pathogen, type and amount of the food consumed, as well as the level of the pathogen in the food. In a few cases, the numbers of listeriae present in those foods implicated in a particular food-borne illness have been reported. In the outbreak caused by Mexican-style cheese, samples contained $10^{3}$ to $10^{4}$ L. monocytogenes per $\mathrm{g}$ of cheese (Linnan, et al., 1988). In another case involving an immunocompromised individual, the incriminated food sample contained $>1100 \mathrm{~L}$. monocytogenes per $\mathrm{g}$ of turkey franks (Wenger et al., 1990). Due to the time between onset of symptoms and laboratory analysis and the fact that $L$. monocytogenes can grow at refrigeration temperatures, the levels of listeriae in the incriminated foods should be carefully considered. As the general age of the population increases and a larger segment of the population is living with immunosuppressive illnesses, the percent of the population at risk for listeriosis will also increase.

\section{Distribution}

L. monocytogenes is ubiquitous in nature and is able to survive in a wide range of environmental conditions. The organism has been isolated from soil, sewage, animal feces and decaying vegetation including silage and other animal feeds (Gray, 1963). $L$. 
monocytogenes was found in all 50 samples of sewage, sewage sludge and river water examined in the United Kingdom, often in excess of Salmonella (Watkins and Sleath, 1981). Listeria has also been found in large numbers in mud samples indicating that this organism is able, not only to survive, but to multiply, particularly in moist environments (Weis and Seeliger, 1975).

Prior to 1980 , listeriosis was primarily a veterinary concern, occurring in a wide variety of animals both domestic and wild. L. monocytogenes has been isolated from at least 42 species of mammals and 22 species of birds, as well as fish and crustaceans (NACMCF, 1991). Many animals appear to be healthy carriers of $L$. monocytogenes. The organism has been isolated from a number of animals that either died from natural causes or were slaughtered for human consumption.

\section{Association with foods}

The incidence of $L$. monocytogenes in selected food products has been reported as high as $45 \%$ in milk, $95 \%$ in pork, $60 \%$ in raw poultry, $79 \%$ in ground beef, and $30 \%$ in some vegetables (Jay, 1992). The Food and Drug Administration (FDA) reported the incidence of $L$. monocytogenes to be $5.1 \%$ in shrimp, $4.9 \%$ in cooked lamb, $1.4 \%$ in cheddar cheese, and 3.8\% in novelty ice cream (Doyle, 1989). Green (1990) found 7.1\% of raw beef samples, $19.3 \%$ of raw broiler necks and backs and $2.8 \%$ of ready-to-eat meats from 4,105 processing plants to the United States were positive for $L$. monocytogenes. A survey of ready-to-eat seafood, conducted as part of the EC 
Coordinated Food Control Program (ECCFCP), revealed the incidence of $L$. monocytogenes to be $4.1 \%$ in smoked fish and $11 \%$ in fish and shellfish. Listeria has also been isolated from shrimp, crabmeat (Archer, 1988), shellfish and fish (Brackett, 1988). Recent surveys conducted in the United Kingdom in ready-to-eat foods indicated that $L$. monocytogenes is generally present at levels $<1000 \mathrm{CFU} / \mathrm{g}$ (Anonymous, 1996). The ubiquitous nature of $L$. monocytogenes allows easy access to food products during various phases of production, processing, manufacture and distribution. Genigeorgis et al. (1990) showed that during processing, chilling, packaging and final retailing of processed turkey, the percentage of samples containing Listeria spp. increased from $4 \%$ to $23 \%$. The prevention of listeriae in raw foods is difficult to achieve. Its presence in processed and packaged foods which have been treated with a listericidal process would suggest postprocessing contamination from the environment has occurred and that strict control measures must be implemented (Sutherland, 1989).

\section{Persistence in food processing environments and foods}

In an environmental study of the prevalence of Listeria spp., Cox et al. (1989) found Listeria spp. in all food plants studied (frozen food factories, dairy plants, Italian cheese plants, ice-cream production, potato processing) except in dry culinary food factories. L. monocytogenes comprised $5-20 \%$ of the listeriae isolated from the different factories. Listeriae was most often found in drains (54\%), followed by stagnant water (46\%), floors (45\%), residues (33\%), and processing equipment (19\%). Since $L$. 
monocytogenes can grow over such a wide temperature and $\mathrm{pH}$ range, the organism may be expected to survive for long periods of time in food processing environments. In a study conducted by Stanfield et al. (1987), viable $L$. monocytogenes was recovered from the surface of inoculated plastic and waxed cardboard milk containers after 14 days storage. The extent to which processed foods become contaminated with $L$. monocytogenes depends on the degree of contact with contaminated surfaces. It has been suggested that microorganisms present in biofilms contribute to post-processing contamination (Mafu et al., 1990; Hood and Zottola, 1995).

The landmark outbreak of listeriosis in 1985, in which Mexican-style cheese was implicated, led to numerous studies investigating the growth and survival of $L$. monocytogenes in dairy products. L. monocytogenes has been shown to persist for extended periods in cottage cheese during storage at $3^{\circ} \mathrm{C}$ (Ryser et al., 1985). $L$. monocytogenes was able to grow to $10^{6}-10^{7} \mathrm{CFU} / \mathrm{g}$ during ripening of Camembert cheese inoculated with levels of $10^{4}-10^{5} \mathrm{CFU} / \mathrm{g}$ (Ryser and Marth, 1987). Other examples of foods inoculated with $L$. monocytogenes in which the organism was able to either survive or grow include ready-to-eat processed meats, Finnish sausage, ground beef, ravioli, and lettuce. An extensive review of the growth and survival of $L$. monocytogenes in foods is provided by Ryser and Marth (1991) and more recently by ICMSF (1996). These reviews also provide excellent summaries of the vast studies performed since the early 1980 s to investigate the organism's ability to survive various preservative strategies including combinations of heat, salt, $\mathrm{pH}$ (acids), antimicrobials, and gas atmospheres. These studies 
indicate that the overall persistence of $L$. monocytogenes in foods is consistent with their survival in many nonfood environments (Jay, 1992).

\section{B. Environmental Stress}

\section{Increased resistance/tolerance}

Both physical and chemical treatments are used in the food processing environment to eliminate and control the presence of pathogenic and spoilage bacteria in foods. Sublethal treatments may result in injured cells which are able to repair and proliferate once placed in an unstressed environment. Bacterial injury, as it relates to the control of microorganisms in food, has primarily been studied with treatments of freezing, heating, irradiation, and antimicrobials. Historically, injured cells have been defined as those cells which can form colonies on nonselective plating media but not on selective plating media (Ray, 1986). From this definition, it would follow that cells exposed to sublethal treatments (stresses) are more susceptible to adverse environments or secondary stresses to which non-injured cells can readily adapt.

There is now evidence that when cells are first exposed to a sublethal stress, they can acquire increased resistance to subsequent lethal levels of that same stress. For example, Foster and Hall (1990) reported that when Salmonella typhimurium was first preshocked with a mild acid ( $\mathrm{pH} 5.8$ ), cells were 100 to 1,000 times more resistant to a subsequent strong acid challenge than their unadapted counterparts. Kroll and Patchett (1992) were also able to demonstrate acid tolerance response in Listeria. This increased 
resistance to a secondary stress is not limited to acid tolerance. Listeria, Salmonella, and Escherichia coli $0157: \mathrm{H} 7$ have all been shown to have an increased heat resistance after being heat shocked at elevated temperatures (Bunning et al., 1990; Christman et al., 1985; Murano and Pierson, 1992). A common requirement of increased resistance/tolerance to secondary stresses is protein synthesis (Jenkins et al., 1988; Foster, 1991).

\section{Cross protection}

Procaryotic cells are known to respond to environmental or chemical stress by inducing specific sets of genes termed stimulons. Each stimulon, and the proteins it produces, is characteristic for a specific stress. Those proteins produced as a consequence of exposure to a sublethal stress confer protection to a subsequent lethal exposure of that same stress. Examples of well characterized stimulons include those for heat shock and oxidative stress (VanBogelen et al., 1987). Recent studies have indicated that stimulons may regulate the production of similar proteins. Two stimulons which regulate the production of common proteins can produce a cross protective effect for the two environmental stresses inducing these stimulons. Therefore, not only do the cells have an increased resistance to the stress triggering that stimulon, but to any other stress which triggers the production of similar proteins. This cross protective effect was first reported by Jenkins et al., (1988), when glucose or nitrogen starved cultures of $E$. coli exhibited enhanced resistance to heat and hydrogen peroxide challenge. Again, protein synthesis was essential for these two cross protections since the addition of chloramphenicol, an 
inhibitor of protein synthesis, prevented the development of thermal and oxidative resistance. Leyer and Johnson (1993) reported cross protection to heat, salt, lactoperoxidase system, and surface active agents (crystal violet, and polymixin B) when $S$. typhimurium was first adapted to acid. They indicated that in addition to altered protein synthesis, changes were also noted in the cell surface properties brought about by classical constitutive $\mathrm{pH}$ homeostasis.

In the environment, microorganisms may endure more than one stress and therefore exhibit complex environmental stress responses. However, to date, there has been few reports on the combined effects of multiple environmental stresses. This area was touched upon when Nystrom (1990) reported on the response of multiple nutrient starvation in marine Vibrio sp. strain CCUG 15956. When cells were starved for glucose, amino acids, ammonium and phosphate simultaneously, a total of 66 proteins were induced. They found that the total number of proteins produced by multiple starvation significantly exceeded the sum of proteins induced by starvation for each of the individual nutrients. In addition, 13 of those proteins induced by multiple starvation were unique and not observed when cells were starved for any one of the individual nutrients. Prestarvation for $1 \mathrm{~h}$ was shown to enhance survival of subsequent multiple-nutrient starvation. When other marine Vibrio spp. were subjected to a severe lack of energy and nutrients, cells demonstrated an increased resistance to autolysis, sonic lysis, hydrostatic pressure, heat and cold shock and increased adherence to a variety of surfaces (Nystrom et 
al., 1990). It is possible that combinations of different environmental stresses may produce responses unique from those obtained from any one individual environmental stress.

\section{Effect on virulence of Listeria monocytogenes}

Microorganisms respond to stresses, both those present in the environment and in foods, by activating numerous genes. Many of these genes are directly or indirectly involved in determining the organism's virulence (Archer, 1996). This phenomena has been extensively studied in Salmonella spp. and E. coli . Mekalanos (1992) described stress-related virulence genes in different microorganisms, including $L$. monocytogenes.

Strains of L. monocytogenes vary in their degree of virulence (Meyers and Martin, 1994). Recent research suggests that the production of LLO is influenced by the growth environment. The virulence of $L$. monocytogenes increases when cells are grown at refrigeration temperatures (Meyers and Martin, 1994). Dallmier and Martin (1990) reported that growth in the presence of $\mathrm{NaCl}$ resulted in an increase in the activity levels of CA, SOD and LLO. Datta and Kothary (1993) demonstrated that temperature and $\mathrm{pH}$ altered LLO production. Production of LLO in L. monocytogenes decreased when the cells were grown at $26^{\circ}$ rather than $36^{\circ} \mathrm{C}$. LLO production was optimum at $\mathrm{pH} 7.0$ and decreased with a decrease in $\mathrm{pH}$.

Even though environmental stresses can influence the production of LLO, there is still debate over whether cells demonstrating an increased LLO production also demonstrate increased virulence in the host. In experimentally infected mice, increased 
LLO production did not result in an increase in virulence. Meyers and Martin (1994) reported that growth at reduced temperatures did not influence virulence for mice infected i.g. or i.p. However, one study demonstrated an increased virulence in mice, when $L$. monocytogenes grown at $4^{\circ} \mathrm{C}$ was administered i.v. but not i.g. Changes in the environmental temperature probably do not significantly increase the virulence of foodborne infections of L. monocytogenes. It appears that the conditions of growth after infection may be more important contributors to virulence (Myers and Martin, 1994).

One environmental stress which could potentially affect the virulence of $L$. monocytogenes in the host is $\mathrm{pH}$. When L. monocytogenes is first exposed to a mild acid stress, it demonstrates an increase lethality in mice relative to that of the wild type when inoculated by the interperitoneal route ( O'Driscoll et al., 1996). Prolonged exposure of L. monocytogenes to strong acid conditions ( $\mathrm{pH} 3.5$ ) resulted in mutants which could constitutively demonstrate increased acid tolerance at all stages of the growth cycle. When acid adapted strains were administered i.g. to mice at a low inocula, increased numbers of these strains were recovered from the spleens of infected mice in greater numbers than found in mice infected with a high inocula of wild type strains. The increased capacity of acid tolerant $L$. monocytogenes to grow in $\mathrm{pH}$ range of 4.4 to 5.7 may aid in its passage through the stomach and its transient residence in the macrophage phagosome (O’Driscoll et al., 1996). 


\section{Biofilms}

Bacterial cells associated with solid surfaces can result in the formation of biofilms. Biofilms are characterized as attached microorganisms (single or multiple species) organized within extensive exoploymer glycocalices. The exoploymer composition is not well defined but is thought to consist largely of polysaccharides. Other substances, organic and inorganic, may also be entrapped in the biofilm matrix.

Biofilms are capable of forming in many different environments (marine environments, water pipelines, heat exchangers, cooling towers, implanted medical devices). In recent years, several reviews have been published emphasizing the importance of biofilm to the food industry (Hood and Zottola, 1995; Wong and Cerf, 1995).

Cells organized as biofilms are known to have an increased resistance to antimicrobial agents above that of their unattached (planktonic) counterparts. Recently, research has been directed towards explaining why microorganisms within biofilms are more resistant than planktonic cells. It has been suggested that the surrounding exopolymer (glycocalyx) of the biofilm excludes and or influences the access of antimicrobial agents to the cell surface of the underlying microorganisms. Though there are reductions in the diffusion coefficients of antimicrobial agents across the glycocalyx, these reductions alone are thought by some researchers to be insufficient to account for the observed recalcitrance (Brown and Gilbert, 1993). 
As a barrier, the glycocalyx not only excludes antimicrobial agents but also limits the availability of key nutrients to organisms within a biofilm. Limitation of nutrients results in slow growth rates and the development of phenotypes which differ from planktonic cells. Changes in the growth rate are often accompanied by alterations in the cell envelope components. Specifically, these are changes in fatty acids, phospholipids, metal cations, envelope proteins and extracellular enzymes. These changes in turn influence the susceptibility of the cell towards antimicrobial agents. Biofilm recalcitrance might therefore relate to the heterogeneity of nutrient deprived phenotypes within the biofilms (Brown and Gilbert, 1993). The increased resistance of microbial biofilms to antimicrobial agents may, in part, be explained as a starvation stress response similar to the stress response demonstrated in planktonic organisms.

In addition to increased or altered protein synthesis, starvation stress is accompanied by an increase in cell number, a decrease in cell size, an increase in cell hydrophobicity and an increase in adhesiveness. One approach for in vitro biofilm development consists of an incubation in low-nutrient media for $36 \mathrm{~h}$, followed by resuspension of harvested cells in a phosphate buffer for $4 \mathrm{~h}$ in the presence of the solid surface (Frank, 1993). It should be noted that when Jenkins et al., (1988) studied the cross protective response of planktonic $E$. coli following starvation, they found starvation for $4 \mathrm{~h}$ provided the maximum protection to later stresses. Other methods may vary slightly, however, most utilize a low nutrient media for cell growth followed by adherence to a solid surface in a phosphate buffer. 
Ren and Frank (1993) have reported on the susceptibility of starved stressed planktonic and biofilm L. monocytogenes to a quaternary ammonium sanitizer (benzalkonium chloride). They concluded that starvation of $L$. monocytogenes is not consistently associated with an increased resistance to benzalknoium chloride. These researchers suggest that the ability of $L$. monocytogenes to survive in food plant environments is attributed to biofilm formation versus the effects of starvation stress. However, Leyer and Johnson (1993) suggested that changes in the outer membrane properties of $S$. typhimurium due to acid adaptation, including an increase in hydrophobicity, could affect the ability of the cell to attach to hydrophobic surfaces and form biofilms. Thus biofilm formation may be a result of an environmental stress induced response. It should be noted that the growth conditions used by Ren and Frank (1993) to induce biofilm formation are similar to those conditions used to induce starvation associated stress responses in the studies cited above. In an earlier study, Lee and Frank (1990) reported on the effect of growth temperature and media on the inactivation of $L$. monocytogenes by chlorine. They found that cells grown in low nutrient media at $35^{\circ} \mathrm{C}$ were more resistant to $5 \mathrm{ppm}$ free chlorine than cells grown at the same temperature in trypticase soy broth. It is possible that the attached bacteria (starvation stressed) could have an increased resistance to other environmental strèsses including the byproducts of competing microflora. 


\section{Bacterial Attachment}

\section{Bacterial attachment models}

One of the initial processes leading to biofilm formation is the adhesion of bacterial cells to solid surfaces. Biofilms are capable of forming on a variety of food contact surfaces which vary in their surface properties (i.e. hydrophobic, hydrophilic). There are 2 primary models proposed, a 2 step and a 3 step process, which describe how microorganisms attach to solid surfaces. The 2 step process (Marshall et al. 1971) involves the transport of bacteria close enough to the surface so that they can be adsorbed. This first step is reversible in that the bacteria can be removed by simple washing. In the second step, which is irreversible, the bacteria are anchored to the surface by extracellular material produced by the bacteria. The 3 step model of Busscher and Weerkamp (1987) describes attachment of bacteria in terms of the distance the microorganism is located from the surface. Distances greater than $50 \mathrm{~nm}$ involve long-range forces. At this distance, attachment is reversible. As the distance between the microorganism and surface approaches $20 \mathrm{~nm}$, electrostatic interactions become involved. This step is at first reversible but, over time, is thought to become irreversible. The final step takes into account distances less than $15 \mathrm{~nm}$, in which additional forces to those in the first 2 steps come into play. The production of adhesive polymers occurs which results in the irreversible attachment of the microorganism to the surface. In both models, the 
occurrence of irreversible attachment is dependent upon the metabolic activity of the microorganism and its ability to produce adhesive materials.

\section{Mechanisms of attachment}

Current theories on the mechanisms by which microorganisms attach to solid substrata include: (1) receptor concept involving interactions between components of the cell and the substratum as in lectin-like interactions, (2) colloidal stability theories involving overall surfaces properties such as hydrophobicity and charge interactions, and (3) thermodynamic approaches based on interfacial free energies (Busscher and Weerkamp, 1987). Attachment of microorganisms to surfaces is metabolically favorable because organic molecules are found to be more concentrated at an interface. When surfaces are immersed in an aqueous environment, macromolecules and other lowmolecular-weight, hydrophobic molecules adsorb to the surface to form a conditioning film. Conditioning films alter both the charge and free energy of the surface. It is not clear to what extent the bacterial cell wall interacts with the conditioning film. The number and type of bacteria that will adhere to a surface, as well as the strength of the attachment, varies with the type of the surface. Surfaces generally are placed into 1 of 2 categories (Lappin-Scott et al., 1992): 
1. The high surface energy materials that are hydrophilic often carrying a negative charge (e.g., glass, metals, or mineral).

2. The low surface energy materials that are more hydrophobic with low charge (either positive or negative). Such surfaces include organic polymers such as plastics and Buna-N rubber.

Surfaces with a higher surface energy and activity more readily adsorb dissolved solutes or nutrients. The amount of nutrients at the surface then in turn affects the rate of bacterial colonization.

Pseudomonas spp. were found to attach in large numbers to hydrophobic plastic with no surface charge (Teflon and polystyrene), in moderate numbers to hydrophilic metals with a positive charge (platinum) and only in small numbers to hydrophilic, negatively charged substrata (glass) (Fletcher and Loeb, 1979). Salmonella typhimurium and $L$. monocytogenes both attach in large numbers to stainless steel and Buna-N rubber. However, when these surfaces were pretreated with milk proteins, attachment of these two organisms to either surface was significantly reduced (Helke et al., 1993). These researchers suggested that the milk proteins tested carried a net negative charge in their suspending menstruum, resulting in a repulsion of the negatively charged proteins adsorbed onto the surface and the negatively charged bacterial cells. Other researchers have reported on the effect of milk proteins on attachment of milk-associated microorganisms. Speers et al. (1984) observed an increase in attachment of milk- 
associated microorganisms to stainless steel and rubber surfaces in the presence of whey proteins. Meadows (1971) reported an increase in attachment of gram negative bacteria to a hydrophilic surface in the presence of casein.

Bacteria have been referred to as living colloids because of their small size, low density, net negative charge and variable degrees of cell surface hydrophobicity. Colloidal chemistry (DLVO theory) has been used to explain some of their behavior at or near surfaces (Pethica, 1980) . Based on colloidal chemistry, bacteria should be repelled electrostatically from surfaces at very low electrolyte concentrations. At higher concentrations, Van der Waals attractive forces can exceed electrical repulsion forces at distances of 10 to $20 \mathrm{~nm}$ from the surface. However, the strong repulsion forces should still prevent a body as large as a bacterium from making direct contact with a surface (Busscher and Weerkamp, 1987). The behavior of bacteria at or near a surface can not be fully explained by chemistry but must also consider any biological responses of the cell that may be involved in attachment. It has been proposed, that the strong repulsive forces, which prevents the bacterium from making direct contact with the surface, are overcome by the production of extracellular polymeric substances (EPS) (Marshall, 1992). Because these substances are not subject to these same repulsive forces, they are able to form a bridge between the bacterium and a food contact surface. This polymer bridging involves combinations of chemical bonding (electrostatic, covalent, and hydrogen), dipole interactions and hydrophobic interactions (Marshall, 1992). 
The composition and quantity of bacterial surface polymers vary considerably and are strongly influenced by growth and environmental conditions. Although extracellular polymers have often been reported as responsible for irreversible adhesion, this is not always the case. Brown et al. (1990) demonstrated widespread adhesion from mixed populations in a carbon-limited culture, despite no obvious evidence of extracellular polymeric production. A nitrogen-limited culture, however, resulted in poor adhesion, although large extracellular polymeric substances were observed.

Paul and Jeffery (1985) studied adhesion of Vibrio proteolytica to hydrophobic and hydrophilic surfaces. These researchers found that the attachment of $V$. proteolytica to a hydrophobic substratum (polystyrene) could be inhibited by greater than $97 \%$ by the proteolytic enzymes trypsin, pronase and chymotrypsin. These same enzymes were ineffective in preventing attachment of $V$. proteolytica to hydrophilic substrata such as glass or tissue culture dishes. These researchers suggested the existence of separate mechanisms for the adhesion of $V$. proteolytica to hydrophobic and hydrophilic substrata.

The nature of the surface, in part, dictates the degree to which microorganisms will attach to that surface, since the same microorganism will attach to different surfaces with varying degrees of efficiency. Numerous researchers have investigated the effect of bacterial surface hydrophobicity on the ability of bacteria to attach (Allison et al., 1990; Mafu et al., 1991). Methods used to determine hydrophobicity include, salt aggregation, electrophoretic mobility, bacterial adherence to hydrocarbons, hydrophobic interaction chromatography (HIC) and contact angle. Using the contact angle method, Mafu et al. 
(1991) determined that the surface free energy of $L$. monocytogenes Scott A is $65.9 \mathrm{~mJ}$. $\mathrm{m}^{-2}$, classifying the microorganism as a hydrophilic organism. The hydrophilic nature of the bacterial surface was furthered confirmed using the salt aggregation and HIC. $L$. monocytogenes aggregated at very high ammonium salt molarities and did not bind to octyl-sepharose using the HIC method.

Based on the thermodynamic concept proposed by Absolom et al. (1983) and Busscher et al. (1987), adhesion of $L$. monocytogenes should be more energetically favorable as the surface free energy of the solid substratum decreases. However, Mafu et al. (1991), did not find correlation between the low surface energy of polypropylene and rubber and the ability of $L$. monocytogenes to attach. In fact, these researchers found that L. monocytogenes could attach to both low and high energy surfaces after short contact times, suggesting that factors other than cell surface hydrophobicity is involved in the adhesion process of this microorganism.

\section{Physiological response of attachment}

Surface-induced stimulation of bacterial activity is well documented. Changes may include smaller cell size or an increased or altered production of extracellular material. The environment at the surface may differ from that of the bulk phase (e.g., $\mathrm{pH}$, redox potential) eliciting a response from the microorganism. Vandevivere and Kirkman (1993) reported that attachment to a solid surface induces exopolymer production by a number of subsurface isolates. When these same isolates were resuspended in fresh medium, 
exoploymer production decreased. The increase in exoploymer synthesis did not involve changes of the specific growth rate, growth stage or limiting nutrient. Much debate exists, however, about whether such stimulation results from derepression/induction, by contact with the surface, through specific operons/genes or is indirect and reflects physio-chemical influences of the surface on the surroundings of the cell wall (van Loosdrecht et al., 1990).

Under different conditions, the change observed in attached cells may be part of a sequence which begins before adhesion with cells in the planktonic state. In such cases, the changes in the cell may influence adhesive properties. The physiological state of the organism influences the rate and, possibly, the extent of attachment. Bryers and Characklis (1982) observed that attachment rate was directly proportional to growth rate in a mixed culture system. Others have reported a decrease in attachment rate with increasing specific growth rate for Pseudomonas. Pickett and Murano (1996) investigated the affect of chemical shock on the ability of $L$. monocytogenes to attach to stainless steel. They reported attachment levels of $L$. monocytogenes to be $10^{3} \mathrm{CFU} / \mathrm{ml}$ for both chemically treated and non-treated cells after a $24 \mathrm{~h}$ exposure period. Because attachment levels were not determined for exposure times shorter than $24 \mathrm{~h}$, it is not known whether chemical shock affected the rate of attachment. Proteins induced by environmental stresses may participate in attachment. Harold and Zottola (1989) have suggested that bacterial attachment to stainless steel surfaces involves a polysaccharide and protein matrix. These researchers observed that trypsin was effective in removing attached cells of P. fragi. 


\section{Adsorption kinetics of microbial adhesion}

Attachment is dependent upon the chemical and physical interactions between the potential substratum and the bacterial surface (Fletcher and Loeb, 1979). Physical chemistry has long been used to study the adsorption of gases onto solid surfaces (e.g., Langmuir equation). However, these theories have typically been applied only to the adhesion of "ideal particles". Microorganisms differ from these "ideal particles" in that, they are constantly changing to respond to their environment. Cells have neither a simple geometry nor a simple, uniform molecular composition. Intracellular chemical reactions are constantly occurring that affect the molecular composition both in the interior and at the surface of the microorganism. Application of thermodynamic principles to microbial adhesion is further complicated by the legitimacy of whether equilibrium conditions are achieved (Rutter and Vincent, 1984). Equilibrium conditions are only achieved in a closed system where no exchange of matter or energy occurs with the surroundings. Biological systems are primarily open systems, in which a steady state at best may be realized.

Even with these recognized limitations, the application of physical chemistry has proven useful in the study of bacterial attachment. Dabros and van de Ven (1983) found a number of similarities between the adhesion of bacterial cells and polystyrene latex particles. The latex particles, which are negatively charged, like a large majority of bacterial cell surfaces, adhered to negatively charged glass. Vanheacke et al. (1990) applied kinetic equations, developed for the adsorption of small particles onto inert surfaces, to describe adhesion of Pseudomonas aeruginosa to stainless steel. For both the 
adhesion of microorganisms and the adhesion of inert particles, the importance of desorption as well as adsorption was emphasized. Many studies on microbial attachment and biofilm formation have arbitrarily defined irreversibly attached cells as those cells which remained attached after simple washing. Irreversible attachment can be better described using thermodynamic principles. A particle is irreversibly attached to a surface when the free energy minimum $\left(G_{\min }\right)$ involved in the particle-surface interaction is large [i.e., $\mathrm{G}_{\min }>10 \mathrm{kT}$, for example], where $\mathrm{k}$ is the rate of the reaction and $\mathrm{T}$ is the temperature at which the reaction occurs (Rutter, and Vincent, 1984).

The Langmuir (1918) equation describes the adsorption of gases onto solid surfaces, for example, a surface having a certain number of adsorption sites $S$ of which $S_{1}$ may be occupied by the adsorbate. With $S_{0}$, representing unoccupied sites, $\mathrm{S}_{0}=\mathrm{S}-\mathrm{S}_{1}$. Adsorption equilibrium is treated as a dynamic state in which the rate of adsorption is equal to the rate of desorption. The rate of adsorption $\left(\mathrm{k}_{2}\right)$ is proportional to the pressure $(\mathrm{P})$ and surface collision frequency of the gaseous adsorbate on the unoccupied sites:

$$
\text { rate of adsorption }=\mathrm{k}_{2} \mathrm{PS}_{0}=\mathrm{k}_{2} \mathrm{P}\left(\mathrm{S}-\mathrm{S}_{1}\right)
$$

The rate of desorption $\left(k_{1}\right)$ is proportional to the number of occupied sites $S_{1}$ :

rate of desorption $=k_{1} S_{1}$ 
Setting the rate of adsorption equal to the rate of desorption, and solving for $S_{1}$ gives

$$
\begin{aligned}
& S_{1}=\theta=\frac{b P}{1+b P}
\end{aligned}
$$

where $\theta$ is the fraction of surface covered and $b=k_{2} / k_{1}$.

Relatively few chemisorption systems obey the simple Langmuir model well, especially at the extremes. The basic model, however, is sound. Often, deviations from the model are attributed to nonuniformity of the test surface. For irreversibly bound cells, the kinetic analysis proposed by Langmuir in the context of gas adsorption may be adopted, where the number of small particles as a function of time $n(t)$ is written as:

$$
\frac{\mathrm{dn}(\mathrm{t})}{\mathrm{dt}}=-\mathrm{kn}(\mathrm{t})[1-\theta(\mathrm{t})]
$$

where $k$ is the rate constant, and $\theta(t)$ is the coverage of the macroscopic surfaces, as given by:

$$
\theta(t)=\frac{\underline{n}_{0}-n(t)}{n_{0}-n_{f}}
$$

where $n_{0}$ and $n_{f}$ are the initial and final number concentrations of the particles in suspension, respectively. This adsorption model is only applicable when attachment is irreversible. For discussions on reversible adhesion see Vincent et al. (1980) and Boughley et al. (1978). 


\section{Detachment from the surface}

Traditionally, detachment of microorganisms from surfaces has been studied in mature biofilms. The detachment phenomena, as it applies to microorganisms within a biofilm, may be categorized as shearing or sloughing. Shearing refers to the continuous removal of small portions of the biofilm. This category of detachment is dependent on fluid dynamic conditions. With an increase in biofilm thickness and fluid shear stress at the biofilm-fluid interface, the rate of detachment also increases. Sloughing refers to a random, massive removal of biofilm attributable to changes within the biofilm environment such as fluctuations in nutrient or oxygen levels. Detachment has also been shown to occur with various chemical treatments. Treatments that have been effective in removing biofilm material from surfaces include: (1) oxidizing biocides (e.g., chlorine), (2) UV radiation, (3) surfactants, and (4) non-oxidizing biocides (Characklis, 1984). Herald and Zottola (1989) found that trypsin, sodium dodecyl sulfate (SDS) and $\mathrm{NaOH}$ were effective in removing cells of Pseudomonas fragi attached overnight to stainless steel. However, when the surface was treated with Cetavolon, a chemical known to react with polysaccharides, detachment did not occur. Addition of Triton-X, a nonionic surfactant, to the surface resulted in stabilization of attached $P$. fragi.

Over the years, the most frequently used methods to enumerate bacteria on surfaces include agar flood method, rinse solution method and agar contact method. It has been noted, that when any one of these methods is repeatedly applied to the same area 
on a surface the number of bacteria removed decreases with each application.

Mathematically this has been expressed as

$$
\mathrm{N}_{\mathrm{T}}=\mathrm{N}_{1} /\left(1-10^{8}\right)
$$

where $N_{1}$ is the number of colonies obtained at the first sampling and $s$ is the slope of the line obtained when $\log$ CFU is plotted against the sample number. Given a linear relationship is obtained, the total number of bacteria that can be removed from the surface, $\mathrm{N}_{\mathrm{T}}$, can be calculated (Wong and Cerf, 1995).

To date, few reports have been published on the removal of attached microorganisms that have yet to form a mature biofilm. However, detachment of microbial cells and related biofilm material occurs from the moment of initial attachment (Characklis, 1984). The ease with which microorganisms shed from surfaces contributes to their ability to spread and contaminate food product items in their vicinity (Eginton et al., 1995). Food-borne pathogens possessing a low infective dose, such as $E$. coli 0157:H7, or pathogens currently regulated as zero tolerance in ready-to-eat foods, such as Salmonella spp. and Listeria monocytogenes, do not have to be present on food contact surfaces at levels consistent with mature biofilms to present a public health threat. A better understanding of the factors affecting the strength of attachment of microorganisms to food contact surfaces is needed. 


\section{Listeria and attachment}

Herald and Zottola (1988) first studied the attachment of L. monocytogenes to a food contact surface. Using scanning electron microscopy (SEM), these investigators demonstrated the ability of $L$. monocytogenes to attach to stainless steel at various temperatures and $\mathrm{pH}$ values. Other researchers have used similar SEM techniques to describe $L$. monocytogenes attachment to various food contact surfaces such as stainless steel, polypropylene, and rubber (Mafu et al., 1990). Recently, Blackman and Frank (1996) demonstrated that $L$. monocytogenes could attach and form single species biofilms on various food processing surfaces including stainless steel, Teflon $\circledast$, nylon, and polyester floor sealant. However, research efforts have largely concentrated on determining the resistance of L. monocytogenes (either attached or within a biofilm) to cleaners and common sanitizers (Frank, 1990; Krysinski et al., 1992; Lee and Frank, 1991; Ren and Frank, 1993). To date, few if any reported studies have addressed the effect of environmental stresses on the ability of $L$. monocytogenes to attach to different surfaces. The capability of $L$. monocytogenes to adhere to surfaces represents a source of potential contamination for a wide variety of material coming in contact with solid surfaces. However, the environmental conditions which affect the rate of adhesion of $L$. monocytogenes to food contact surfaces are not well understood and have not been defined. 
MANUSCRIPTS FORMATTED FOR PUBLICATION

IN

JOURNAL OF FOOD PROTECTION 


\title{
III. EFFECT OF ENVIRONMENTAL STRESS ON THE ABILITY OF LISTERLA MONOCYTOGENES SCOTT A TO ATTACH TO FOOD CONTACT SURFACES
}

\author{
L. Michele Smoot and Merle D. Pierson
}

Department of Food Science and Technology, Virginia Tech, Blacksburg, VA 24061 


\begin{abstract}
Attachment of Listeria monocytogenes Scott A to Buna-N rubber and stainless steel under different temperature and $\mathrm{pH}$ conditions at the time of cell growth or at the time of attachment were investigated. All experiments were conducted in sterile phosphate buffer to avoid cell growth during exposure to the test surfaces. Numbers of attached cells increased with increasing attachment temperature $\left(10^{\circ}\right.$ to $\left.45^{\circ} \mathrm{C}\right)$ and exposure time for both test surfaces. Maximum levels of attached cells were obtained when cell growth occurred at $30^{\circ} \mathrm{C}$. Downward, but not upward, shifts in the cell suspension holding temperature prior to attachment to Buna-N rubber resulted in reduced adhered cell populations. Maximum levels of adhered cells to Buna-N rubber were not affected by adjustments of the attachment medium pH between 4 to 9 . However, after short contact times (i.e. less than $30 \mathrm{~min}$ ), levels of attached cells were lower when attachment occurred under alkaline conditions. Growth $\mathrm{pH}$ was also found to affect the levels of adhered cell populations to Buna-N rubber. L. monocytogenes Scott A was found to attach at higher levels on stainless steel than Buna-N rubber for all temperature and $\mathrm{pH}$ parameters evaluated in this study. Greater differences in attached cell populations were also observed for Buna-N rubber during the first $30 \mathrm{~min}$ of exposure when compared to stainless steel for all temperature and $\mathrm{pH}$ conditions investigated.
\end{abstract}




\section{INTRODUCTION}

Both physical and chemical treatments are used in food processing to eliminate and control the presence of pathogenic and spoilage microorganisms in foods. When cleaning and sanitizing regimes are poorly executed or inadequate, microorganisms may remain in the processing environment in an injured state. sublethal treatments or stresses (i.e. heat, anaerobiosis, oxidation, starvation, cold shock, ethanol) can result in unique adaptive responses by bacteria, including those of public health concern $(3,7,13,17,18,21,25,31)$. For example, starvation stress is often accompanied by an increase in cell number, a decrease in cell size, an increase in cell surface hydrophobicity and an increase in adhesiveness. these factors make the bacteria more prone to adhere to solid surfaces where they benefit from an enhanced nutrient status (20). Nystrom et al. (24) demonstrated increased adherence of Vibrio spp. to a variety of surfaces after nutrient depletion. Continued adhesion and growth of adhering bacteria eventually leads to biofilm formation.

L. monocytogenes is ubiquitous in nature, being found on soil, feces, plants and in water samples (22). Consequently, this pathogen is frequently found on raw materials used in food processing. Cox et al. (5) demonstrated that listeriae could be found in all types of food production environments. Once present in the processing environment, control of L. monocytogenes has proven to be difficult. Although improvements have 
been made in controlling $L$. monocytogenes in food systems, its presence in the processing environment is still readily found.

A number of studies have demonstrated the ability of $L$. monocytogenes to attach and form biofilms on food contact surfaces $(2,11)$. To date, the majority of research in the food industry addressing adhered L. monocytogenes has focused on the ability of this microorganism to resist environmental stresses $(8,12,15,16,26)$. Herald and Zottola (11) first studied the attachment of $L$. monocytogenes to a food contact surface. Other researchers have used similar SEM techniques to describe L. monocytogenes attachment to various food contact surfaces such as stainless steel, polypropylene, and rubber $(2,19)$. However, only a few studies have addressed what affect environmental stresses have on the ability of $L$. monocytogenes to attach to different surfaces. The capability of $L$. monocytogenes to adhere to surfaces represents a source of potential contamination for a wide variety of material coming in contact with solid surfaces. The environmental conditions which affect adhesion of $L$. monocytogenes to food contact surfaces are not well understood. Therefore, the objective of this study is to determine, in a quantitative manner, the effects of different environmental conditions on the ability of Listeria monocytogenes Scott A to food contact surfaces. 


\section{MATERIALS AND METHODS}

Test organism and culture maintenance

L. monocytogenes strain Scott A was obtained from the culture collection of the Department of Food Science and Technology, Virginia Polytechnic Institute and State University, Blacksburg VA. The culture was maintained on trypticase soy agar (TSA, Difco, Detroit, MI) supplemented with $0.6 \%$ yeast extract (YE, Difco) slants (TSA-YE) held at $4^{\circ} \mathrm{C}$. Prior to use, the culture was subcultured on 2 consecutive days in trypticase soy broth (TSB, Difco) supplemented with $0.6 \%$ yeast extract (Difco) (TSB-YE) and incubated at $37^{\circ} \mathrm{C}$.

\section{Test surfaces}

Buna-N rubber, obtained from M. G. Newell Greensboro, NC, and stainless steel (type 304, \#4 finish), were used for attachment of $L$. monocytogenes. The test surfaces were cut into $2 \times 5 \mathrm{~cm}$ coupons (ca. $2 \mathrm{~mm}$ in thickness), washed by soaking in warm alkaline cleaner (Klenzade, Division of Ecolab Inc., St. Paul, MN) overnight and rinsed repeatedly with distilled water. The surfaces were sterilized by autoclaving for $15 \mathrm{~min}$ at $121^{\circ} \mathrm{C}$ 


\section{Attached cell development}

One $\mathrm{ml}$ of a 18-24 h TSB-YE culture was used to inoculate $250 \mathrm{ml}$ of TSB-YE pre-tempered to the growth temperature. Cells were incubated at the growth temperature with shaking (100 rpm) and grown to mid-log phase based on previous growth curve studies. Mid-log phase cells were harvested by centrifugation, washed and resuspended in an equal volume of sterile phosphate buffer (0.02 M Potassium Phosphate Buffer, pH 7.0) (PB). One ml aliquots of the washed cell suspension were used to inoculate multiple 250 $\mathrm{ml}$ screw cap flasks containing $99 \mathrm{ml}$ of PB pre-tempered to the attachment temperature to give a target level of $1 \times 10^{7} \mathrm{CFU} / \mathrm{ml}$. After incubation for $15 \mathrm{~min}$ with shaking (100 rpm) at the attachment temperature, 1 sterile Buna-N rubber or stainless steel coupon pretempered to the attachment temperature was added to each flask. Incubation with shaking was continued at the test temperature. Coupons for each test surfaces were removed after $0,5,10,15,20,30,60$, and $120 \mathrm{~min}$ of exposure. Test surfaces were prepared for enumeration and attached cells were quantitated as described below.

\section{Enumeration of attached cells}

To enumerate attached cell populations the test surfaces were first rinsed in $20 \mathrm{ml}$ volumes of the sterile PB. This rinse step was repeated 4 more times to remove any reversibly attached cells. Viable counts on the rinse buffer established that less than $1 \mathrm{CFU}$ per $\mathrm{ml}$ was detected in the fifth rinse. After the last rinse, the buffer was aspirated and the 
side of the surface which had been positioned upward in the flask during exposure to the cell suspension was swabbed with a calcium alginate swab. The swab was transferred to $10 \mathrm{ml}$ of sterile PB and the sample serially diluted in $0.1 \%$ peptone. Attached cells were enumerated on TSA-YE spread plates incubated at $37^{\circ} \mathrm{C}$ for $48 \mathrm{~h}$. Duplicate surfaces were enumerated at each attachment period and the average number of cells was calculated as CFU per $\mathrm{cm}^{2}$ test surface. Swabbed surfaces were pour plated with TSA-YE and incubated at $37^{\circ} \mathrm{C}$ for $48 \mathrm{~h}$ to ensure that all attached cells had been removed.

\section{Effect of temperature on attachment}

Three sets of experiments were performed to determine the effect of temperature on the ability of $L$. monocytogenes to attach to the test surfaces. The first set determined the effect of growth temperature prior to attachment. Cells were grown to mid-log phase in TSB-YE at either $10^{\circ}, 30^{\circ}$ or $42^{\circ} \mathrm{C}$ with shaking. For each growth temperature, test surfaces (Buna-N rubber only) were added to test cell suspensions at $30^{\circ} \mathrm{C}$ as previously described. Triplicate trials were performed for each growth temperature.

The second set of experiments was designed to determine the effect of temperature at the time of attachment. In these experiments, cells were grown to mid-log phase at $30^{\circ} \mathrm{C}$. Test cell suspensions were prepared as previously described and held for 15 min at either $10^{\circ}, 30^{\circ}$ or $45^{\circ} \mathrm{C}$ prior to the addition of Buna-N rubber surfaces. Stainless steel surfaces were tested at attachment temperatures of $10^{\circ}, 30^{\circ}$, and $45^{\circ} \mathrm{C}$ only. After exposure for the pre-determined times, surfaces were removed and attached cells enumerated. Triplicate trials were performed for each attachment temperature. 
The third set of experiments was performed to determine the effect of shifts in temperature on the ability of $L$. monocytogenes to attach to Buna-N rubber surfaces. In these experiments, cells were grown to mid-log phase in TSB-YE at $30^{\circ} \mathrm{C}$. Ten $\mathrm{ml}$ of the washed cell suspension was used to inoculate flasks containing $90 \mathrm{ml}$ of PB pre-tempered to $37^{\circ} \mathrm{C}$. After $15 \mathrm{~min}$ at $37^{\circ} \mathrm{C}, 10 \mathrm{ml}$ aliquots were removed and used to inoculate flasks containing $90 \mathrm{ml}$ of $\mathrm{PB}$ pre-tempered to $45^{\circ} \mathrm{C}$. The Buna-N rubber surfaces were immediately added and held for the pre-determined exposure times prior to enumeration. This experiment was then repeated where cells were grown to mid-log at $30^{\circ} \mathrm{C}$, shifted to $21^{\circ} \mathrm{C}$ and attached at $10^{\circ} \mathrm{C}$. Triplicate trials were performed for each temperature shift. The cell concentration in the test suspensions for all experimental trials was maintained at approximately $1 \times 10^{7} \mathrm{CFU} / \mathrm{ml}$.

\section{Effect of pH on attachment}

The following experiments were performed to determine the effect of $\mathrm{pH}$ on the ability of $L$. monocytogenes to attach to the test surfaces. The first set of trials were designed to determine the effect of growth $\mathrm{pH}$ prior to attachment. Cells were grown to mid-log phase at $30^{\circ} \mathrm{C}$ in TSB-YE adjusted to either $\mathrm{pH} 5.5,7.0$ or 8.5. For each growth $\mathrm{pH}$, the test surfaces were added to the cell suspension in $\mathrm{PB}(\mathrm{pH} 7.0)$ and incubated at $30^{\circ} \mathrm{C}$ as previously described. Triplicate trials were performed for each growth $\mathrm{pH}$.

Cells were grown to mid-log phase at $30^{\circ} \mathrm{C}$ in TSB-YE (pH 7.0) to determine the effect of $\mathrm{pH}$ at the time of attachment to Buna-N rubber. Test cell suspensions were 
prepared in sterile $\mathrm{PB}$ adjusted to either $\mathrm{pH} 4.0,5.0,6.0,7.0,8.0$, or 9.0. After addition and exposure for the pre-determined times, surfaces were removed and attached cells enumerated. Triplicate trials were performed at each attachment $\mathrm{pH}$ level. 


\section{RESULTS}

\section{Effect of temperature on attachment}

Cells of $L$. monocytogenes Scott A were able to attach to Buna-N rubber and stainless steel at all temperatures evaluated (Figures 1 and 2). The numbers of attached cells increased with increasing temperature and exposure time for both Buna-N rubber and stainless steel. During the first 10 min of exposure, levels of attached L. monocytogenes were consistently higher on stainless steel across all test temperatures. Attached cell populations at $45^{\circ} \mathrm{C}$ and $10^{\circ} \mathrm{C}$ differed by approximately 1 log on Buna-N rubber and 0.5 $\log$ on stainless steel after exposure for $120 \mathrm{~min}$. A comparison of the maximum number of adhered cells obtained for the 2 test surfaces at the different attachment temperatures indicated that higher levels of attachment occurred on stainless steel (Figure 3). When the temperature for cell attachment was decreased, the difference in the maximum number of adhered cells detected on the 2 different surfaces was shown to increase.

The effect of growth temperature on attachment of $L$. monocytogenes to Buna-N rubber at $30^{\circ} \mathrm{C}$ was determined (Figure 4). Cells grown at $30^{\circ} \mathrm{C}$ prior to exposure to the test surface resulted in the highest concentration of attached cells, irrespective of the exposure time. The lowest concentration of attached cells, after $120 \mathrm{~min}$ of contact with the test surface, was observed for cells grown at $10^{\circ} \mathrm{C}$. Cells grown at $42^{\circ} \mathrm{C}$ were found to have adhered cell populations similar to $30^{\circ} \mathrm{C}$ grown cells at the end of the test period. However, the adhered population for $42^{\circ} \mathrm{C}$ grown cells was found to be approximately 1 
$\log$ lower than that observed for $30^{\circ} \mathrm{C}$ grown cells during the first $10 \mathrm{~min}$ of exposure to Buna-N rubber (Figure 4).

The effect of shifts in temperature on the attachment of $L$. monocytogenes to Buna-N rubber was studied (Figure 5). An increase in temperature from $30^{\circ}$ to $37^{\circ} \mathrm{C}$ for 15 min prior to exposure to Buna-N rubber at $45^{\circ} \mathrm{C}$ did not appear to affect the ability of L. monocytogenes to adhere to this surface. At all sampling times, similar attached cell populations at $45^{\circ} \mathrm{C}$ were obtained for both shifted and non-shifted cells. A decrease in temperature from $30^{\circ}$ to $21^{\circ} \mathrm{C}$ for $15 \mathrm{~min}$ prior to attachment at $10^{\circ} \mathrm{C}$ did, however, result in attachment levels which differed from cells attached at $10^{\circ} \mathrm{C}$ with no prior temperature shift. Over the 120 min exposure period, the concentration of attached cells at $10^{\circ} \mathrm{C}$ was consistently lower for cells which were shifted to $21^{\circ} \mathrm{C}$ prior to attachment. Maximum attachment levels of non-shifted cells were approximately 2 logs higher than the maximum level obtained for shifted cells.

\section{Effect of $p H$ on attachment}

L. monocytogenes was able to attach to Buna- $\mathrm{N}$ rubber at all $\mathrm{pH}$ values evaluated (Figure 6). The maximum levels of attached L. monocytogenes (grown in TSB-YE, pH 7.0 at $30^{\circ} \mathrm{C}$ ) obtained on Buna-N rubber after the $120 \mathrm{~min}$ exposure period was not affected by altering the $\mathrm{pH}$ of the attachment environment within the $\mathrm{pH}$ range of 4 to 9 . However, alkaline $\mathrm{pH}$ levels resulted in lower numbers of attached cells at short contact times when compared to neutral or acidic attachment conditions. 
Attachment of L. monocytogenes to Buna-N rubber and stainless steel in PB (pH 7.0) after growth to mid-log in TSB-YE adjusted to either $\mathrm{pH} 5.5,7.0$ or 8.5 was determined (Figures 7 and 8). On Buna-N rubber, the highest concentration of adhered cells occurred for the $\mathrm{pH} 7.0$ grown cells. The maximum level of attached cells, occurring after $120 \mathrm{~min}$ exposure time, was approximately $1 \times 10^{4} \mathrm{CFU} / \mathrm{cm}^{2}$ for $\mathrm{pH} 7.0,1 \times 10^{3}$ $\mathrm{CFU} / \mathrm{cm}^{2}$ for $\mathrm{pH} 8.5$, and $1.5 \times 10^{2} \mathrm{CFU} / \mathrm{cm}^{2}$ for $\mathrm{pH} 5.5$ grown cells. After $5 \mathrm{~min}$ exposure time, the concentration of attached cells on Buna-N rubber ranged from $3.0 \mathrm{x}$ $10^{2} \mathrm{CFU} / \mathrm{cm}^{2}$ to $<10 \mathrm{CFU} / \mathrm{cm}^{2}$ for $\mathrm{pH} 7.0$ and $\mathrm{pH} 5.5$ grown cells, respectively. Similarly on stainless steel, the highest concentration of attached cells across all sampling times was obtained for $\mathrm{pH} 7.0$ grown cells and the lowest concentration was obtained for pH 5.5 grown cells. Higher numbers of adhered cells were obtained on stainless steel for all growth $\mathrm{pH}$ values tested, regardless of the exposure time, when compared to Buna-N rubber (Figure 9). 


\section{DISCUSSION}

Attachment is dependent upon the chemical and physical interactions between the potential substratum, the bacterial surface, and the polymeric adhesive $(\sigma)$. The influence of a number of surface properties, both substratum and bacterium, on attachment have been investigated (e.g., hydrophobicity, surface charge, surface free energy, and extracellular polymer production). Buna-N rubber and stainless steel were used in this study because of their widespread use in the food industry and because they differ in their physical properties. Buna-N rubber is hydrophobic and stainless steel is hydrophilic, though it is thought to possess hydrophobic regions. The original surface characteristics of a substratum can be altered by the aqueous environment. Surfaces are conditioned by adsorption of molecules from the surrounding bulk fluid. Adsorbed molecules, both organic and inorganic, in turn alter the surface properties of the substratum. Bacterial attachment to conditioned surfaces has been shown to differ depending upon the molecules adsorbed and the microorganisms present. Helke et al. (10) reported a decrease in the level of attachment of L. monocytogenes and Salmonella typhimurium in the presence of

milk proteins. While others have reported an increase in attachment in the presence of whey proteins (28). Adhesion to food contact surfaces has also been reported in Ringer's solution (30) and pork liquor (4). It appears that conditioning of a surface with organic molecules is not required for adhesion to occur and may even result in reduced levels of microorganisms that initially attach to that surface (12). 
In this study $L$. monocytogenes, suspended in PB, was able to attach to both test surfaces within short contact times. In addition, the time to attach and the extent of attachment to the surfaces was influenced by the environmental conditions. A number of researchers have previously demonstrated the ability of $L$. monocytogenes to attach to Buna-N rubber and stainless steel. Mafu et al. (19) observed attachment of $L$. monocytogenes, using SEM, to rubber and stainless steel after 20 min contact time. $L$. monocytogenes was shown to adhere to stainless steel, polypropylene, glass and rubber to varying degrees at both $20^{\circ}$ and $4^{\circ} \mathrm{C}$. Herald and Zottola (11) used SEM to demonstrate adherence of L. monocytogenes to stainless steel at different temperatures and $\mathrm{pH}$ levels. However, few if any attempts have been made to quantitate the levels of attachment to food contact surfaces under different environmental conditions.

Environmental conditions are known to affect cell surface characteristics. Growth rate as well as growth phase have been shown to influence the regulatory mechanisms which determine cell surface properties (9). Exposure to acid stress conditions has resulted in specific outer membrane proteins being produced in $S$. typhimurium which in turn caused an increase in cell surface hydrophobicity (17). Temperature has been widely reported to affect protein synthesis. Jones et al. (14) reported the synthesis of unique outer membrane proteins by $E$. coli when growth occurred at $10^{\circ} \mathrm{C}$. These researchers suggested that the presence of new outer membrane proteins accounted for the increased stability of attached cells in the absence of an extracellular matrix. 
In recent years, the majority of biofilm research within the food industry has focused on the resistance of microorganisms within biofilms to common sanitizers and other antimicrobials. Very little work has been directed toward identifying environmental variables which influence the attachment of microorganisms to food contact surfaces. A need for further investigations on the relative importance of extracellular polymers, metabolic rate, motility, $\mathrm{pH}$, temperature, etc. on attachment of microorganisms to surfaces was suggested by Rutter and Vincent (27).

Evaluating both temperature and $\mathrm{pH}$ on the ability of L. monocytogenes to attach, we found that environmental conditions influenced the attachment of this microorganism to food contact surfaces. Temperature at the time of attachment affected the ability of $L$. monocytogenes to attach to both Buna-N rubber and stainless steel. For Buna-N rubber, cells grown at $30^{\circ} \mathrm{C}$ adhered to a greater extent when attachment occurred at $45^{\circ} \mathrm{C}$. Lower levels of attachment occurred at $10^{\circ} \mathrm{C}$ when compared to the higher temperatures investigated. Others have reported increased attachment when conditions for metabolic activity are most favorable $(11,29)$. The decrease in attachment at the lower temperature may, in part, result from a decrease in hydrophobic interactions between the cell surface and the hydrophobic surface of the Buna-N rubber. Differences observed in the attachment curves (Figures 1 and 2) at the high and low attachment temperatures were greater on Buna-N rubber than on stainless steel which would support the involvement of hydrophobic interactions. 
Attached cell populations were highest for cells grown at $30^{\circ} \mathrm{C}$ when metabolic activity was optimum as compared to the other growth temperatures (Figure 4). The differences in adhered cell populations observed for cultures grown at $10^{\circ}, 30^{\circ}$ and $42^{\circ} \mathrm{C}$ cannot be attributed to growth phase, since all cells were grown to mid-log phase prior to attachment. The numbers of adhered cells may, however, reflect the growth rate of the microorganism. Growth rates have previously been shown to influence cell surface hydrophobicity. Allison et al. (l) demonstrated that the surface hydrophobicities of various Gram-negative species were directly related to growth rate.

No difference in attached cell populations was observed when test cell suspensions experienced an upward temperature shift (Figure 5). However when the temperature was shifted down, the extent of attachment occurring on Buna-N rubber was reduced when compared to cells which were attached at $10^{\circ} \mathrm{C}$ with no prior temperature shift. When growing cells are shifted to temperatures within the normal growth range, growth continues at a rate characteristic of the new temperature. However, when cells are shifted to an extreme high or low temperature, the growth rate decreases dramatically, sometimes even stopping altogether for a period of time (23). The differences in attachment observed in this temperature shift experiment may be a result of changes in growth rate. The shift from $30^{\circ}$ to $10^{\circ} \mathrm{C}$ did not affect the attachment process (since attachment has been found to occur very rapidly) as much as for those cells which had undergone a shift to $21^{\circ} \mathrm{C}$ prior to exposure to the test surface. This temperature change may have resulted in an altered growth or metabolic rate which in turn affected the attachment process. 
Herald and Zottola (11) reported higher numbers of attached cells to stainless steel at $\mathrm{pH} 7.0$ and 8.0 when compared to $\mathrm{pH}$ 5.0. These researchers were using SEM to observe attached cells after contact to the test surface in TSB for 18-36 h. The increase in attachment was attributed to the optimum metabolic activity for this organism between $\mathrm{pH}$ 7.0 and 8.0. No attempts were made to determine the influence of growth rate or growth phase on attachment during these extended contact times. We found maximum levels of adhered cells on Buna- $\mathrm{N}$ rubber were reached within the 120 min exposure time and did not differ for all attachment $\mathrm{pH}$ conditions studied (Figure 6). However, differences in attached cell populations throughout the 120 min exposure were observed when cells were grown to mid-log at either $\mathrm{pH} 5.5,7.0$, or 8.5. Higher numbers of attached cells were detected on both surfaces when grown at a $\mathrm{pH}$ level optimum for metabolic activity (i.e. $\mathrm{pH}$ 7.0) Although effects of growth $\mathrm{pH}$ on adhered cell populations were observed on both test surfaces, a marked decrease in attachment to Buna-N rubber occurred when cells were first grown to mid-log at $\mathrm{pH} 5.5$.

In this study, L. monocytogenes was found to attach at higher levels on stainless steel, irrespective of the environmental conditions. These findings are consistent with others who have used SEM techniques to demonstrate greater attachment to stainless steel when compared to Buna-N rubber $(11,19)$.

In conclusion, we showed that exposing cells of $L$. monocytogenes to sublethal levels of environmental stress such as $\mathrm{pH}$ and temperature can affect the ability of this pathogen to attach to common food contact surfaces. These results indicate that 
fundamental food processing parameters can influence the persistence of $L$. monocytogenes in the processing environment. A better understanding of those processing conditions which affect attachment of microorganisms is needed to prevent biofilm development. Further investigations into the affect of extreme environmental stress on the ability of pathogenic microorganisms to adhere to surfaces is warranted. Such studies could provide valuable insights into the attachment mechanisms and perhaps lead to better methods of control. 


\section{ACKNOWLEDGMENTS}

This study was supported in part by the Virginia Agricultural Experiment Station. 


\section{REFERENCES}

1. Allison, D. A., D. J. Evans, M. R. W. Brown and P. Gilbert. 1990. Surface hydrophobicity of Pseudomonas biofilms cultured at various specific growth rates. FEMS Microbiol. Lett. 71:101-104.

2. Blackman, I. C. and J. F. Frank. 1996. Growth of Listeria monocytogenes as a biofilm on various food-processing surfaces. J. Food Prot. 59:827-831.

3. Bunning, V. K., R. G. Crawford, J. T. Tierney and J. T. Peeler. 1990. Thermotolerance of Listeria monocytogenes and Salmonella typhimurium after sublethal heat shock. Appl. Environ. Microbiol. 56:3216-3219.

4. Chamberlain, A. H. L. and S. Johal. 1987. Biofilms on meat processing surfaces. In: Biodeterioration 7. D. R. Houghton, R. N. Smith and H. O. W. Eggins (eds.). Elsevier Applied Science, London \& New York. pp. 57-61.

5. Cox, L. J., T. Kleiss, J. L. Cordier, C. Cordellana, P. Konkel, C. Pedrazzini, R. Beumer and A Siebenga. 1989. Listeria spp. in food processing, non-food and domestic environments. Food Microbiol. 6:49-61.

6. Fletcher, M. and G. I Loeb. 1979. Influence of substratum characteristics on the attachment of a marine pseudomonad to solid surfaces. Appl. Environ. Microbiol. 37:67-72.

7. Foster, J. W. 1991. Salmonella acid shock proteins are required for the adaptive acid tolerance response. J. Bacteriol. 173:6896-6902.

8. Frank, J. F. and R. A. Koffi. 1990. Surface-adherent growth of Listeria monocytogenes is associated with increased resistance to surfactant sanitizers and heat. J. Food Prot. 53:550-554.

9. Gilbert, P., D. J. Evans, I. G. Duguid and M. R. W. Brown. 1991. Surface characteristics and adhesion of Escherichia coli and Staphylococcus epidermidis. J. Appl. Bacteriol. 71:72-77.

10. Helke, D. M., E. B. Somers and A. C. L. Wong. 1993. Attachment of Listeria monocytogenes and Salmonella typhimurium to stainless steel and buna-N in the presence of milk and milk components. J Food Prot. 56:479-484. 
11. Herald, P. J. and E. A. Zottola. 1988. Effect of various agents on the attachment of Pseudomonas fragi to stainless steel. J. Food Sci. 54:461-464.

12. Hood, S. K. and E. A. Zottola. 1995. Biofilms in food processing. Food Control. 6:9-18.

13. Jenkins, D. E., J. E. Schultz and A. Matin. 1988. Starvation-induced cross protection against hydrogen peroxide challenge in Escherichia coli. J. Bacteriol. 170:3910-3914.

14. Jones, P. G., R. A., Van Bogelen and F. C. Neidhardt. 1987. Induction of proteins in response to low temperature in Escherichia coli. J. Bacteriol. 169:2092-2095.

15. Krysinski, E. P., L. J. Brown and T. J. Marchisello. 1992. Effect of cleaners and sanitizers on Listeria monocytogenes attached to product contact surfaces. J. Food Prot. 55:246-251.

16. Lee, S. H. and J. F. Frank. 1991. Inactivation of surface-adherent Listeria monocytogenes by hypochlorite and heat. J. Food Protect. 54:4-6.

17. Leyer, G .J. and E. A. Johnson. 1993. Acid adaptation induces cross-protection against environmental stress in Salmonella typhimurium. Appl. Environ. Microbiol. 59:1842-1847.

18. Lou, Y. and A. E. Yousef. 1996. Resistance of Listeria monocytogenes to heat after adaptation to environmental stresses. J Food Prot. 59:465-471.

19. Mafu, A. A., D. Roy, J. Goulet and P. Magney. 1990. Attachment of Listeria monocytogenes to stainless steel, glass, polypropylene, and rubber surfaces after short contact times. J. Food Prot. 53:742-746.

20. Marshall, K. C. 1992. Biofilms: An overview of bacterial adhesion, activity, and control at surfaces. ASM News 58:202-207.

21. Murano, E. A. and M. D. Pierson. 1992. Effect of heat shock and growth atmosphere on the heat resistance of Escherichia coli 0157:H7. J. Food Prot. 55:171-175.

22. National Advisory Committee on Microbiological Criteria for Foods. 1991. Listeria monocytogenes. Int. J. Food Microbiol. 14:185-246.

23. Neidhardt, F. C. J. L. Ingraham and M. Schechter. 1990. The effect of 
23. Neidhardt, F. C. J. L. Ingraham and M. Schechter. 1990. The effect of temperature, pressure, and pH, p. 226-246. In: Physiology of the bacterial cell: a molecular approach. Sinauer Associates, Inc. Sunderland, Massachusetts.

24. Nystrom, T., K. Flardh and S. Kjelleberg. 1990. Response to multiple-nutrient starvation in marine Vibrio sp. strain CCUG 15956. J. Bacteriol. 172:7085-7097.

25. O'Driscoll, B., C. G. M. Gahan and C. Hill. 1996. Adaptive acid tolerance in Listeria monocytogenes: Isolation of an acid-tolerant mutant which demonstrates increased virulence. Appl. Environ. Microbiol. 62:1693-1698.

26. Ren, T. and J. F. Frank. 1993. Susceptibility of starved planktonic and biofilm Listeria monocytogenes to quaternary ammonium sanitizer as determined by direct viable and agar plate counts. J. Food Prot. 56:573-576.

27. Rutter, P. R. and B. Vincent. 1984. Physiochemical interactions of the substratum, microorganisms, and the fluid phase. In: Microbial Adhesion and Aggregation . K. C. Marshall (ed.) New York, pp: 21-38.

28. Speers, J. G. S. and A. Gilmour. 1985. The influence of milk and milk components on the attachment of bacteria to farm dairy equipment surfaces. J. Appl. Bacteriol. 59:325-332.

29. Stanley, P. M. 1983. Factors affecting the irreversible attachment of Pseudomonas aeruginosa to stainless steel. Can. J. Microbiol. 29:1493-1499.

30. Suarez, B., C. M. Perreiros and M. Criado. 1992. Adherence of psychrotrophic bacteria to dairy equipment surfaces. J. Dairy Res. 59: 381-388.

31. VanBogelen, R. A., P. M. Kelley and F. C. Neidardt. 1987. Differential induction of heat shock, SOS, and oxidative stress regulons and accumulation of nucleotides in Escherichia coli. J. Bacteriol. 169:26-32. 


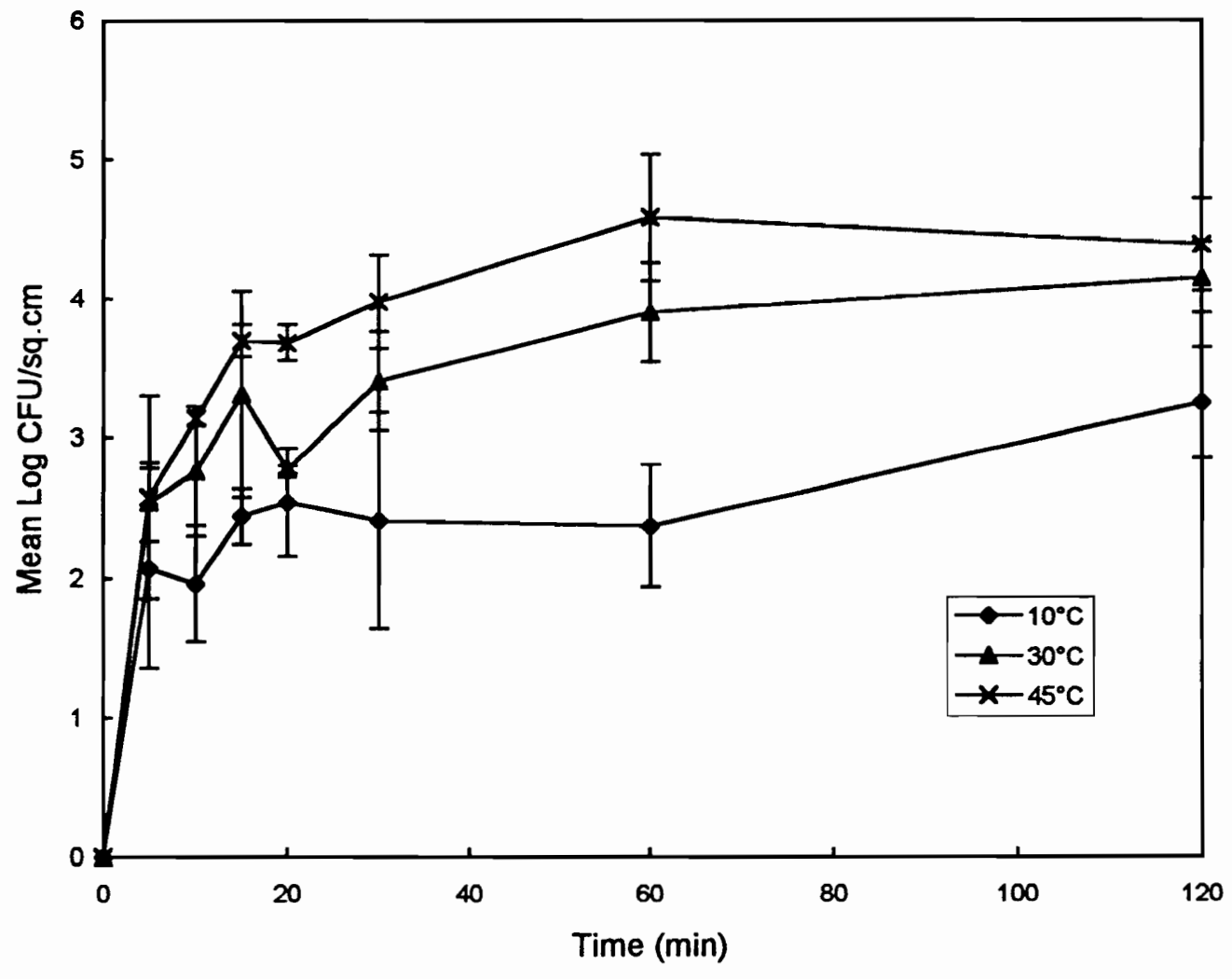

Figure 1. Attachment profile for Listeria monocytogenes Scott A grown to mid-log at $30^{\circ} \mathrm{C}$ in TSB-YE (pH 7.0) and exposed to BunaN rubber at $10^{\circ}, 30^{\circ}$, and $45^{\circ} \mathrm{C}$ in $P B(p H 7.0)$ for $120 \mathrm{~min}$. 


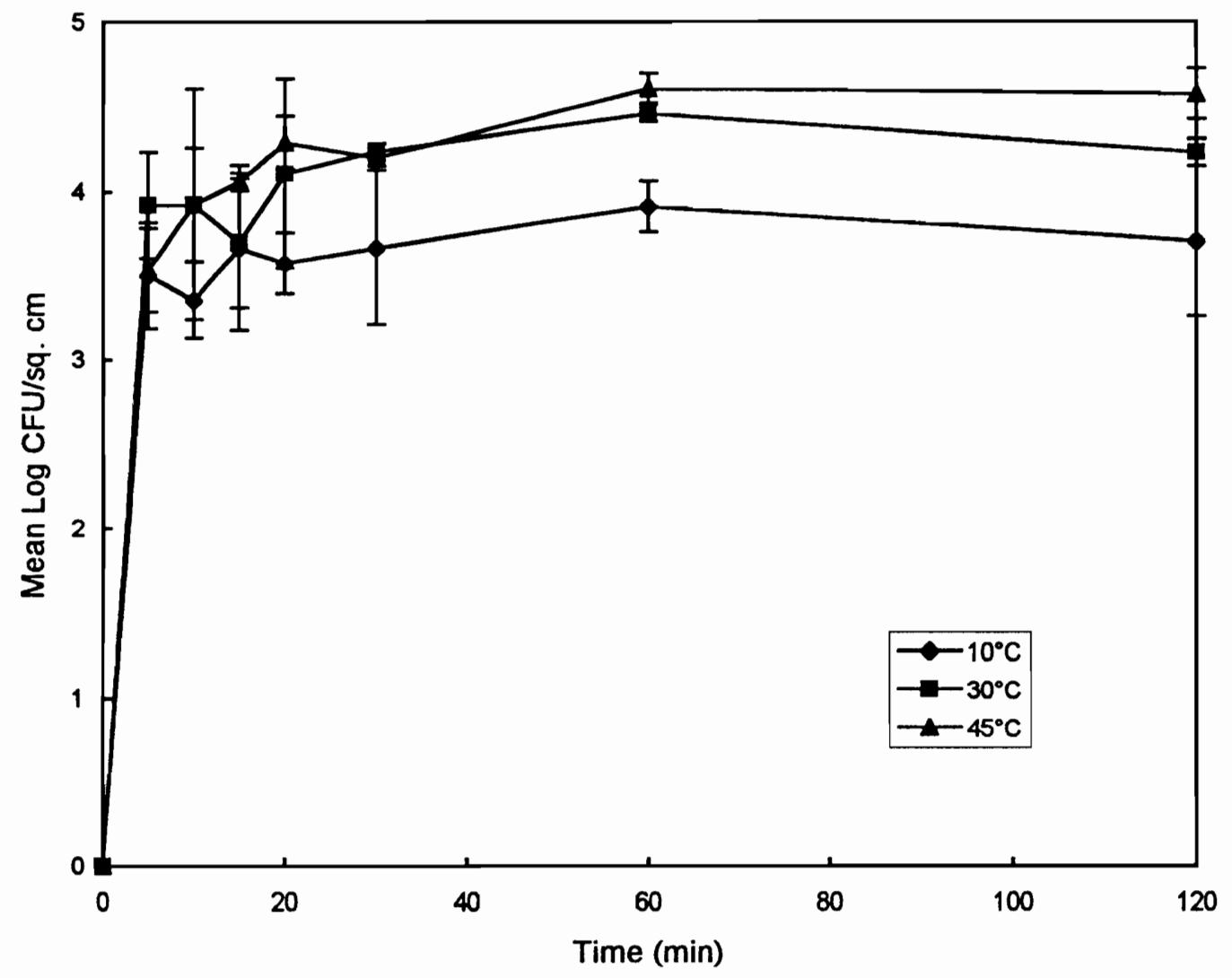

Figure 2. Attachment profile for Listeria monocytogenes Scott A grown to mid-log at $30^{\circ} \mathrm{C}$ in TSB-YE ( $p H$ 7.0) and exposed to stainless steel at $10^{\circ}, 30^{\circ}$, and $45^{\circ} \mathrm{C}$ in $P B(p H 7.0)$ for $120 \mathrm{~min}$. 


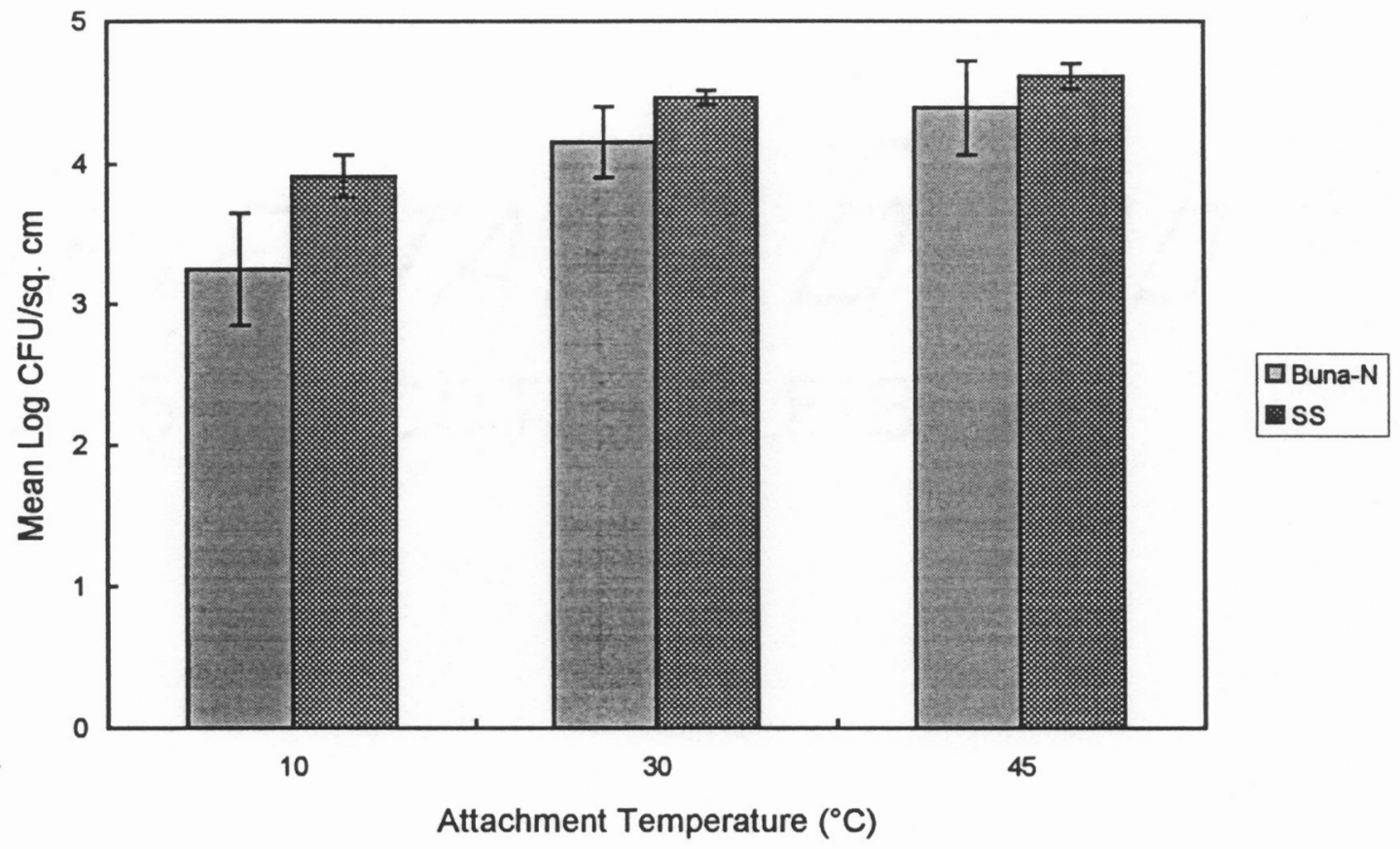

Figure 3. Effect of attachment temperature on maximum number of Listeria monocytogenes Scott A detected on Buna-N rubber and stainless steel surfaces after 120 min exposure in $P B(p H 7.0)$. 


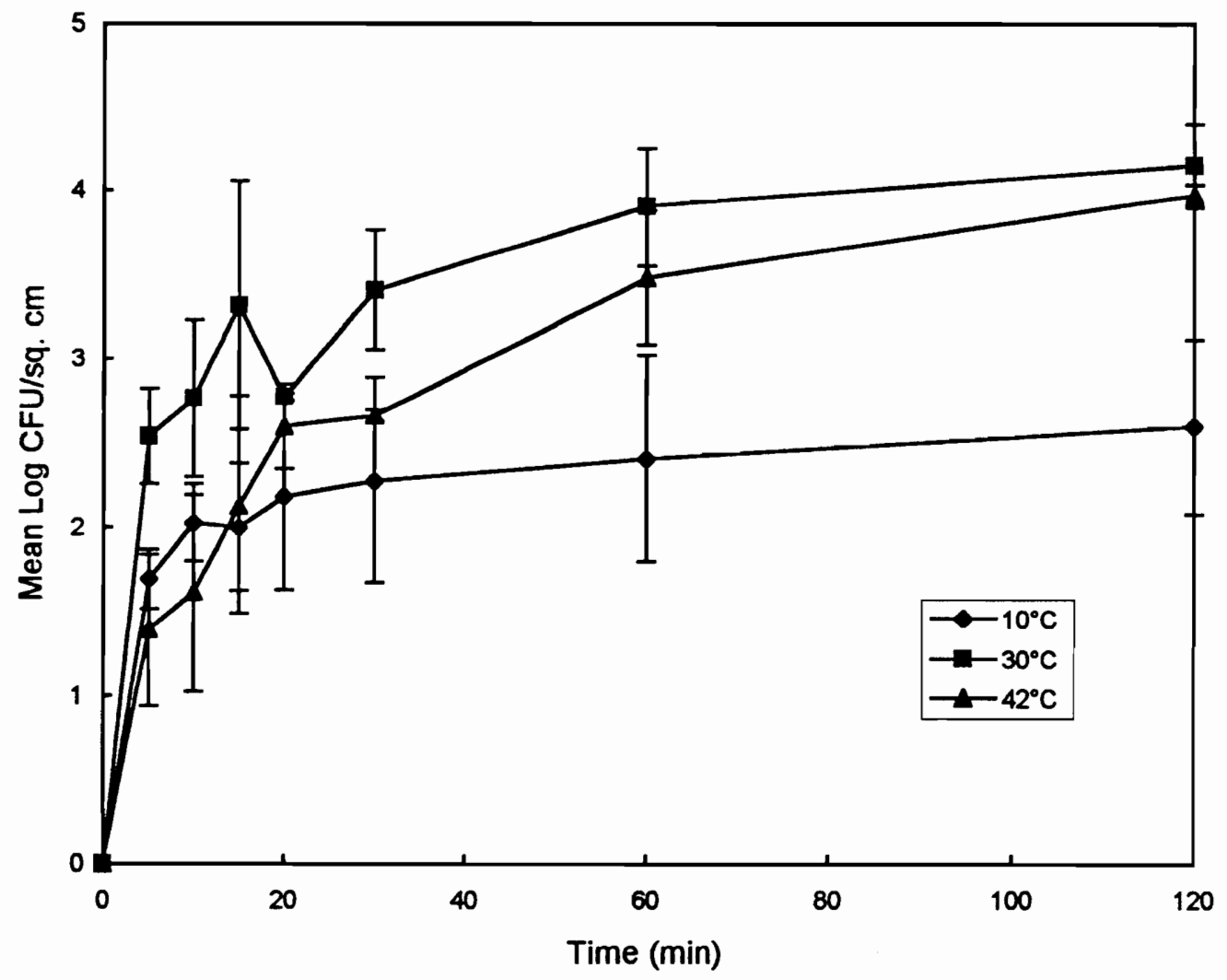

Figure 4. Attachment profile for Listeria monocytogenes Scott A grown to mid-log at $10^{\circ}, 30^{\circ}$, and $42^{\circ} \mathrm{C}$ in TSB-YE (pH 7.0) and exposed to Buna-N rubber at $30^{\circ} \mathrm{C}$ in $\mathrm{PB}$ (pH 7.0) for 120 min. 


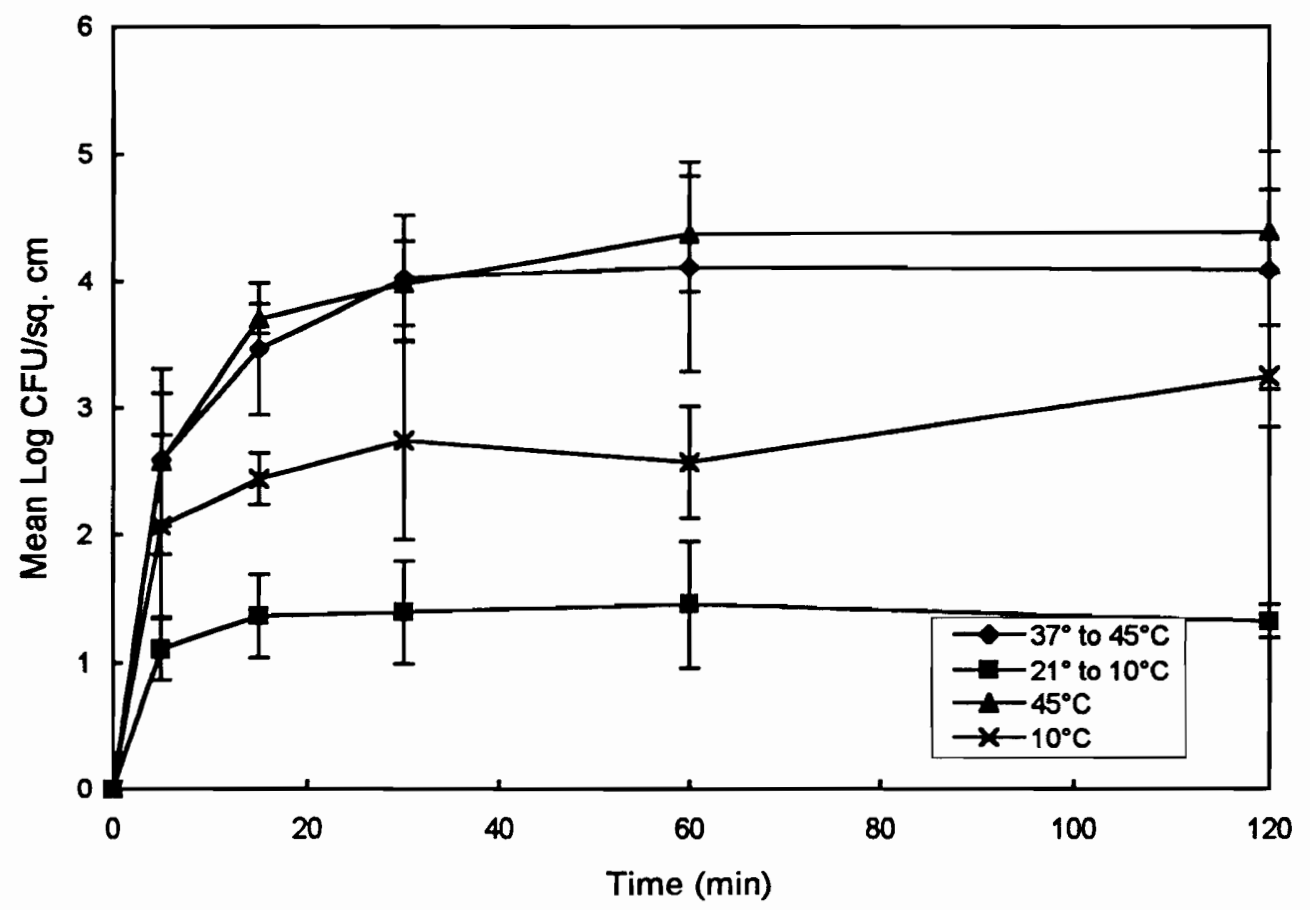

Figure 5. Attachment profile for Listeria monocytogenes Scott A grown to mid-log at $30^{\circ} \mathrm{C}$ in TSB-YE ( $p H$ 7.0), held at either $37^{\circ}$ or $21^{\circ} \mathrm{C}$ for $15 \mathrm{Min}$ in $\mathrm{PB}(\mathrm{pH} 7.0)$ and exposed to Buna-N rubber at $45^{\circ}$ and $10^{\circ} \mathrm{C}$ in $P B(p H 7.0)$, respectively, for $120 \mathrm{~min}$. 


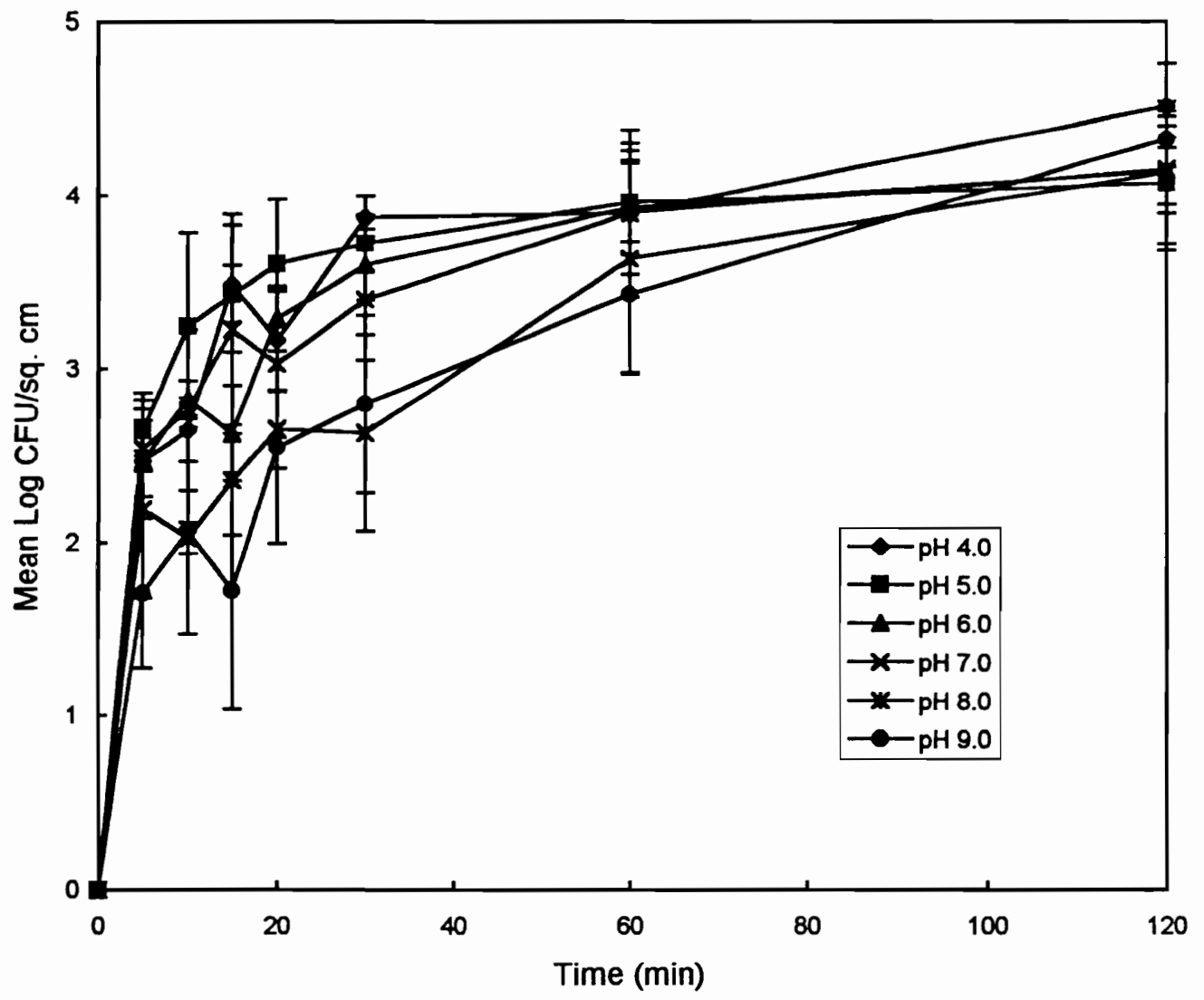

Figure 6. Attachment profile for Listeria monocytogenes Scott A grown to mid-log at $30^{\circ} \mathrm{C}$ in TSB-YE (pH 7.0) and exposed to Buna$N$ rubber in $P B$ adjusted to $p H 4.0,5.0,6.0,7.0,8.0$, and 9.0 for $120 \mathrm{~min}$. 


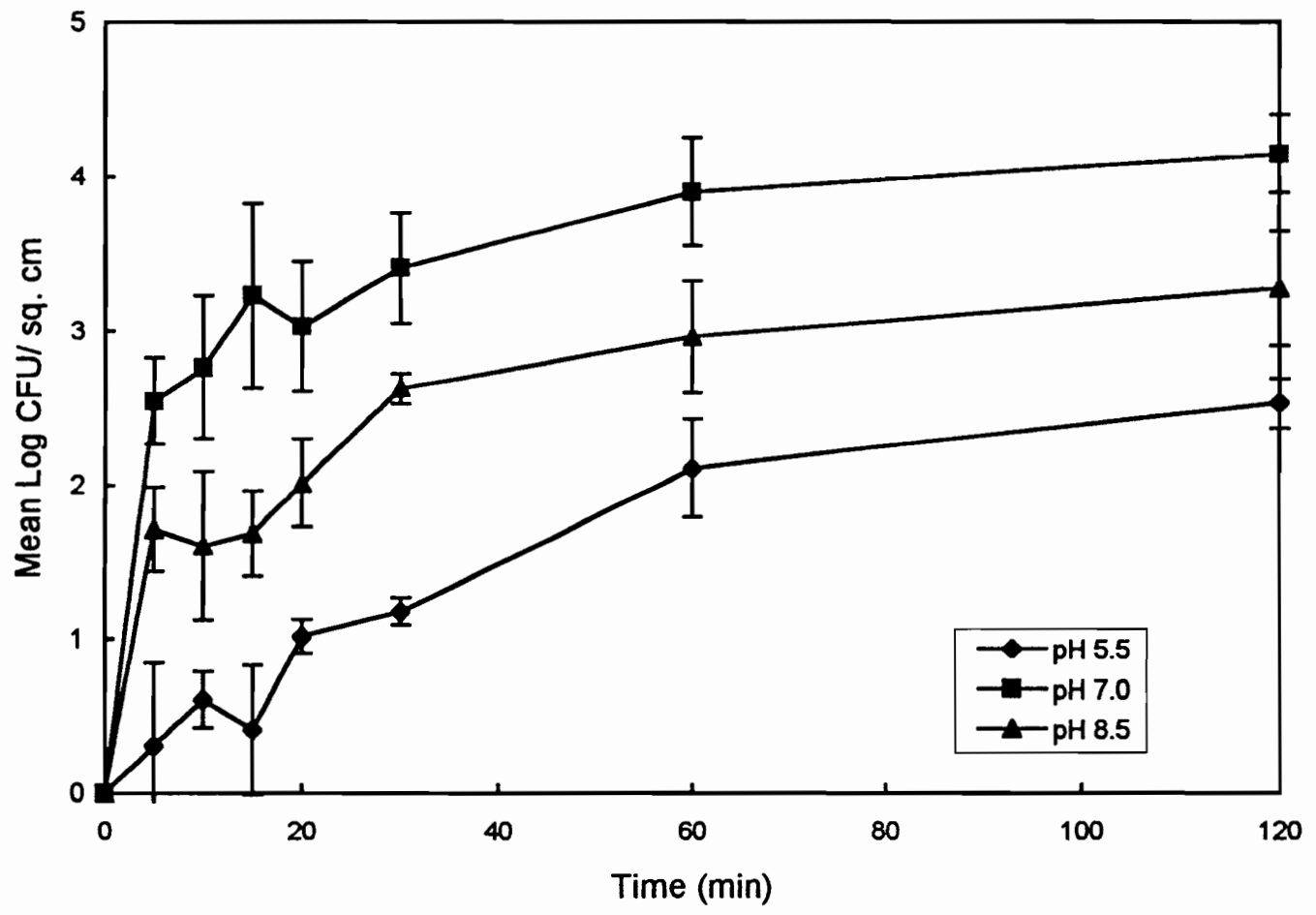

Figure 7. Attachment profile for Listeria monocytogenes Scott A grown to mid-log in pH 5.5, 7.0, and 8.5 TSB-YE at $30^{\circ} \mathrm{C}$ and exposed to Buna-N rubber at $30^{\circ} \mathrm{C}$ in $\mathrm{PB}(\mathrm{pH}$ 7.0) for $120 \mathrm{~min}$. 


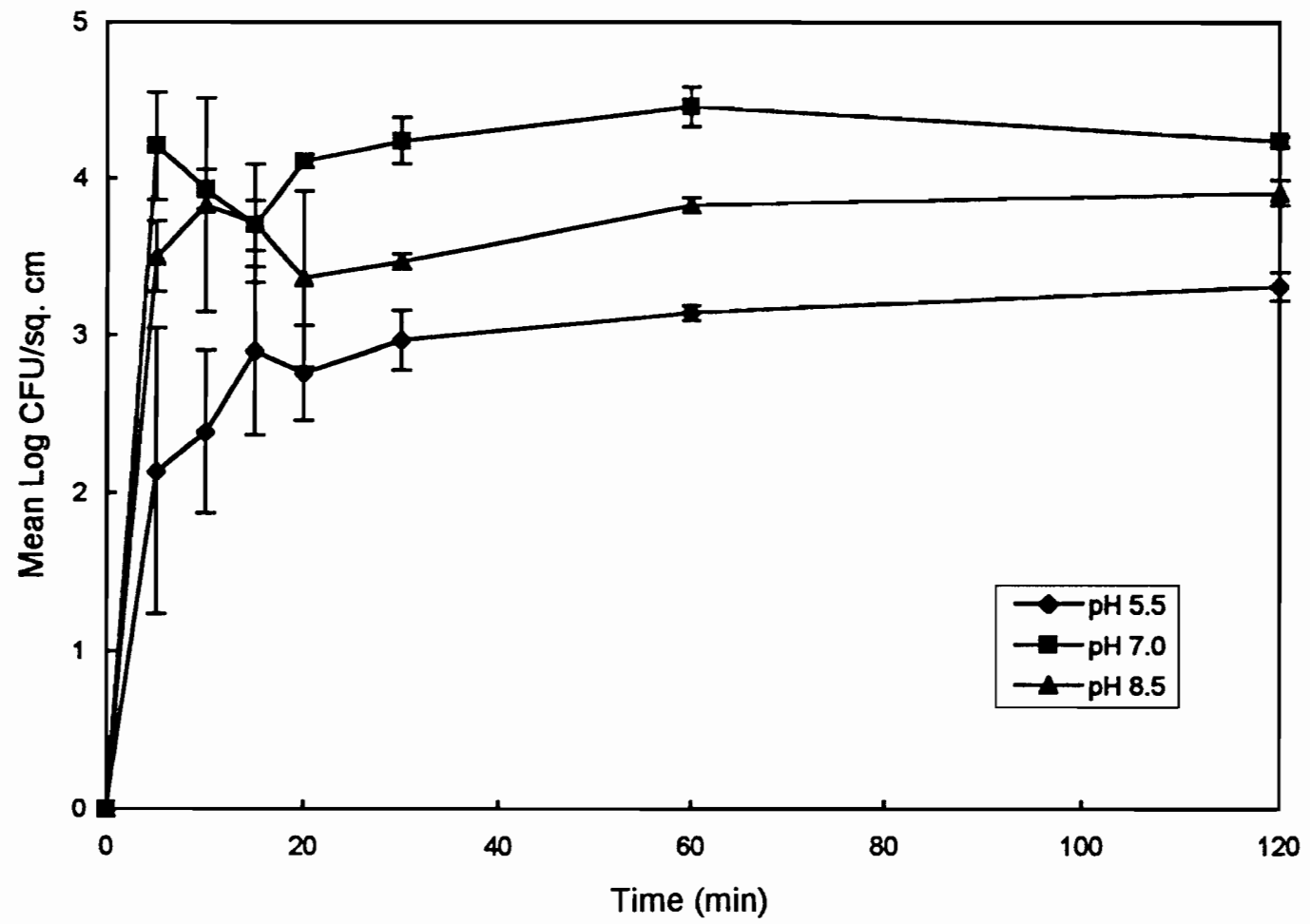

Figure 8. Attachment profile for Listeria monocytogenes Scott A grown to mid-log in $p H 5.5,7.0$, and $8.5 T S B-Y E$ at $30^{\circ} \mathrm{C}$ and exposed to stainless steel at $30^{\circ} \mathrm{C}$ in $P B(p H 7.0)$ for $120 \mathrm{~min}$. 


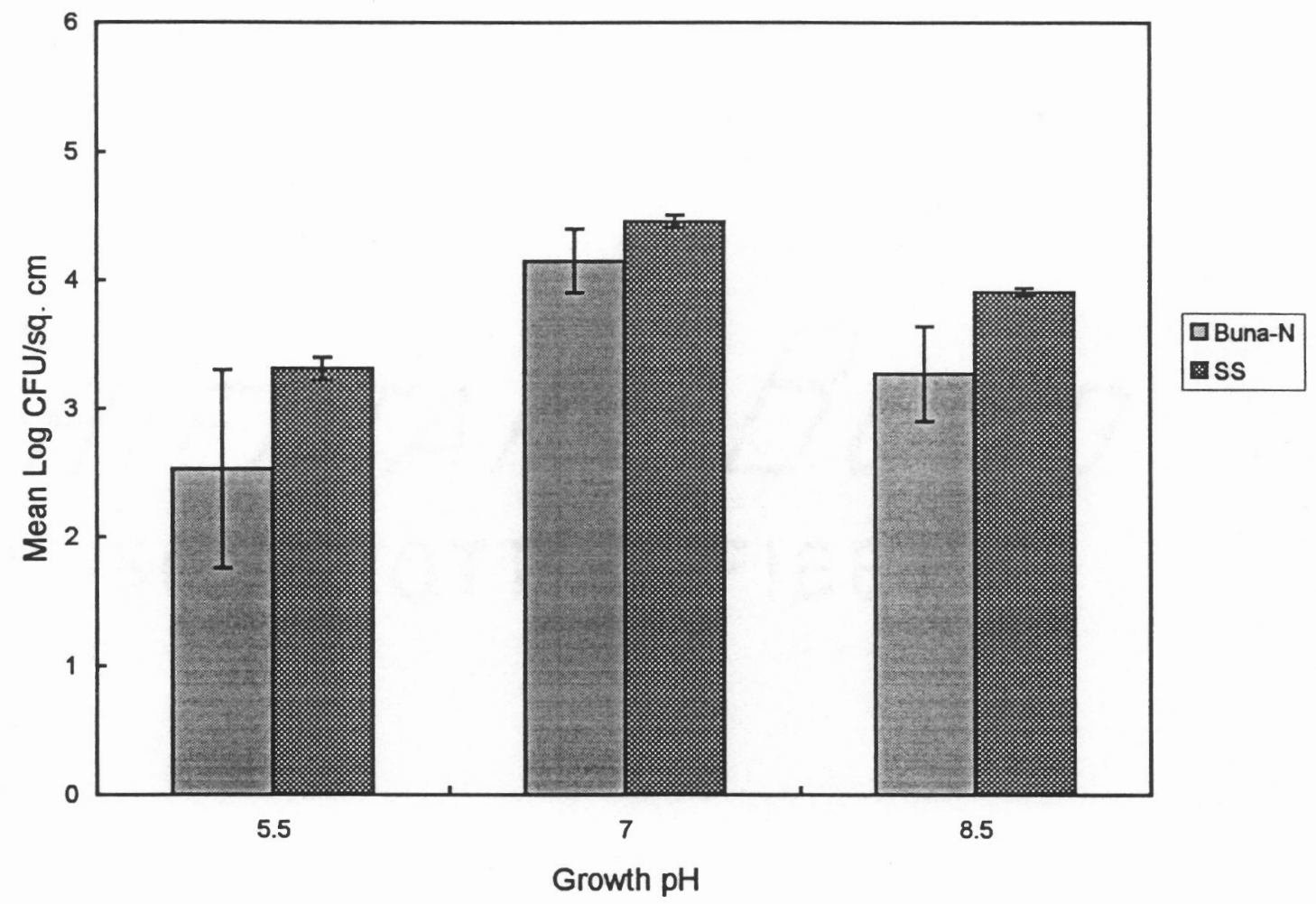

Figure 9. Effect of growth $p H$ on maximum number of Listeria monocytogenes Scott A detected on Buna-N rubber and stainless steel surfaces after 120 min exposure in $P B$ at $30^{\circ} \mathrm{C}$. 
IV. INFLUENCE OF ENVIRONMENTAL STRESS ON KINETICS OF ATTACHMENT OF LISTERIA MONOCYTOGENES SCOTT A TO BUNA-N RUBBER AND STAINLESS STEEL

L. Michele Smoot and Merle D. Pierson

Department of Food Science and Technology, Virginia Tech, Blacksburg, VA 24061 


\begin{abstract}
Attachment and detachment of Listeria monocytogenes Scott A to Buna-N rubber and stainless steel under varying conditions of temperature and $\mathrm{pH}$ were investigated in laboratory model systems. Numbers of attached cells increased with increasing attachment temperature $\left(10^{\circ}\right.$ to $45^{\circ} \mathrm{C}$ ) and time (up to $120 \mathrm{~min}$ ) for both test surfaces. Compared to Buna- $\mathrm{N}$ rubber, the rate of attachment to stainless steel was markedly more rapid for all temperature and $\mathrm{pH}$ conditions studied and could not be calculated. Rate of attachment to Buna-N rubber was found to be significantly lower when cells were attached at $10^{\circ} \mathrm{C}$. Growth temperature did not significantly affect rates of adhesion to Buna-N rubber. Altering the medium $\mathrm{pH}$ during attachment between 4 to 9 demonstrated that rates of adhesion were slower under alkaline conditions. Growth $\mathrm{pH}$ was also found to significantly affect rates of attachment to Buna-N rubber. Detachment of cells adhered to Buna-N rubber was significantly affected by growth temperature, but not growth $\mathrm{pH}$. Significant differences in detachment were also found between Buna-N rubber and stainless steel, inferring stronger attachment to Buna-N rubber. Cell surface hydrophobicity was found to be affected by both growth temperature and growth $\mathrm{pH}$. However, changes in hydrophobicity could not be correlated to differences in rates of attachment. Addition of $0.01 \%$ trypsin to the attachment medium during cell exposure to either test surface resulted in a $99.9 \%$ reduction in the adhered cell population when compared to controls. This would suggest that proteins play a role in the initial attachment process of L. monocytogenes.
\end{abstract}




\section{INTRODUCTION}

Over the past decade, Listeria monocytogenes has been regarded as one of the leading causes of foodborne illness. The organism has been found in a wide range of food products including dairy, meat, poultry, seafood as well as fruits and vegetables (30). Its high mortality rate, wide occurrence in nature and ability to grow at refrigeration temperatures has prompted regulatory agencies in some countries to implement a zero tolerance of L. monocytogenes in ready-to-eat foods. For microorganisms in which a zero tolerance is in effect, the presence of attached cells may be as significant a threat to the production of safe food as well developed biofilms (17). The ability of $L$. monocytogenes to attach to various surfaces has been well documented $(4,12,14,19,21,25)$. The presence of $L$. monocytogenes on food contact surfaces represents a source of potential contamination. From the moment of initial attachment, detachment of microbial cells and related biofilm material from surfaces occurs (7). The ease with which microorganisms shed from surfaces contributes to their ability to spread and contaminate food product items in their vicinity (9).

Microorganisms in the environment behave differently from those grown under optimal conditions in laboratory media. Recently, numerous studies investigating the effects of environmental stress on microorganisms have been published $(5,11,18,23,24,29,32,33)$. Responses to environmental stress include a decrease in cell size, altered growth rate, changes in the cell surface properties such as degree of 
hydrophobicity and an increased resistance to severe stress or stresses due to altered protein synthesis. Leyer and Johnson (23) observed the synthesis of specific outer membrane proteins and increased cell surface hydrophobicity in acid adapted cells of Salmonella typhimurium. These researchers suggested that acid stress could affect the ability of this microorganism to attach to hydrophobic surfaces. Herald and Zottola (15) first studied the attachment of $L$. monocytogenes to a food contact surface using SEM. Other researchers have used similar SEM techniques to describe $L$. monocytogenes attachment to various food contact surfaces such as, stainless steel, polypropylene, and rubber (25). The environmental conditions which affect the rate of adhesion of $L$. monocytogenes to food contact surfaces, however, are not well understood or defined.

Studies from other scientific disciplines have reported Langmuir isotherm-type curves for attachment of microorganisms to surfaces $(6,31)$. Although Langmuir's theory of gas adsorption has typically been applied to ideal particles, the Langmuir equation has been useful in describing the kinetics of attachment of a number of microorganisms. In a previous study, we reported on the attachment of $L$. monocytogenes to stainless steel and Buna-N rubber under different environmental conditions (38). In this study we further investigate how temperature and $\mathrm{pH}$ affects attachment to food contact surfaces by examining rates of attachment and ease of detachment. 


\section{MATERIALS AND METHODS}

\section{Test organism and culture maintenance}

L. monocytogenes strain Scott A was obtained from the culture collection of the Department of Food Science and Technology, Virginia Polytechnic Institute and State University, Blacksburg VA. The culture was maintained on trypticase soy agar (TSA, Difco, Detroit, MI) supplemented with $0.6 \%$ yeast extract (YE, Difco) slants (TSA-YE) held at $4{ }^{\circ} \mathrm{C}$. Prior to use, the culture was subcultured on 2 consecutive days in trypticase soy broth (TSB, Difco) supplemented with $0.6 \%$ yeast extract (Difco) (TSB-YE) and incubated at $37^{\circ} \mathrm{C}$.

\section{Test surfaces}

Buna-N rubber, obtained from M. G. Newell Greensboro, NC, and stainless steel (type 304, \#4 finish), were used for attachment of $L$. monocytogenes. The test surfaces were cut into $2 \times 5 \mathrm{~cm}$ coupons (ca. $2 \mathrm{~mm}$ in thickness), washed by soaking in warm alkaline cleaner (Klenzade, Division of Ecolab Inc., St. Paul, MN) overnight and rinsed repeatedly with distilled water. The surfaces were sterilized by autoclaving for $15 \mathrm{~min}$ at $121^{\circ} \mathrm{C}$ 
Attached cell development

One $\mathrm{ml}$ of a 18-24 h TSB-YE culture was used to inoculate $250 \mathrm{ml}$ of TSB-YE pre-tempered to the growth temperature. Cells were incubated at the growth temperature with shaking (100 rpm) and grown to mid-log phase based on previous growth curve studies. Mid-log phase cells were harvested by centrifugation, washed and resuspended in an equal volume of sterile phosphate buffer (0.02 M Potassium Phosphate Buffer, pH 7.0) (PB). One $\mathrm{ml}$ aliquots of the washed cell suspension were used to inoculate multiple 250 $\mathrm{ml}$ screw cap flasks containing $99 \mathrm{ml}$ of PB pre-tempered to the attachment temperature to give a target level of $1 \times 10^{7} \mathrm{CFU} / \mathrm{ml}$. After incubation for $15 \mathrm{~min}$ with shaking (100 rpm) at the attachment temperature, 1 sterile Buna-N rubber or stainless steel coupon pretempered to the attachment temperature was added to each flask. Incubation with shaking was continued at the test temperature. Coupons for each test surfaces were removed after $0,5,10,15,20,30,60$, and 120 min of exposure. Test surfaces were prepared for enumeration and attached cells were quantitated as described below.

\section{Enumeration of attached cells}

To enumerate attached cell populations the test surfaces were first rinsed in $20 \mathrm{ml}$ volumes of the sterile PB. This rinse step was repeated 4 times to remove any reversibly attached cells. Viable counts on the rinse buffer established that less than 1 CFU per $\mathrm{ml}$ was detected in the fifth rinse. After the last rinse, the buffer was aspirated and the side of the surface which had been positioned upward in the flask during attachment was swabbed with a calcium alginate swab. The swab was transferred to $10 \mathrm{ml}$ of sterile PB and the 
sample serially diluted in $0.1 \%$ peptone. Attached cells were enumerated on TSA-YE spread plates incubated at $37^{\circ} \mathrm{C}$ for $48 \mathrm{~h}$. Duplicate surfaces were enumerated at each attachment period and the average number of cells was calculated as CFU per $\mathrm{cm}^{2}$ test surface. Swabbed surfaces were pour plated with TSA-YE and incubated at $37^{\circ} \mathrm{C}$ for $48 \mathrm{~h}$ to ensure that all attached cells had been removed.

\section{Effect of temperature on attachment}

Attachment profiles developed in previous experiments (38) investigating the effects of temperature were used to calculate rates of adhesion. Rates of adhesion were determined for cells grown at either $10^{\circ}, 30^{\circ}$ or $42^{\circ} \mathrm{C}$ and attached at $30^{\circ} \mathrm{C}$ to Buna-N rubber and cells grown at $30^{\circ} \mathrm{C}$ and attached at either $10^{\circ}, 30^{\circ}$ or $45^{\circ} \mathrm{C}$ to stainless steel and Buna-N rubber.

\section{Effect of pH on attachment}

Attachment profiles developed in previous experiments (38) investigating the effects of $\mathrm{pH}$ were used to calculate rates of adhesion. Rates of adhesion were determine for cells grown at either $\mathrm{pH} 5.5,7.0$ or 8.5 and attached at $\mathrm{pH} 7.0$ to Buna-N rubber and stainless steel as well as for cells grown at $\mathrm{pH} 7.0$ and attached at either $\mathrm{pH} 4.0,5.0,6.0$, $7.0,8.0$ or 9.0 to Buna-N rubber. 


\section{Salt Aggregation Test}

The effect of growth temperature on the cell surface hydrophobicity was determined using the salt aggregation test (SAT) as described by Rozgonyi et al. (35) and Mafu et al. (26). One ml of an 18-24 h culture was used to inoculate $250 \mathrm{ml}$ of TSB-YE pre-tempered to either $10^{\circ}, 30^{\circ}$ or $42^{\circ} \mathrm{C}$. Cells were grown to mid-log with shaking (100 rpm). For each growth temperature, $1 \mathrm{ml}$ was centrifuged and resuspended in an equal volume of $0.02 \mathrm{M}$ sodium phosphate buffer containing $0.85 \% \mathrm{NaCl}(\mathrm{pH} 6.8)$. Twenty-five $\mu 1$ was placed on a glass depression slide and mixed with $40 \mu 1$ of $2.0,3.0$, and $4.0 \mathrm{M}$ ammonium sulfate in $0.02 \mathrm{M}$ sodium phosphate buffer. The bacterium-salt solution mixture was gently rotated for $15 \mathrm{~min}$ at room temperature using a Tekmar shaker. The lowest concentration of ammonium sulfate resulting in aggregation visible with the naked eye under white-light illumination was scored as the positive SAT hydrophobicity value. Hydrophobicity measurements were repeated 4 times for each growth temperature. The effect of growth $\mathrm{pH}$ on the hydrophobicity of $L$. monocytogenes was similarly determined on mid-log phase cells grown at $30^{\circ} \mathrm{C}$ in TSB-YE adjusted to either $\mathrm{pH} 5.5,7.0$ or 8.5.

\section{Effect of trypsin on attachment}

Trypsin IX (EC 3.4.21.4) was obtained from Sigma Chemical Co., St. Louis, MO. A stock solution of $1.0 \%(w / v)$ trypsin was prepared fresh each day of use by dissolving in distilled water and filter sterilizing with a $0.45 \mu \mathrm{m}$ Acrodisc (Gelman Sciences, Ann Arbor, MI). 
Cells were grown to mid-log phase at $30^{\circ} \mathrm{C}$ and the test suspension was prepared as previously described. One $\mathrm{ml}$ of the stock trypsin solution was added to $99 \mathrm{ml}$ of the test suspension to give a final concentration of $0.01 \%(w / v)$ trypsin. After 15 min at $30^{\circ} \mathrm{C}$ with shaking, the test surfaces were added. After the pre-determined exposure times, surfaces were removed and both planktonic and attached cells enumerated. Duplicate trials were performed for each test surface.

\section{Rate of attachment}

Rates of attachment for L. monocytogenes under selected temperature and $\mathrm{pH}$ conditions were calculated as follows for the first $60 \mathrm{~min}$ of cell exposure to the test surface. Based on the Langmuir analysis of molecular adsorption, the concentration of irreversibly adsorbed cells as a function of time, $n(t)$ may be written as

$$
\frac{d \theta}{d t}=k \cdot c(t) \cdot N[1-\theta(t)]
$$

where $\mathrm{N}$ is the number of surface sites and is dependent on the surface area of the test surface. $C(t)$ is the concentration of the cells at time t. $\theta(t)$ is the coverage of the surface as a function of time and is given by

$$
\theta=\frac{\underline{n}_{0}-n(t)}{n_{0}-n_{f}}
$$


where $n_{0}$ and $n_{f}$ are the initial and final concentrations of cells in suspension, respectively. Integration of equation 1 yields

$$
\ln (1-\theta)=-k \cdot c(t) \cdot N(t)
$$

A plot of $\ln (1-\theta)$ versus $\mathrm{t}$ should give a straight line from which $\mathrm{k}$ can be determined when the number of sites and cell concentration are held constant (e.g. slope $=-k \cdot C(t)$. $\mathrm{N})$. When straight line plots are not obtained, $\mathrm{k}$ is implied to be dependent on coverage $(20)$.

\section{Detachment assays}

The mathematical expression used by Eginton et al. (9) to describe the ease of removal of Pseudomonas aureginosa, Staphylococcus epidermidis and Escherichia coli from various food processing surfaces, was used in this study to investigate the removal of L. monocytogenes attached to the test surfaces under different temperature and $\mathrm{pH}$ conditions. To determine the effect of growth temperature on the removal of $L$. monocytogenes from Buna-N rubber, cells were grown to mid-log phase at either $10^{\circ}, 30^{\circ}$ or $42{ }^{\circ} \mathrm{C}$ in TSB-YE and the test suspension prepared as previously described. Buna-N rubber surfaces were exposed to the test cell suspension for $60 \mathrm{~min}$ and rinsed prior to enumeration of attached cells. The surfaces were then gently placed on a pre-dried TSAYE plates with the side positioned upward in the test suspensions in contact with the agar 
surfaces. After $1 \mathrm{~min}$, the surfaces were removed and similarly placed on fresh pre-dried TSA-YE plates. This step was repeated for at least 20 successive plates. To facilitate spread plating, $0.1 \mathrm{ml}$ of $0.1 \%$ peptone was added to the agar surfaces. For the last transfer, the surfaces were placed face up in a petri dish and pour plated with TSA-YE. Colonies remaining on the surface were visible after $48 \mathrm{~h}$ incubation at $37^{\circ} \mathrm{C}$. To compare differences in ease of removal between surface types, stainless steel coupons were exposed to the test cell suspension of $L$. monocytogenes grown to mid-log at $30^{\circ} \mathrm{C}$ and analyzed as described above.

Cells were grown at $30^{\circ} \mathrm{C}$ in TSB-YE adjusted to either $\mathrm{pH} 5.5,7.0$ or 8.5 to determine the effect of growth $\mathrm{pH}$ on the removal of $L$. monocytogenes from Buna-N rubber. The test surface was exposed to the cell suspension (PBS, pH 7.0) for $60 \mathrm{~min}$, surfaces rinsed and attached cells enumerated by successive plating on TSA-YE as described for the temperature trials. All surfaces were evaluated in triplicate for both temperature and $\mathrm{pH}$ experiments.

The mean number of CFU/plate was plotted against the plate succession number and lines of best fit were determined by linear regression. The data was fitted to the following equation

$$
\mathrm{CFU}=\mathrm{A} 10^{\mathrm{kN}}
$$


where CFU is the number of colonies on any given TSA-YE plate, $\mathrm{A}$ is a constant, $\mathrm{N}$ is the plate succession number and $\mathrm{k}$ is a reduction exponent.

\section{Statistical analysis of data}

All attachment experiments examined in this study for adhesion rate determinations were performed in triplicate utilizing replicate coupons. Data were analyzed using twoway analysis of variance (Excel software, Microsoft Corp., Redmond, WA) for all experimental conditions and surface combinations. All detachment experiments were repeated at least 3 times and mean reduction exponents were analyzed by one-way analysis of variance. Means for both attachment and detachment experiments were separated using Duncan's multiple range test employing an $\alpha$ level of 0.05 . 


\section{RESULTS}

\section{Effect of temperature and $p H$ on rate of attachment}

Rates of attachment $\left(\mathrm{k}, \mathrm{min}^{-1}\right)$ for the growth and attachment temperature combinations were determined over the first $60 \mathrm{~min}$ of cell exposure to Buna-N rubber (Table 1). No significant difference $(P>0.01)$ was found in the rates of attachment determined at the three growth temperatures; $10^{\circ}, 30^{\circ}$, and $42^{\circ} \mathrm{C}$. The attachment rate of cells grown to mid-log at $30^{\circ} \mathrm{C}$ and attached at $10^{\circ} \mathrm{C}$ to Buna-N rubber were significantly lower $(\mathrm{P}<0.001)$ than the rates obtained for $30^{\circ} \mathrm{C}$ grown cells attached at $30^{\circ}$ or $45^{\circ} \mathrm{C}$.

The effect of growth and attachment $\mathrm{pH}$ on the rate of adherence by $L$. monocytogenes to Buna-N was determined (Table 2). Cells grown to mid-log at pH 7.0 had a significantly $(P<0.001)$ higher rate of attachment when compared to cells grown at $\mathrm{pH} 5.5$, but not when compared to cells grown at $\mathrm{pH} 8.5$. Rates determined for the different $\mathrm{pH}$ values, indicated slower attachment occurred at alkaline $\mathrm{pH}$. At $\mathrm{pH} 9$, attachment occurred at a rate significantly slower $(\mathrm{P}<0.001)$ than rates obtained at $\mathrm{pH} 7$ and lower. Attachment rates obtained under acidic conditions were not significantly different from attachment rates obtained under neutral conditions.

Compared to Buna-N rubber, attachment of $L$. monocytogenes to stainless steel was noticeably more rapid for all temperature and $\mathrm{pH}$ combinations investigated. However, attachment rates to stainless steel could not be determined, since after 5 min of exposure to the test surface, adhered cell concentrations were already at or near the maximum level of attachment observed during the 120 min sampling period. 
Effect of temperature and $p H$ on hydrophobicity

The results of the SAT for $L$. monocytogenes grown at different temperatures and $\mathrm{pH}$ levels are presented in Figure 1. Cells grown at $30^{\circ} \mathrm{C}$ in TSB-YE (pH 7.0) were more hydrophilic (i.e. aggregating at $4 \mathrm{M}$ ammonium sulfate) than those cells grown at either $10^{\circ}$ or $42^{\circ} \mathrm{C}$ in the same growth medium. When cells were grown in TSB-YE adjusted to $\mathrm{pH} 8.5$, the cell surface was found to be more hydrophobic (i.e. aggregating at $2 \mathrm{M}$ ammonium sulfate) than the surfaces of those cells grown in TSB-YE adjusted to either pH 5.5 or 8.5 .

\section{Effect of trypsin on attachment}

The effect of trypsin on attachment of L. monocytogenes to Buna-N rubber and stainless steel was determined (Figure 2). Cells exposed to the Buna-N rubber at $30^{\circ} \mathrm{C}$ in the presence of $0.01 \%$ trypsin reached a maximum attachment concentration of $<10$ $\mathrm{CFU} / \mathrm{cm}^{2}$ after $120 \mathrm{~min}$ of surface exposure. No attachment was observed during the first $30 \mathrm{~min}$ of exposure. Low concentrations of adhered cells were also observed on stainless steel when cells were exposed to this surface in the presence of trypsin. Maximum concentrations of attachment obtained on stainless steel approached $10 \mathrm{CFU} / \mathrm{cm}^{2}$. Planktonic cell concentrations were measured during the exposure period to determine if the enzyme had affected cell viability. Levels of viable planktonic cells remained unchanged throughout the 120 min exposure period. Compared to levels of attachment 
observed in the absence of trypsin, adhered cell populations over the 120 min exposure were reduced by $99.9 \%$ on both test surfaces.

\section{Effect of growth temperature and $\mathrm{pH}$ on detachment}

Using the successive blotting/transfer plate method of Eginton et al. (9), the detachment of $L$. monocytogenes adhered to test surfaces under selected environmental conditions was investigated. Results of experiments performed to characterize the effect of growth temperature (i.e., $10^{\circ}, 30^{\circ}$, and $42^{\circ} \mathrm{C}$ ) on detachment of adhered cells from Buna-N rubber are graphically illustrated in Figure 3. Similar experiments were performed for cells grown at $30^{\circ} \mathrm{C}$ and adhered to stainless steel (data not shown). The influence of growth medium $\mathrm{pH}$ (i.e., 5.5, 7.0, and 8.5) on detachment of cells adhered to Buna-N rubber is shown in Figure 4. For both growth parameters investigated, it was found that as the plate succession number increased, the mean CFU per plate decreased exponentially. Regression analyses were performed and lines of best fit determined. Details of the regression analysis of cell detachment from the two test surfaces are summarized in Table

3. The reduction exponents (e.g., $\mathrm{k})$ for the lines of best fit differed significantly $(\mathrm{P}<$ 0.01 ) between adhered cells grown at $10^{\circ} \mathrm{C}$ and cells grown at $30^{\circ} \mathrm{C}$, for Buna-N rubber. However, reduction exponents determined for cells grown at different $\mathrm{pH}$ values prior to attachment to Buna-N rubber were found not to differ significantly. The $k$ values determined for cells grown at $30^{\circ} \mathrm{C}$ at $\mathrm{pH} 7.0$ and adhered to both Buna-N rubber and stainless steel were found to differ significantly $(\mathrm{P}<0.01)$. 


\section{DISCUSSION}

L. monocytogenes has been quantitatively shown to attach to Buna-N rubber and stainless steel within short contact times (38). The ability of $L$. monocytogenes to attach to Buna-N rubber and stainless steel has also been previously reported by several workers using SEM techniques $(15,25)$. Buna-N rubber and stainless steel were used in this study because of their widespread use in the food industry and because they differ in their surface properties. Buna-N rubber is hydrophobic and has a lower surface free energy than stainless steel. Stainless steel is hydrophilic, although it is thought to possess hydrophobic regions. Substratum properties for food contact surfaces have also been characterized (26). Studies investigating the affect of surface properties (e.g., hydrophobicity, surface charge, surface free energy, and extracellular polymer production) for both substratum and bacterium, on attachment have been reported $(2,10,13,26,36)$.

Environmental conditions are known to affect cell surface characteristics $(3,23)$. Growth rate as well as growth phase have been shown to influence the regulatory mechanisms which determine cell surface properties (13). Very little work has been directed toward identifying environmental variables which influence the adhesion rates of microorganisms to food contact surfaces using defined biological systems. Rutter and Vincent (36) suggested the need for further investigations on the relative importance of extracellular polymers, specific and nonspecific binding sites, metabolic rate, motility, 
$\mathrm{pH}$, temperature, etc. on microbial attachment. Attempts in other scientific disciplines to describe the microbial adhesion process have largely been in terms of colloidal chemistry or surface free energy. The theory of surface free energy predicts adhesion will occur when the process results in a decrease in free energy. However, Mafu et al. (20), did not find a correlation between the surface energy of a substratum and the ability of $L$. monocytogenes to attach. Several researchers have noted that the kinetics of adhesion to different substrata leads to Langmuir isotherm-type curves $(6,31)$. Attachment profiles for L. monocytogenes to Buna-N rubber and stainless steel exhibited typical Langmuir adsorption curves (38). Therefore, the Langmuir equation for irreversible adsorption was used to determine the rates of attachment to Buna- $\mathrm{N}$ rubber for the different environmental conditions.

We found that the temperature at the time of attachment affected the ability of $L$. monocytogenes to attach to both Buna-N rubber and stainless steel (Table 1). For Buna-N rubber, cells grown at $30^{\circ} \mathrm{C}$ adhered at a faster rate when attachment occurred at $45^{\circ} \mathrm{C}$. Attachment occurred at a significantly slower rate at $10^{\circ} \mathrm{C}$ when compared to the higher temperatures investigated. Since attachment was greater with an increase in temperature, regardless of the surface, the higher temperatures may have lowered the energy of activation of chemical reactions at the cell-substratum interface which are involved with the attachment process.

Growth temperature prior to attachment did not affect the rate of adhesion to Buna-N rubber (Table 1). L. monocytogenes possess multiple nonpolar flagella at 
temperatures less than $30^{\circ} \mathrm{C}(15)$. Surface structures such as flagella and fimbriae are thought to play a role in attachment (10). Growth at $10^{\circ} \mathrm{C}$ did not significantly influence the rate of attachment. The differences in rates of adhesion noted in this study cannot be attributed to growth phase, since all cells were grown to mid-log phase prior to attachment.

We applied the equation of Arrhenius to further investigate how temperature affects the rate of bacterial attachment within the temperature range studied. The Arrhenius equation which has been used to describe how temperature affects the rate of chemical reactions is given below:

$$
v=S e^{-\Delta E R T}
$$

Where $v$ is the velocity of the reaction, $S$ is a constant, $\Delta \mathrm{E}$ is the activation energy of the reaction, $R$ is the gas constant and $T$ is the temperature in $K$. In its logarithmic form the equation becomes

$$
\log v=(-\Delta \mathrm{E} / 2.3 \mathrm{R})(1 / \mathrm{T})+S
$$

The logarithm of the velocity of a chemical reaction is a linear function of the reciprocal of absolute temperature: the line has a negative slope $(-\Delta \mathrm{E} / 2.3 \mathrm{R})$ from which the value of the activation energy can be calculated. If an Arrhenius plot is made for bacterial rate of 
attachment (k), rather than for the chemical reaction rate, a similar response is observed (Figure 5). This plot demonstrates that for the temperature range studied, normal chemical kinetics seem to apply. To our knowledge, this is the first time that a relationship between temperature and rate of attachment for $L$. monocytogenes to a food contact surface has been reported. From this plot, the $\mathrm{E}_{\mathrm{a}}$ for attachment of $L$. monocytogenes to Buna-N rubber can be calculated for a given temperature. The magnitude of the $\mathrm{E}_{\mathrm{a}}$ indicates the temperature dependence of the reaction. The determination of the $E_{2}$ may be useful in comparing the temperature dependence of $L$. monocytogenes attachment to various food contact surfaces under different environmental conditions.

Initial rates of attachment determined on Buna- $\mathrm{N}$ rubber did not differ between $\mathrm{pH}$ 4.0 to $\mathrm{pH} 7.0$ (Table 2). Alkaline $\mathrm{pH}$ levels (i.e. 8.0 and 9.0) however, resulted in a decrease in the rate of attachment. Structures on the cell surface possessing charged groups such as lipopolysaccharides and proteins have been shown to be affected by changes in $\mathrm{pH}$. Sign and amplitude of the cell surface potential is determined by the $\mathrm{pH}$ in the environment (28). Several researchers have confirmed the production of a polysaccharide by $L$. monocytogenes $(15,25,36)$. A number of bacteria produce extracellular polymers which are thought to promote irreversible attachment. These polymers have been identified as acidic polysaccharides (39). As the $\mathrm{pH}$ increases, there is an increase in the overall anionic charge of these polymer molecules resulting from the dissociation of acidic groups. Lewis et al., (22) suggested that since the majority of 
surfaces in contact with aqueous solutions are negatively charged, electrostatic repulsion between the bacterial surface and solid substratum would be greater at a more alkaline $\mathrm{pH}$.

The $\mathrm{pH}$ during growth prior to attachment was shown to affect the rate of attachment observed on both Buna-N rubber and stainless steel (Table 2). Cells grown at $\mathrm{pH} 7.0$ attached to Buna-N rubber at significantly higher rates when compared to the other growth $\mathrm{pH}$ values. The affect of growth $\mathrm{pH}$ was greater on Buna-N rubber than on stainless steel. Although the growth $\mathrm{pH}$ was also shown to alter the cell surface hydrophobicity (Figure 1), the difference in hydrophobicity could not be correlated to the observed attachment of $L$. monocytogenes to the test surfaces.

The surface free energy of $L$. monocytogenes is approximately $66 \mathrm{~mJ} \cdot \mathrm{m}^{-2}(1,26)$. Absolom et al., (I) classified a microorganism as hydrophilic when its surface free energy is within the range of 65 to $69 \mathrm{~mJ} \cdot \mathrm{m}^{-2}$. The hydrophobicity of various strains of $L$. monocytogenes Scott A as determined by hydrophobic interaction chromatography (HIC) and SAT has been previously reported (26). Low $\mathrm{pH}$ or high ionic strengths were required for the expression of hydrophobicity. L. monocytogenes was found to bind to the octyl-sepharose column only when the $\mathrm{pH}$ neared the isoelectric point of the microorganism (i.e. $\mathrm{pH}$ range 2 to 3.5). Using the SAT, these same researchers also reported aggregation of cells with 3 and $4 \mathrm{M}$ ammonium sulfate. Our results further confirm the low hydrophobic nature of this microorganism. In addition, it was found that altering the $\mathrm{pH}$ or temperature of the growth environment resulted in changes in the cell surface hydrophobicity (Figure 1). 
In this study, L. monocytogenes was found to attach at a faster rate to stainless steel than to Buna-N rubber, irrespective of the environmental conditions. These findings are consistent with others who have used SEM techniques to demonstrate greater attachment to stainless steel when compared to Buna-N rubber $(15,25)$. The surface free energies based on polar and dispersion components would thermodynamically predict that adhesion of $L$. monocytogenes would be more energetically favorable as the surface free energy of the solid substratum decreases. Rubber surfaces have a lower surface free energy than stainless steel and adhesion would be expected to be more favorable to this surface. However, factors other than cell surface hydrophobicity such as surface charges and the presence of an exopolymer, may also be important in the adhesion process to stainless steel, glass, polypropylene and rubber surfaces (26).

Marshall et al. (27) described the attachment process as a two stage process (i.e. reversible and irreversible). The bacterium comes in contact with the surface and is weakly held in place by electrostatic and Van der Waals Forces. The second or irreversible attachment involves physical attachment of the cell to the surface by extracellular polymeric substances produced by the cell. The role of extracellular polymers in attachment is, to date, unclear. Using carbohydrate disrupting compounds, Herald and Zottola (16) demonstrated a decrease in adherence of $P$. fragi to stainless steel. Other reports indicate that extracellular material is not required for attachment but may help stabilize biofilms $(2,8)$. Paul and Jeffrey (34) proposed that attachment of Vibrio proteolytica to hydrophilic and hydrophobic surfaces occurs by different mechanisms. 
Using proteolytic enzymes, these researchers found greater than $97 \%$ inhibition of attachment to hydrophobic surfaces. These same enzymes however did not affect attachment to hydrophilic surfaces. In this study, attachment of $L$. monocytogenes to Buna-N rubber and stainless steel in the presence of trypsin was reduced by $99.9 \%$ on both test surfaces over the $120 \mathrm{~min}$ exposure. The reduction in attachment observed in the presence of a proteolytic enzyme would suggest that proteins rather than polysaccharides play a role in the initial attachment process.

Another approach for studying attachment has been the investigation the detachment of microorganisms from surfaces. Eginton et al., (9) investigated the ease of removal of several microorganisms from surfaces possessing different surface properties. They inferred that the ease of removal could be related to the strength of attachment to that surface by comparison of reduction exponents. It would be beneficial to know what environmental conditions, if any, favor detachment. Hood and Zottola (17) have introduced the term biotransfer potential as any microorganism associated with a surface that could eventually lead to contamination of food. In this study, after an $1 \mathrm{~h}$ contact time in PBS ( $\mathrm{pH} 7.0$ ), reduction coefficients calculated from successive plating of the surface on TSA-YE did not differ for adhered cells grown at the 3 different $\mathrm{pH}$ levels prior to attachment. As previously mentioned, growth $\mathrm{pH}$ was found to affect the rate of attachment and cell surface hydrophobicity. However, changes in the cell surface hydrophobicity were not found to influence the apparent strength of attachment. Although attachment of $L$. monocytogenes to stainless steel occurred at a faster rate and to a greater 
extent, comparison of reduction exponents determined for cells grown at $30^{\circ} \mathrm{C}$ and attached to either surface at $30^{\circ} \mathrm{C}$ indicated that the strength of attachment was greater on Buna-N rubber.

In summary we have shown that exposure of $L$. monocytogenes to environmental stresses, such as $\mathrm{pH}$ and temperature, can significantly affect the rate and strength of attachment of this pathogen to common food contact surfaces. Inhibition of attachment in the presence of a proteoplytic enzyme suggests proteins are involved in the initial attachment process of L. monocytogenes. Given that extreme environmental conditions are known to dramatically alter protein synthesis, further investigations into the relationship between stress related proteins and the ability of pathogenic microorganisms to adhere to surfaces is warranted. Such studies could provide a better understanding of the attachment mechanisms to food contact surfaces and perhaps lead to better methods of control of $L$ monocytogenes in the food processing environment. 


\section{ACKNOWLEDGMENTS}

This study was supported in part by the Virginia Agricultural Experiment Station. 


\section{REFERENCES}

1. Absolom, D. R., F. V. Lamberti, Z. Policova, W. Zingg, C. J. van Oss and A. W. Neumann. 1983 Surface thermodynamics of bacterial adhesion. Appl. Environ. Microbiol. 46:90-97.

2. Allison, D. A. and I. W. Sutherland. 1987. The role of exopolysaccharide in adhesion of freshwater bacteria. J. Gen. Microbiol. 133:1319-1327.

3. Allison, D. A., D. J. Evans, M. R. W. Brown and P. Gilbert. 1990. Surface hydrophobicity of Pseudomonas biofilms cultured at various specific growth rates. FEMS Microbiol. Lett. 71:101-104.

4. Blackman, I. C. and J. F. Frank. 1996. Growth of Listeria monocytogenes as a biofilm on various food-processing surfaces. J. Food Prot. 59:827-831.

5. Bunning, V. K., R. G. Crawford, J. T. Tierney and J. T. Peeler. 1990. Thermotolerance of Listeria monocytogenes and Salmonella typhimurium after sublethal heat shock. Appl. Environ. Microbiol. 56:3216-3219.

6. Busscher, H. J., M. H. W. J. C. Uyen, A. W. J. van Pelt, A. H. Weerkamp and J. Arends. 1986. Kinetics of Adhesion of the Oral Bacterium Streptococcus sanguis $\mathrm{CH} 3$ to polymers with different surface free energies. Appl. Environ. Microbiol. 51:910-914.

7. Characklis, W. G. 1984. Biofilm Development: A Process Analysis. In: Microbial Adhesion and Aggregation. K. C. Marshall (ed.). Dahlem Konferenzen. New York. Springer-Verlag.

8. Dewanti, R. and A. C. L. Wong. 1995. Influence of culture conditions on biofilm formation by Escherichia coli 0157:H7. Int. J. Food Microbiol. 26:147-164.

9. Eginton, P. J., H. Gibson, J. Holah, P. S. Handley and P. Gilbert. 1995. The influence of substratum properties on the attachment of bacterial cells. Colloids and Surfaces. 5:153-159.

10. Fletcher, M. and G. I Loeb. 1979. Influence of substratum characteristics on the attachment of a marine pseudomonad to solid surfaces. Appl. Environ. Microbiol. 37:67-72.

11. Foster, J. W. 1991. Salmonella acid shock proteins are required for the adaptive acid tolerance response. J. Bacteriol. 173:6896-6902. 
12. Frank, J. F. and R. A. Koffi. 1990. Surface-adherent growth of Listeria monocytogenes is associated with increased resistance to surfactant sanitizers and heat. J. Food Prot. 53:550-554.

13. Gilbert, P., D. J. Evans, I. G. Duguid and M. R. W. Brown. 1991. Surface characteristics and adhesion of Escherichia coli and Staphylococcus epidermidis. J. Appl. Bacteriol. 71:72-77.

14. Helke, D. M., E. B. Somers and A. C. L. Wong. 1993. Attachment of Listeria monocytogenes and Salmonella typhimurium to stainless steel and buna- $\mathrm{N}$ in the presence of milk and milk components. J Food Prot. 56:479-484.

15. Herald, P. J. and E. A. Zottola. 1988. Attachment of Listeria monocytogenes to stainless steel surfaces at various temperatures and $\mathrm{pH}$ values. J. Food Sci. 53:1549-1552.

16. Herald, P. J. and E. A. Zottola. 1989. Effect of various agents on the attachment of Pseudomonas fragi to stainless steel . J. Food Sci. 54:461-464.

17. Hood, S. K. and E. A. Zottola. 1995. Biofilms in food processing. Food Control. 6:9-18.

18. Jones, P. G., R. A. Van Bogelen and F. C. Neidhardt. 1987. Induction of proteins in response to low temperature in Escherichia coli. J. Bacteriol. 169:2092-2095.

19. Krysinski, E. P., L. J. Brown and T. J. Marchisello. 1992. Effect of cleaners and sanitizers on Listeria monocytogenes attached to product contact surfaces. J. Food Prot. 55:246-251.

20. Langmuir, I. 1918. Adsorption of gases onto plane surfaces of gas, mica and platinum. J. Am. Chem. Soc. July/August: 289-291.

21. Lee, S. H. and J. F. Frank. 1991. Inactivation of surface-adherent Listeria monocytogenes by hypochlorite and heat. J. Food Protect. 54:4-6.

22. Lewis, S. J., A. Gilmour and D. E. Johnston. 1989. Factors influencing the detachment of a polymer-associated Acinetobacter sp. from stainless steel. Int. J. Food Microbiol. 8:155-164.

23. Leyer, G. J. and E. A. Johnson. 1993. Acid adaptation induces cross-protection against environmental stress in Salmonella typhimurium. Appl. Environ. Microbiol. 59:1842-1847. 
24. Lou, Y. and A. E. Yousef. 1996. Resistance of Listeria monocytogenes to heat after adaptation to environmental stresses. J. Food Prot. 59:465-471.

25. Mafu, A. A., D. Roy, J. Goulet and P. Magney. 1990. Attachment of Listeria monocytogenes to stainless steel, glass, polypropylene, and rubber surfaces after short contact times. J. Food Prot. 53:742-746.

26. Mafu, A. A., D. Roy, J. Goulet and L. Savone. 1991. Characterization of physiochemical forces involved in adhesion of Listeria monocytogenes to surfaces. Appl. Environ. Microbiol. 57:1868-1973.

27. Marshall, K. C. 1992. Biofilms: An overview of bacterial adhesion, activity, and control at surfaces. ASM News 58:202-207.

28. Mozes, N. and P. G. Rouxhet. 1987. Methods for measuring hydrophobicity of microorganisms. J. Microbiol. Methods 6: 99-112.

29. Murano, E. A. and M. D. Pierson. 1992. Effect of heat shock and growth atmosphere on the heat resistance of Escherichia coli 0157:H7. J. Food Prot. 55:171-175.

30. National Advisory Committee on Microbiological Criteria for Foods. 1991. Listeria monocytogenes. Int. J. Food Microbiol. 14:185-246.

31. Neumann, A. M., O. S. Hum, D. W. Francis, W. Zingg and C. J. van Oss. 1980. Kinetics and thermodynamic aspects of platelet adhesion from suspension to various substrates. J. Biomed. Mater. Res. 14:499-509.

32. Nystrom, T., K. Flardh and S. Kjelleberg. 1990. Response to multiple-nutrient starvation in marine Vibrio sp. strain CCUG 15956. J. Bacteriol. 172:7085-7097.

33. O'Driscoll, B., C. G. M. Gahan and C. Hill. 1996. Adaptive acid tolerance in Listeria monocytogenes: Isolation of an acid-tolerant mutant which demonstrates increased virulence. Appl. Environ. Microbiol. 62:1693-1698.

34. Paul, J. H. and W. H. Jeffrey. 1985. Evidence of separate adhesion mechanisms for hydrophobic and hydrophilic surfaces in Vibrio proteolytica. Appl. Environ. Microbiol 50:431-437.

35. Rozgonyi, F., K. R. Szitha, S. Hjerten and T. Wadstrom. 1985. Standardization of salt aggregation test for reproducible determination of cell-surface hydrophobicity with special reference to Staphylococcus species. J. Appl. Bacteriol. 59:451-457. 
36. Rutter, P. R. and B. Vincent. 1984. Physiochemical interactions of the substratum, microorganisms, and the fluid phase. In: Microbial Adhesion and Aggregation . K. C. Marshall (ed.) New York, pp: 21-38.

37. Smith, C. W. and N. Metzger. 1962. Demonstration of capsular structure on Listeria monocytogenes. Path. Microbiol. 25:499.

38. Smoot, L. M. and M. D. Pierson. 1996. Effects of environmental stress on the ability of Listeria monocytogenes Scott A to attach food contact surfaces. J. Food Prot. (Submitted).

39. Sutherland, I. W. 1980. Polysaccharides in the adhesion of marine and fresh water bacteria. In R. C. W. Berkley, J. M. Lynch, J. Melling, P. R. Rutter and B. Vincent (Eds.), Microbial Adhesion to Surfaces, Ellis Horwood, Chichester, pp. 329-338. 
TABLE 1. Effect of temperature on the rate of attachment by Listeria monocytogenes Scott A to Buna-N rubber in $P B(p H 7.0){ }^{A, B}$

Growth

I. Temperature $\left({ }^{\circ} \mathrm{C}\right)$

10

30

42

II. 30

30

30
Attachment

Temperature $\left({ }^{\circ} \mathrm{C}\right)$

30

30

30

10

$0.0229^{a} \pm 0.0072$

30

$0.0469^{b} \pm 0.0156$

45

$$
\underline{\mathrm{k}\left(\mathrm{min}^{-1}\right)}+\underline{\mathrm{s} . \mathrm{d}}
$$

$0.0323^{2} \pm 0.0035$

$0.0469^{2} \pm 0.0156$

$0.0477^{\mathrm{a}} \pm 0.0140$

$A$ - Data represent mean attachment rates obtained from 3 independent trials. $\mathrm{k}$ values were determined during the first $60 \mathrm{~min}$ of surface exposure at each temperature combination.

$B$ - Means within the same data set having different letters are significantly different at $\mathrm{P}<0.001$. 
TABLE 2. Effect of $p H$ on the rate of attachment by Listeria monocytogenes Scott $A$ to Buna-N rubber in $P B$ at $30^{\circ} C^{A, B}$

I. Growth $\mathrm{pH}$

5.5

7.0

8.5
Attachment pH

7.0

7.0

7.0 $\underline{\mathrm{k}\left(\min ^{-1}\right)} \pm \underline{\mathrm{s} . \mathrm{d}}$

$0.0240^{2} \pm 0.0009$

$0.0469^{b} \pm 0.0156$

$0.0378^{\mathrm{a}, \mathrm{b}} \pm 0.0084$
II. $\quad 7.0$

7.0

7.0

7.0

7.0

7.0
4.0

5.0

6.0

7.0

8.0

9.0
$0.0535^{2} \pm 0.0242$

$0.0592^{\mathrm{a}} \pm 0.0130$

$0.0491^{\mathrm{a}} \pm 0.0261$

$0.0469^{\mathrm{a}, \mathrm{b}} \pm 0.0156$

$0.0346^{b, c} \pm 0.0114$

$0.0265^{c} \pm 0.0071$

$A$ - Data represent mean attachment rates obtained from 3 independent trials. $\mathrm{k}$ values were determined during the first $60 \mathrm{~min}$ of surface exposure at each $\mathrm{pH}$ combination.

$B$ - Means within the same data set having different letters are significantly different at $\mathrm{P}<0.001$. 
TABLE 3. Regression analysis of adhered Listeria monocytogenes Scott A removed from Buna-N rubber and stainless steel by successive blotting on TSA-YE plates. CFU = $A \cdot 10^{-k N}$, where $C F U$ is the mumber of colonies transferred, $k$ is the removal exponent, $A$ the intercept and $N$ the plate succession number. ${ }^{A, B}$

\begin{tabular}{|c|c|c|c|c|c|}
\hline $\begin{array}{c}\text { Test } \\
\text { Surface }\end{array}$ & $\begin{array}{l}\text { Growth } \\
\text { Temperature }\left({ }^{\circ} \mathrm{C}\right)\end{array}$ & $\begin{array}{c}\text { Growth } \\
\text { pH }\end{array}$ & $\mathbf{A}$ & $\mathbf{k}$ & $r^{2}$ \\
\hline \multirow[t]{3}{*}{ I. Buna-N rubber } & 10 & 7.0 & 2.85 & $-0.13^{\mathrm{a}}$ & 0.92 \\
\hline & 30 & 7.0 & 2.75 & $-0.08^{b}$ & 0.96 \\
\hline & 42 & 7.0 & 2.63 & $-0.10^{\mathrm{a}, \mathrm{b}}$ & 0.91 \\
\hline \multirow[t]{3}{*}{ II. Buna-N rubber } & 30 & 5.5 & 2.54 & -0.10 & 0.95 \\
\hline & 30 & 7.0 & 3.17 & -0.08 & 0.96 \\
\hline & 30 & 8.5 & 2.92 & -0.09 & 0.93 \\
\hline III. Buna-N rubber & 30 & 7.0 & 3.17 & $-0.08^{a}$ & 0.96 \\
\hline Stainless steel & 30 & 7.0 & 5.52 & $-0.20^{b}$ & 0.89 \\
\hline
\end{tabular}

$A$ - Data represent means obtained from 3 independent trials.

$B-\mathrm{k}$ values within the same data set having different letters are significantly different at the $\mathrm{P}<0.01$ level. 


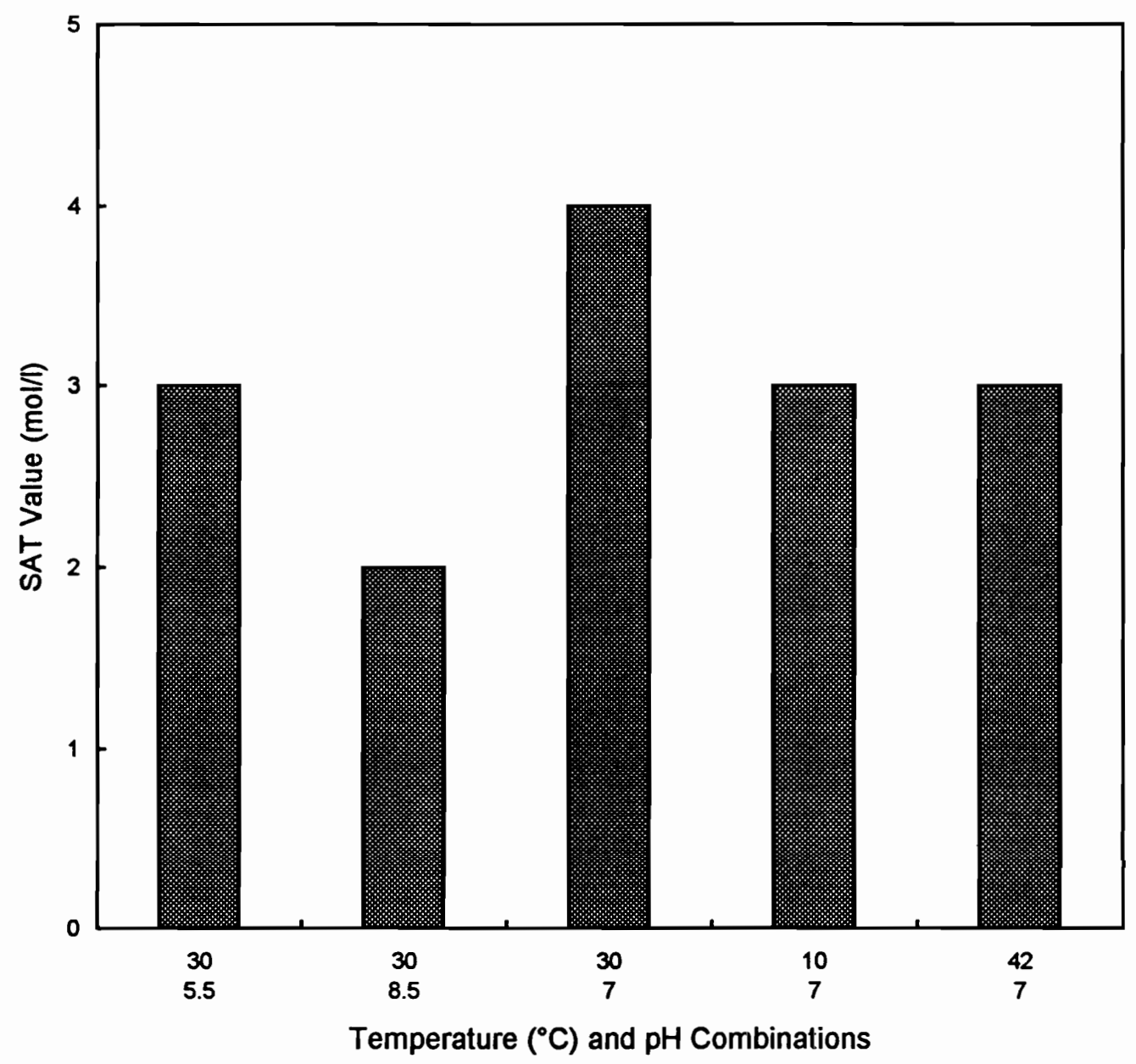

Figure 1. SAT values as a measure of hydrophobicity for $\mathrm{L}$. monocytogenes Scott A grown in TSB-YE at various $p H$ and temperature combinations. 


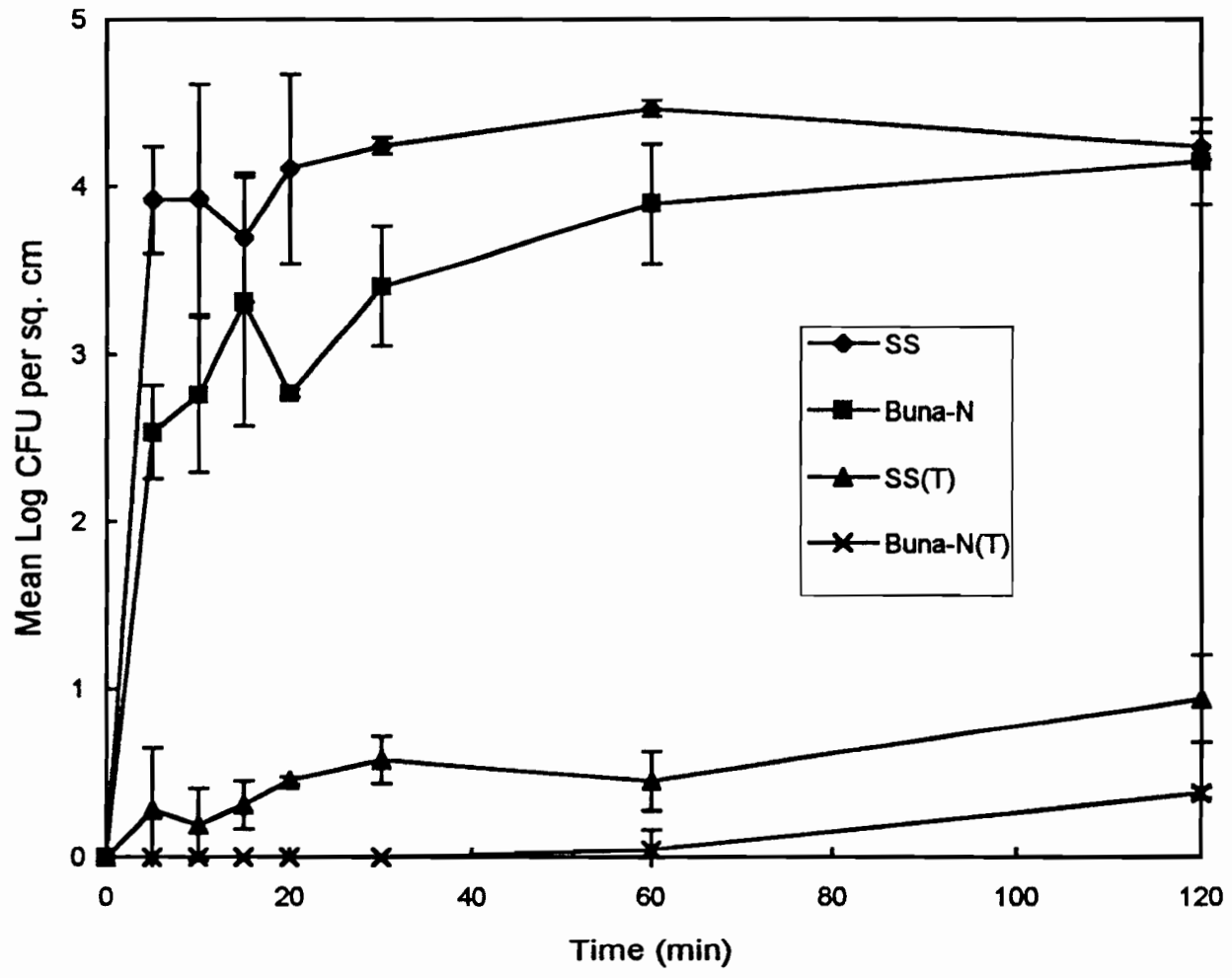

Figure 2 . Listeria monocytogenes Scott A grown to mid-log at $30^{\circ} \mathrm{C}$ and attached to Buna-N rubber (Buna-N) and stainless steel (SS) at $30^{\circ} \mathrm{C}$ in $\mathrm{PB}$ (pH 7.0) with or without $0.01 \%$ trypsin (T). 


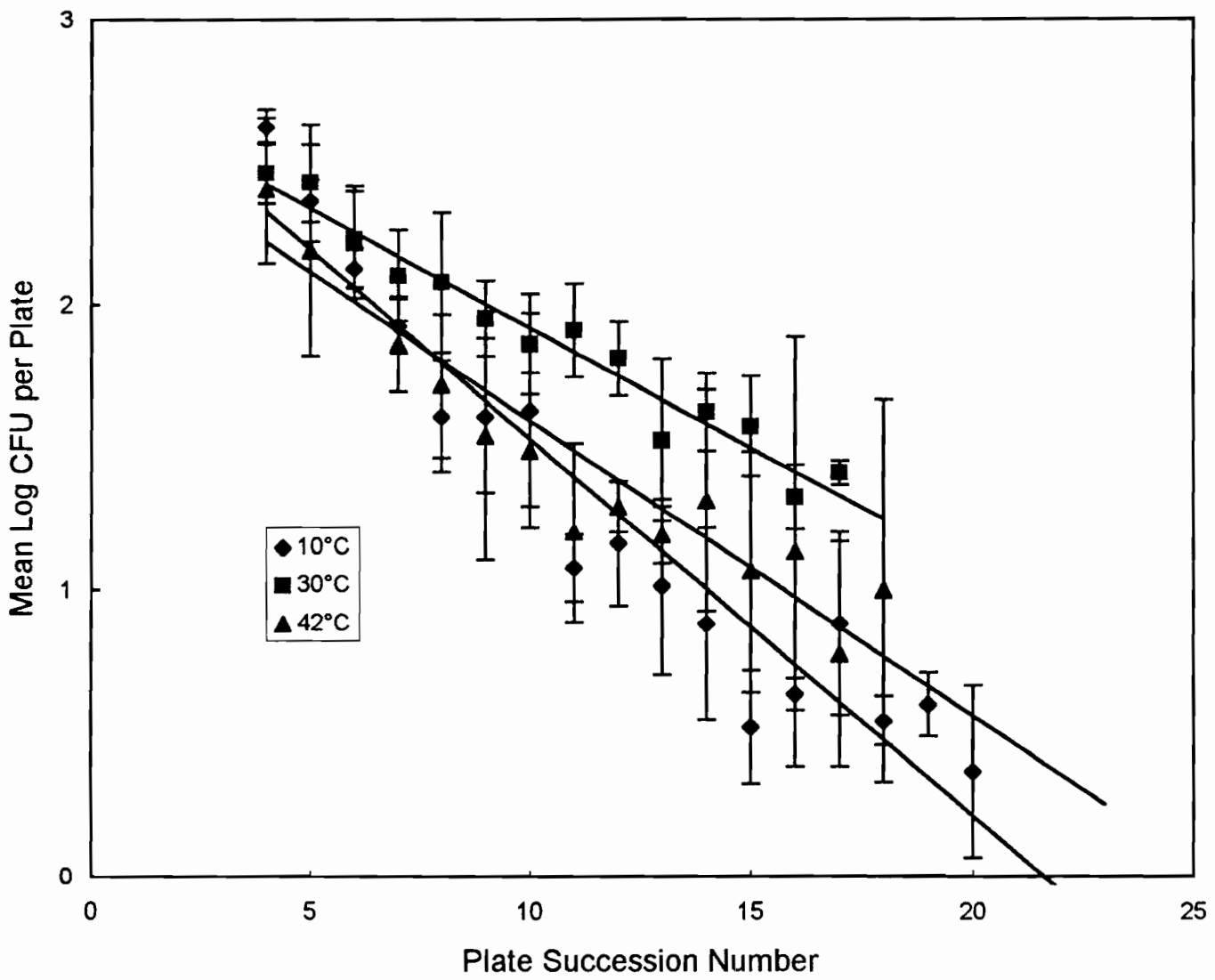

Figure 3. Detachment of Listeria monocytogenes Scott $A$ after growth to mid-log in TSB-YE (pH 7.0) at $10^{\circ}, 30^{\circ}$ or $42^{\circ} \mathrm{C}$ and exposure to Buna-N rubber for 60 min in $P B(p H 7.0)$. 


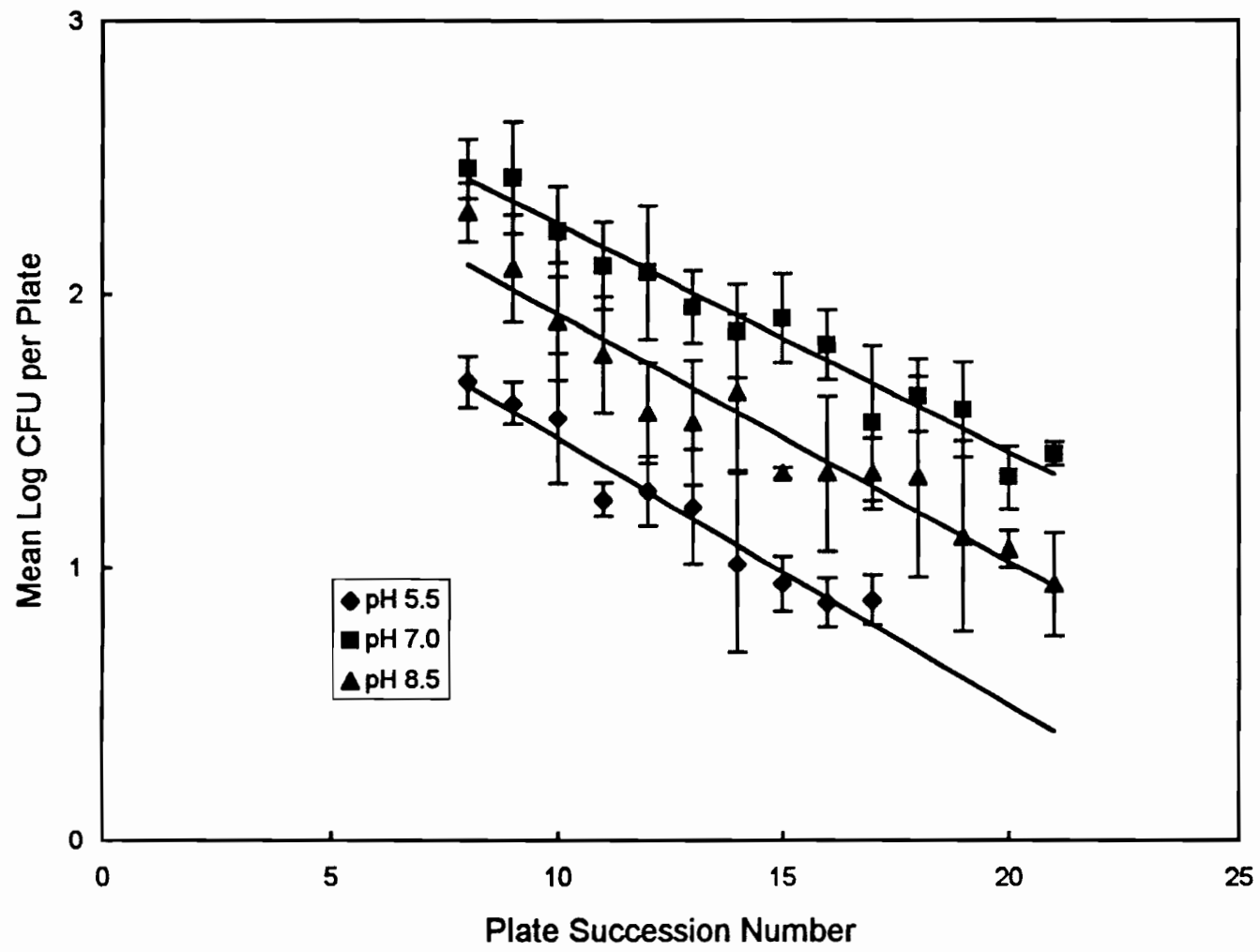

Figure 4. Detachment of Listeria monocytogenes Scott A after growth to mid-log in TSB-YE adjusted to either $p H 5.5,7.0$, or 8.5 and exposure to Buna-N rubber for 60 min in $P B(p H 7.0)$. 


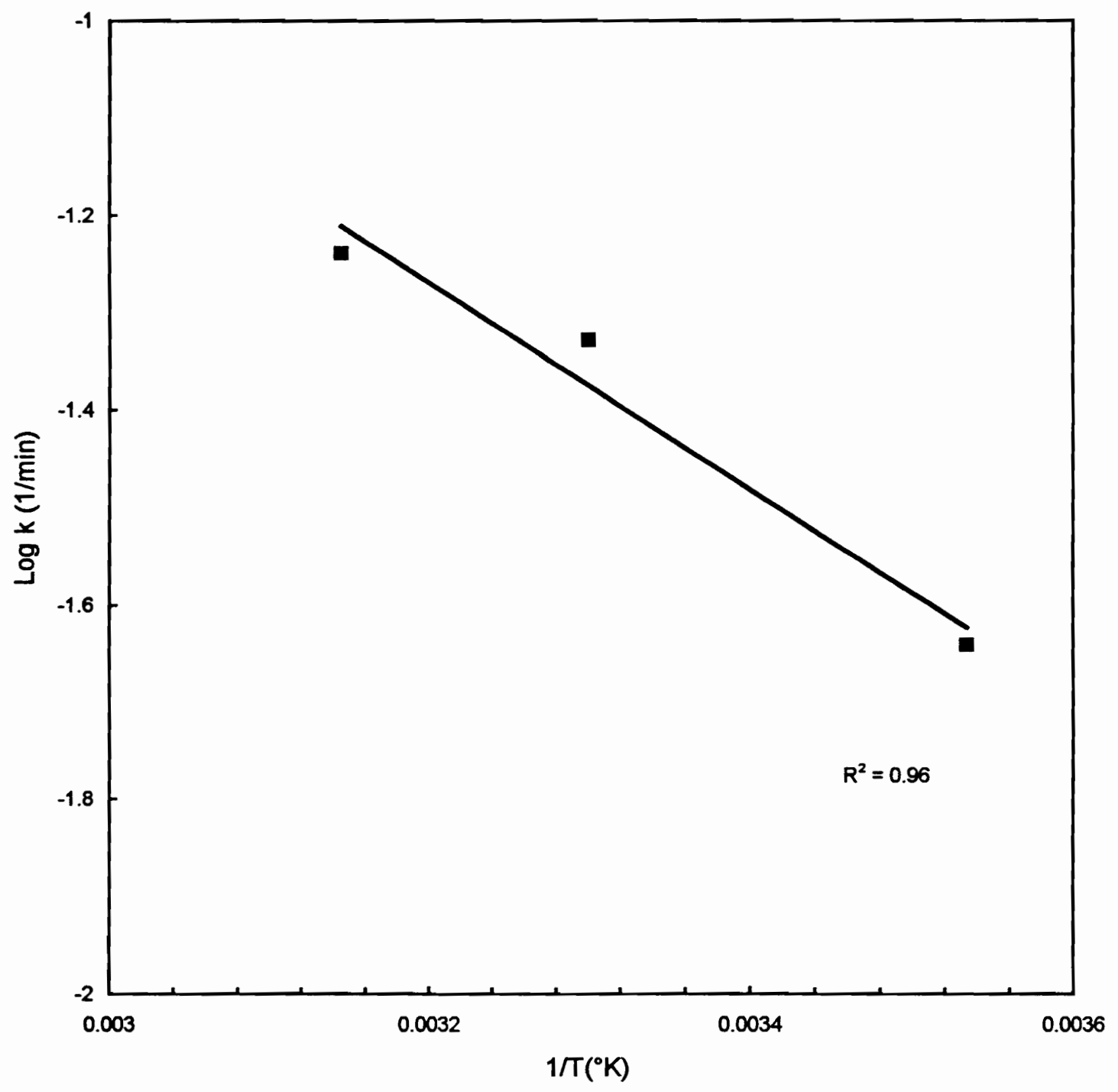

Figure 5. Arrhenius plot for the attachment of Listeria monocytogenes Scott A to Buna-N rubber at $10^{\circ}, 30^{\circ}$, and $45^{\circ} \mathrm{C}$. 


\section{LITERATURE CITED}

Absolom, D. R., F. V. Lamberti, Z. Policova, W. Zingg, C. J. van Oss and A. W. Neumann. 1983. Surface thermodynamics of bacterial adhesion. Appl. Environ. Microbiol. 46:90-97.

Allison, D. A. and I. W. Sutherland. 1987. The role of exopolysaccharide in adhesion of freshwater bacteria. J. Gen. Microbiol. 133:1319-1327.

Allison, D. A., D. J. Evans, M. R. W. Brown and P. Gilbert. 1990. Surface hydrophobicity of Pseudomonas biofilms cultured at various specific growth rates. FEMS Microbiol. Lett. 71:101-104.

Anonymous. 1996. Control of Listeria. International Food Safety News. Vol. 5. No. 6 pages 8-9. ISSN 09609784 Research Information, Ltd.

Archer, D. 1988. Isolation of Listeria monocytogenes from seafood. Working paper. WHO Conference on Listeriosis, Feb. 15-19, 1988. WHO, Geneva.

Archer, D. 1996. Preservation microbiology and safety: Evidence that stress enhances virulence and triggers adaptive mutations. Trends in Food Science and Technol. 7:91-95.

Blackman, I. C. and J. F. Frank. 1996. Growth of Listeria monocytogenes as a biofilm on various food-processing surfaces. J. Food Prot. 59:827-831.

Boughley, M. T., M. M. Duckworth, A. Lips and A. L. Smith. 1978. The observation of weak primary minima in the interaction of polystyrene with nylon. J. Chem. Soc. Faraday Trans. I 74:2200-2208.

Brackett, R. E. 1988. Presence and persistence of Listeria monocytogenes in food and water. Food Technol. 4:162-164.

Bryers, J. D. and W. G. Characklis. 1982. Processes governing primary biofilm formation. Biotech. Bioeng. 24:2451-2476.

Brown, M. R. W. and P. Gilbert. 1993. Sensitivity of biofilms to antimicrobial agents. J. Bacteriol. Sym. Suppl. 74:87S-97S. 
Brosch, R., B. Catimel, G. Milon, C. Burchrieser, E. Vindel and J. Rocourt. 1993. Virulence heterogeneity of Listeria monocytogenes strains from various sources (food, human, animal) in immunocompetent mice and its association with typing characteristics. J. Food Prot. 56:296-301.

Brown, M. R. W., P. J. Collier and P. Gilbert. 1990. Influence of growth rate on susceptibility to antimicrobial agents: modifications of the cell envelope and batch and continuous culture studies. Antimicrobial Agents and Chemotherapy 34:1623-1613.

Bunning, V. K., R. G. Crawford, J. T. Tierney and J. T. Peeler. 1990. Thermotolerance of Listeria monocytogenes and Salmonella typhimurium after sublethal heat shock. Appl. Environ. Microbiol. 56:3216-3219.

Busscher, H. J. and A. H. Weerkamp. 1987. Specific and non-specific interactions in bacterial adhesion to solid substrata. FEMS Microbiol. Rev. 46:165-173.

Busscher, H. J., M. H. W. J. C. Uyen, A. W. J. van Pelt, A. H. Weerkamp and J. Arends. 1986. Kinetics of Adhesion of the Oral Bacterium Streptococcus sanguis CH3 to polymers with different surface free energies. Appl. Environ. Microbiol. 51:910-914.

Chamberlain, A. H. L. and S. Johal. 1987. Biofilms on meat processing surfaces. In: Biodeterioration 7. D. R. Houghton, R. N. Smith and H. O. W. Eggins (eds.). Elsevier Applied Science, London \& New York. pp. 57-61.

Characklis, W. G. 1984. Biofilm Development: A Process Analysis. In: Microbial Adhesion and Aggregation. K. C. Marshall (ed.). Dahlem Konferenzen. New York. Springer-Verlag.

Christman, M. F., R. W. Morgan, F. S. Jacobson, and B. N. Ames. 1985. Cell 41: 753.

Cox, L. J., T. Kleiss, J. L. Cordier, C. Cordellana, P. Konkel, C. Pedrazzini, R. Beumer and A Siebenga. 1989. Listeria spp. in food processing, non-food and domestic environments. Food Microbiol. 6:49-61.

Dabros, T. and T. G. M. van de Ven. 1983. A direct method for studying particle deposition onto solid surfaces. Coll. Polym. Sci. 261:694-707.

Datta, A. R. 1994. Factors controlling expression of virulence genes in Listeria monocytogenes. Food Microbiol. 11:123-129.

Datta, A. R. and M. H. Kothary. 1993. Effects of glucose, growth temperature, and $\mathrm{pH}$ on listeriolysin O production in Listeria monocytogenes. Appl. Environ. Microbiol. 59:3495-3497. 
Dawes, E. S. 1984. Unbalanced growth and starvation. In: Andrew, M. H. E. and A. D. Russell (eds.). The revival of injured microbes. Soc. Appl. Bacteriol. Ser. 12, London: Academic Press. pp: 19-43.

Dewanti, R. and A. C. L. Wong. 1995. Influence of culture conditions on biofilm formation by Escherichia coli 0157:H7. Int. J. Food Microbiol. 26:147-164.

Eginton, P. J., H. Gibson, J. Holah, P. S. Handley and P. Gilbert. 1995. Strength of adhesion of bacteria to surfaces in biofilms. Bioline. pp. 61-64.

Eginton, P. J., H. Gibson, J. Holah, P. S. Handley and P. Gilbert. 1995. The influence of substratum properties on the attachment of bacterial cells. Colloids and Surfaces. 5:153-159.

Farber, J. M., W. H. Ross, and J. Harwig. 1996. Health risk assessment of Listeria monocytogenes in Canada. Internat. J. Food Microbiol. 30:145-156.

Fletcher, M. and G. I Loeb. 1979. Influence of substratum characteristics on the attachment of a marine pseudomonad to solid surfaces. Appl. Environ. Microbiol. 37:6772 .

Foster, J. W. 1991. Salmonella acid shock proteins are required for the adaptive acid tolerance response. J. Bacteriol. 173:6896-6902.

Foster, J. W. and H. K. Hall. 1990. Adaptive acidification tolerance response of Salmonella typhimurium. J. Bacteriol. 172:771-778.

Frank, K. F. 1993. Microbial ecology of Listeria monocytogenes biofilms associated with food processing plant environments. Paper no. 98, presented at the 80th meeting of IAMFES, Atlanta, Ga., Aug. 1-4.

Frank, J. F. and R. A. Koffi. 1990. Surface-adherent growth of Listeria monocytogenes is associated with increased resistance to surfactant sanitizers and heat. J. Food Prot. $53: 550-554$.

Gaughran, E. R. L. 1947. The saturation of bacterial lipids as a function of temperature. J. Bacteriol. 55: 506.

Genigeorgis, C. A., P. Oanca, and D. Dutulescu. 1990. Prevalence of Listeria spp. in turkey meat at the supermarket and slaughterhouse level. J. Food. Prot. 53:282-288. 
Geoffroy, C., J. L. Gaillard, J. E. Alouf and P. Berche. 1989. Production of thioldependent haemolysins by Listeria monocytogenes. J. Gen. Micorbiol. 135:481-487.

Gilbert, P., D. J. Evans, I. G. Duguid and M. R. W. Brown. 1991. Surface characteristics and adhesion of Escherichia coli and Staphylococcus epidermidis. J. Appl. Bacteriol. 71:72-77.

Gray, M. L. 1963. Epidemiological aspects of listeriosis. A. J. Pub. Hlth. 53:554-563.

Heckles, J. F., B. Blackett, J. S. Everson and M. E. Ward. 1976. The influence of surface charge on the attachment of Neisseria gonorrhea to human cells. J. Gen. Microbiol. 96:359.

Helke, D. M., E. B. Somers and A. C. L. Wong. 1993. Attachment of Listeria monocytogenes and Salmonella typhimurium to stainless steel and buna- $\mathrm{N}$ in the presence of milk and milk components. J Food Prot. 56:479-484.

Herald, P. J. and E. A. Zottola. 1989. Effect of various agents on the attachment of Pseudomonas fragi to stainless steel. J. Food Sci. 54:461-464.

Hood, S. K. and E. A. Zottola. 1995. Biofilms in food processing. Food Control. 6:9-18.

ICMSF. 1996. Microorganisms in foods 5: Microbiological Specifications of Food Pathogens, Blackie Academic and Professional. New York. pages 141-182.

Jay, J. M. 1992. Modern Food Microbiology. 4th edition. Chapman and Hall. New York, NY

Jenkins, D. E., J. E. Schultz and A. Matin. 1988. Starvation-induced cross protection against hydrogen peroxide challenge in Escherichia coli. J. Bacteriol. 170:3910-3914.

Jones, P. G., R. A. Van Bogelen and F. C. Neidhardt. 1987. Induction of proteins in response to low temperature in Escherichia coli. J. Bacteriol. 169:2092-2095.

Kroll, R. G. and R. A. Patchett. 1992. Induced acid tolerance in Listeria monocytogenes. Lett. in Appl. Microbiol. 14:224-227.

Krysinski, E. P., L. J. Brown and T. J. Marchisello. 1992. Effect of cleaners and sanitizers on Listeria monocytogenes attached to product contact surfaces. J. Food Prot. 55:246-251.

Langmuir, I. 1918. Adsorption of gases onto plane surfaces of gas, mica and platinum. J. Am. Chem. Soc. July/August: 289-291. 
Lappin-Scott, H. M., J. W. Costerton and T. J. Marrie. 1992. Biofilms and Biofouling. In: Encyclopedia of Microbiology. Vol. 1. pages 277-284. Academic Press, Inc.

Lee, S. and J. F. Frank. 1991. Inactivation of surface-adherent Listeria monocytogenes hypochlorite and heat. J. Food Prot. 54: 4-6.

Lewis, S. J., A. Gilmour and D. E. Johnston.. 1989. Factors influencing the detachment of a polymer-associated Acinetobacter sp. from stainless steel. Internat. J. Food Micorbiol. 8: 155-164.

Leyer, G .J. and E. A. Johnson. 1993. Acid adaptation induces cross--protection against environmental stress in Salmonella typhimurium. Appl. Environ. Microbiol. 59:18421847.

Linnan, M. J., L .Mascola, X. D. Lou, V. Goulet, S. May, C. Salminen, D. W. Hird, M. L. Yonekura, P. Hayes, R. Weaver, A. Audurier, B. D. Plikaytis, S. L. Fannin, A. Kleks and C. V. Broome. 1988. Epidemic listeriosis associated with Mexican-style cheese. N. Eng. J. Med. 319:823-828.

Lou, Y. and A. E. Yousef. 1996. Resistance of Listeria monocytogenes to heat after adaptation to environmental stresses. J. Food Prot. 59:465-471.

Mafu, A. A., D. Roy, J. Goulet and P. Magney. 1990. Attachment of Listeria monocytogenes to stainless steel, glass, polypropylene, and rubber surfaces after short contact times. J. Food Prot. 53:742-746.

Mafu, A. A., D. Roy, J. Goulet and L. Savone. 1991. Characterization of physiochemical forces involved in adhesion of Listeria monocytogenes to surfaces. Appl. Environ. Microbiol. 57:1868-1973.

Marshall, K. C. 1992. Biofilms: An overview of bacterial adhesion, activity, and control at surfaces. ASM News 58:202-207.

Marshall, K. C. 1971. Mechanism of the initial events in the sorption of marine bacteria to surfaces. J. Gen. Microbiol. 68:337-348.

Meadows, P. S. 1971. The attachment of bacteria to solid surfaces. Arch. Microbiol. 75:374-381.

Mekalanos, J. J. 1992. Environmental signals controlling expression of virulence determinants in bacteria. J. Bacteriol. 174: 1-7. 
Mozes, N. and P. G. Rouxhet. 1987. Methods for measuring hydrophobicity of microorganisms. J. Microbiol. Methods 6: 99-112.

Mozes, N. and P. G. Rouxhet. 1987. Methods for measuring hydrophobicity of microorganisms. J. Microbiol. Methods 6: 99-112.

Murano, E. A. and M. D. Pierson. 1992. Effect of heat shock and growth atmosphere on the heat resistance of Escherichia coli 0157:H7. J. Food Prot. 55:171-175.

National Advisory Committee on Microbiological Criteria for Foods. 1991. Listeria monocytogenes. Internat. J. Food Microbiol. 14:185-246.

Neidhardt, F. C. J. L. Ingraham and M. Schechter. 1990. The effect of temperature, pressure, and pH, p. 226-246. In: Physiology of the bacterial cell: a molecular approach. Sinauer Associates, Inc. Sunderland, Massachusetts.

Neumann, A. M., O. S. Hum, D. W. Francis, W. Zingg and C. J. van Oss. 1980. Kinetics and thermodynamic aspects of platelet adhesion from suspension to various substrates. J. Biomed. Mater. Res. 14:499-509.

Nystrom, T., K. Flardh and S. Kjelleberg. 1990. Response to multiple-nutrient starvation in marine Vibrio sp. strain CCUG 15956. J. Bacteriol. 172:7085-7097.

O'Driscoll, B., C. G. M. Gahan and C. Hill. 1996. Adaptive acid tolerance in Listeria monocytogenes: Isolation of an acid-tolerant mutant which demonstrates increased virulence. Appl. Environ. Microbiol. 62:1693-1698.

Parnas, H. and D. Cohen. 1976. The optimal strategy for the metabolism of reserve materials in microorganisms. J. Theoretical Biol. 56:19-55.

Paul, J. H. and W. H. Jeffrey. 1985. Evidence of separate adhesion mechanisms for hydrophobic and hydrophilic surfaces in Vibrio proteolytica. Appl. Environ. Microbiol 50:431-437.

Pethica, B. A. 1980. Microbial and cell adhesion. In: Microbial adhesion to surfaces. R. C. W. Berkley, J. M. Lynch, J. Melling, P. R. Rutter, and B. Vincent (eds.), John Wiley and Sons, New York.

Pickett, E. L. and E. A. Murano. 1996. Sensitivity of Listeria monocytogenes to sanitizers after exposure to a chemical shock. J. Food Prot. 59:374-378. 
Pinner, R. W., A. Schuchat, B. Swaminathan, P. S. Hayes, K. A. Deaver, R. E. Weaver, B. D. Plikaytis, M. Reeves, C.V. Broome and J. D. Wenger. 1992. Role of Foods in Sporadic Listeriosis. J. American Medical Assoc. 267: 2046-2050.

Ray, B. 1986. Impact of bacterial injury and repair in food microbiology: Its past, present, and future. J. Food Prot. 49:651-655.

Ren, T. and J. F. Frank. 1993. Susceptibility of starved planktonic and biofilm Listeria monocytogenes to quaternary ammonium sanitizer as determined by direct viable and agar plate counts. J. Food Prot. 56:573-576.

Rozgonyi, F., K. R. Szitha, S. Hjerten and T. Wadstrom. 1985. Standardization of salt aggregation test for reproducible determination of cell-surface hydrophobicity with special reference to Staphylococcus species. J. Appl. Bacteriol. 59:451-457.

Rutter, P. R. and B. Vincent. 1984. Physiochemical interactions of the substratum, microorganisms, and the fluid phase. In: Microbial Adhesion and Aggregation . K. C. Marshall (ed.) New York, pp: 21-38.

Ryser, E. T. and E. H. Marth. 1987. Fate of Listeria monocytogenes during the manufacture and ripening of camembert cheese. J. Food Prot. 50:372-378.

Ryser, E. T. and E. H. Marth. 1991. Listeria, Listeriosis and Food Safety. New York, Marcel Dekker.

Ryser, E. T., E. H. Marth and M. P. Doyle. 1985. Survival of Listeria monocytogenes during manufacture and storage of cottage cheese. J. Food Prot. 48:746-750.

Schlech III, W. F. 1992. Expanding the horizons of foodborne listeriosis. J. Amer. Med. Assoc. Vol. 267, No. 15., pp: 2081-2082.

Schuchat, A., K. A. Deaver, J. D. Wenger, B. D. Plikaytis, L. Mascola, R. W. Pinner, A. L. Reingold and C. V. Broome. 1992. Foods in sporadic listeriosis. J. Amer. Med. Assoc. Vol. 267, No. 15 pp: 2041-2045.

Smith, C. W. and N. Metzger. 1962. Demonstration of capsular structure on Listeria monocytogenes. Path. Microbiol. 25:499.

Sokolovic, Z. and W. Goebel. 1989. Synthesis of listeriolysin in Listeria monocytogenes under heat shock conditions. Infect. Immun. 57:295-298.

Speers, J. G. S. and A. Gilmour. 1985. The influence of milk and milk components on the attachment of bacteria to farm dairy equipment surfaces. J. Appl. Bacteriol. 59:325-332. 
Stanfield, J. T., C. R. Wilson, W. H. Andrews and G. J. Jackson. 1987. Potential role of refrigerated milk packaging in the transmission of listeriosis and salmonellosis. J. Food Prot. 50:730-732.

Stanley, P. M. 1983. Factors affecting the irreversible attachment of Pseudomonas aeruginosa to stainless steel. Can. J. Microbiol. 29:1493-1499.

Suarez, B., C. M. Perreiros and M. Criado. 1992. Adherence of psychrotrophic bacteria to dairy equipment surfaces. J. Dairy Res. 59: 381-388.

Sutherland, I. W. 1980. Polysaccharides in the adhesion of marine and fresh water bacteria. In R. C. W. Berkley, J. M. Lynch, J. Melling, P. R. Rutter and B. Vincent (Eds.), Microbial Adhesion to Surfaces, Ellis Horwood, Chichester, pp. 329-338.

Sutherland, P. S. 1989. Listeria monocytogenes. In: Foodborne microorganisms of public health concern. (4th ed.) Buckle, K. A. (ed.). AIFST (NSW Branch) Food Microbiology Group. pages: $289-311$.

van Loosedrecht, M. C. M., J. Lyklema, W. Norde and A. J. B. Zinder. 1990. Influence of interfaces on microbial activity. Microbiol. Rev. 54:75-87.

VanBogelen, R. A., P. M. Kelley and F. C. Neidardt. 1987. Differential induction of heat shock, SOS, and oxidative stress regulons and accumulation of nucleotides in Escherichia coli. J. Bacteriol. 169:26-32.

Vandevivere, P and D. L. Kirchman. 1993. Attachment stimulates exopolysaccharide synthesis by a bacterium. Appl. Environ. Microbiol. 59:3280-3286.

Vanhaecke, E., J. P. Remon, M. Moors, F. Raes, D. De Rudder and A. Van Peteghem. 1990. Kinetics of Pseudomonas aeruginosa adhesion to 304 and 316-L stainless steel: role of cell surface hydrophobicity. Appl. Environ. Microbiol. 56:788-795.

Vincent, B., M. Jafellici, P. F. Luckham and T. F. T. Tadros. 1980. Adsorption of small positive particles onto large negative particles in the presence of polymer. II. Adsorption equilibrium and kinetics as a function of temperature. J. Chem. Soc. Faraday Trans. F I 76:674-682.

Watkins, J. and K. P. Sleath. 1981. Isolation and enumeration of Listeria monocytogenes from sewage, sewage sludge and river water. J. Appl. Bacteriol. 50:1-9.

Weiss, J. and H. P. R. Seeliger. 1975. Incidence of Listeria monocytogenes in nature. Appl. Microbiol. 30:29-33. 
Wenger, J. D., B. Swaminathan, P. S. Hayes, S. S. Green, M. Pratt, R. W. Pinner, A. Schuchat and C. V. Broome. 1990. Listeria monocytogenes contamination of turkey franks: evaluation of a production facility. J. Food Prot. 53:1015-1019.

Wong, A. C. L. and O. Cerf. 1995. Biofilms: Implications for hygiene monitoring of dairy plant surfaces. In: Bulletin of the International Dairy Federation 302. pp. 40-44. 
The author, Linda Michele (Martin) Smoot, was born in Birmingham, Alabama on April 3, 1966. She received her Bachelor of Science Degree in Microbiology and Cell Science (1988) and Masters Degree in Food Science and Human Nutrition (1991) from the University of Florida, Gainesville, Florida. While attending the University, the author worked as a microbiologist for $\mathrm{ABC}$ Research Corporation in Gainesville. After completion of her Masters Degree, she continued employment at $\mathrm{ABC}$ Research as a Research Microbiologist. In January 1993, the author entered the Department of Food Science and Technology at Virginia Tech, Blacksburg, Virginia and is currently a Doctoral Candidate. On September 16, 1995, the author married Dr. Les Smoot in Birmingham. In August 1996, Mrs. Smoot accepted the position of Research Microbiologist in the Department of Food Safety and Quality at the Nestlé Research Center, Lausanne, Switzerland. Mrs. Smoot currently lives in Montreux, Switzerland with her husband, who also works for Nestec S.A.

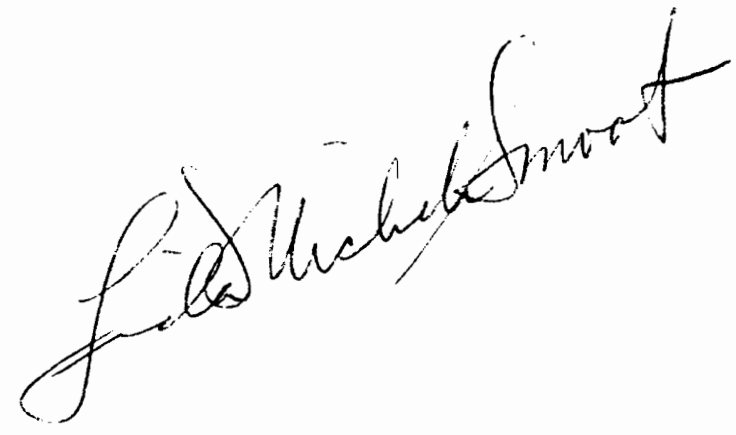

